Cláudia Hespanholo Nascimento

\title{
Estudo do erro de posicionamento do eixo $X$ em função da temperatura de um centro de usinagem
}





\section{Cláudia Hespanholo Nascimento}

\section{Estudo do erro de posicionamento do eixo $X$ em função da temperatura de um centro de usinagem}

Tese apresentada à Escola de Engenharia de São Carlos da Universidade de São Paulo, para a obtenção de Título de Doutora em Engenharia de Produção, na Área de Concentração em Processos e Gestão de Operações.

Orientador: Prof. Dr. Reginaldo Teixeira Coelho 
AUTORIZO A REPRODUÇÃO TOTAL OU PARCIAL DESTE TRABALHO, POR QUALQUER MEIO CONVENCIONAL OU ELETRÔNICO, PARA FINS DE ESTUDO E PESQUISA, DESDE QUE CITADA A FONTE.

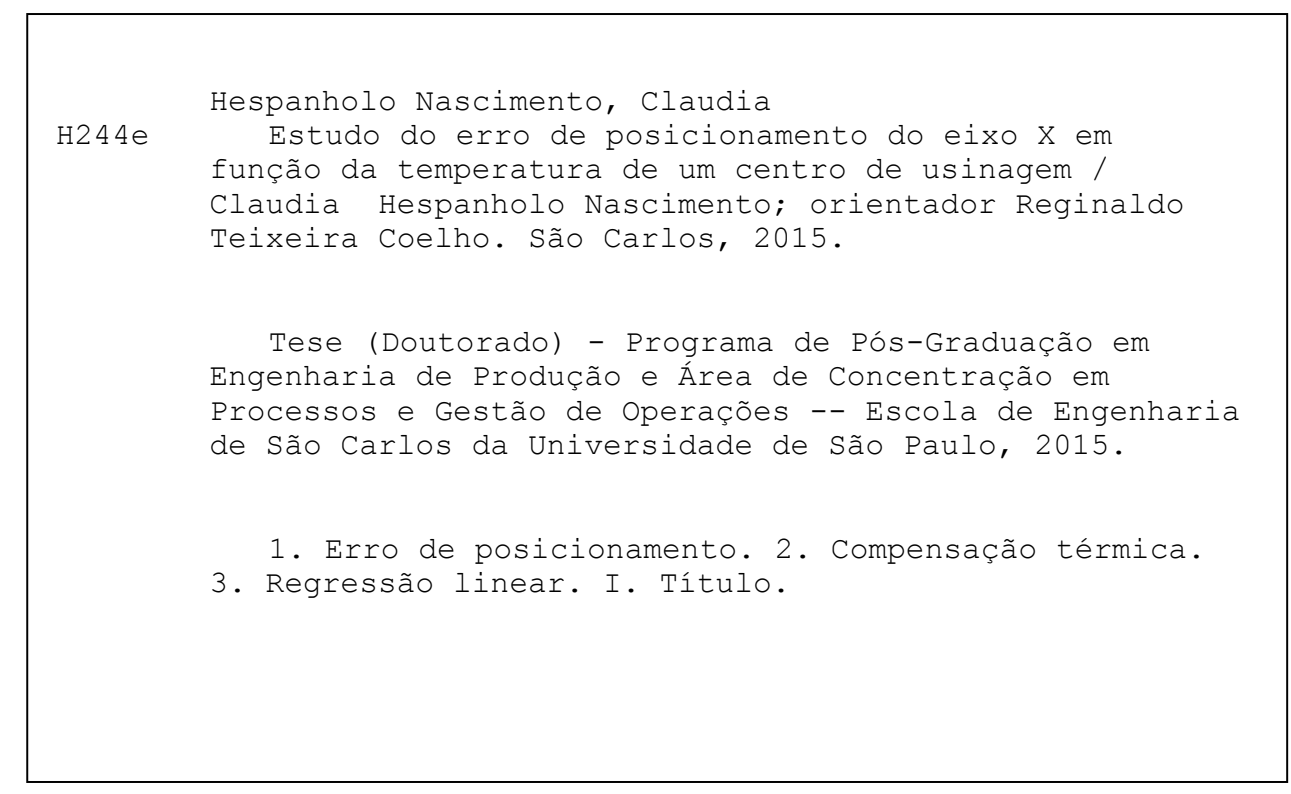




\section{FOLHA DE JULGAMENTO}

Candidata: Bacharel CLAUDIA HESPANHOLO NASCIMENTO

Título da tese: "Estudo do erro de posicionamento do eixo X em função da temperatura de um centro de usinagem".

Data da defesa: 07/08/2015

\section{Comissão Julgadora:}

Prof. Titular Reginaldo Teixeira Coelho (Orientador)

(Escola de Engenharia de São Carlos/EESC)

Prof. Dr. Alessandro Roger Rodrigues

(Escola de Engenharia de São Carlos/EESC)

Prof. Dr. Sergio Henrique Evangelista

(Universidade Federal de São Carlos/UFSCar)

Profa. Dra. Maria Célia Oliveira

(Universidade Metodista de Piracicaba/UNIMEP)

Profa. Dra. Patrícia Alves Barbosa

(Universidade Federal do Espírito Santo/UFES)

\section{Resultado:}

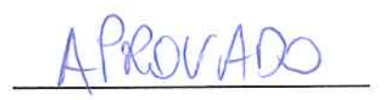

Aprovada
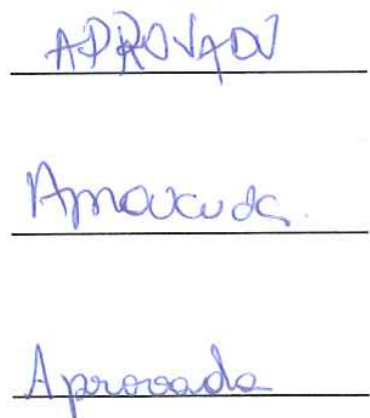

Coordenador do Programa de Pós-Graduação em Engenharia de Produção Profa. Associada Daisy Aparecida do Nascimento Rebelatto

Presidente da Comissão de Pós-Graduação:

Prof. Associado Paulo César Lima Segantine 
Aos meus avós Maria e Moacir (in memoriam) 


\section{Epígrafe}

É preciso correr muito para ficar no mesmo lugar. Se você quer chegar a outro lugar, corra duas vezes mais.

(Lewis Carroll, Alice no País das Maravilhas) 


\section{Agradecimentos}

"A gratidão é o ato de reconhecimento de uma pessoa por alguém que lhe prestou um benefício, um auxilio, ou um favor. Em um sentido mais amplo, pode ser explicada também como recognição abrangente pelas situações e dádivas que a vida lhe proporcionou e ainda proporciona".

Desde que decidi mudar minha área de pesquisa, encontrei o apoio que precisava no Laboratório de Processos Avançados e Sustentabilidade, no Departamento de Engenharia de Produção da Universidade de São Paulo. Sob orientação do Prof. Dr. Reginaldo Teixeira Coelho desenvolvi minha capacidade de pesquisa e tive algumas oportunidades de mostrar nosso trabalho em congressos internacionais, assim como o doutorado sanduíche. Conquistas importantes para o ingresso na carreira acadêmica. Agradeço à orientação, confiança e paciência. Prof. Reginaldo, muito obrigada!

Devo agradecer também ao Prof. Dr. Philip Koshy que me recebeu como aluna visitante no Departamento de Engenharia Mecânica da universidade canadense McMaster. Me ajudou e me auxiliou durante sete meses em Hamilton. Durante este tempo, o Prof. Koshy me incluiu em seu grupo de pesquisa, onde aprendi muito sobre o trabalho desta equipe e também mostrei um pouco do trabalho realizado aqui no Brasil. Não tenho palavras para descrever a experiência de conhecer pessoas de diferentes culturas e sobretudo, respeitá-las.

Os funcionários do Departamento de Engenharia de Produção também possuem papel fundamental no andamento dos projetos realizados por nós, alunos. Em especial, gostaria de agradecer ao técnico Adolfo Ferrarin Neto que foi o responsável pela relização dos ensaios experimentais deste trabalho, à técnica administrativa Jessyca Aparecida Duarte e a especialista de laboratório Juliana Aparecida Paganelli pelo apoio.

Os companheiros de laboratório que me acompanham e/ou me acompanharam desde o mestrado, agradeço muito pela amizade, paciência e convivência durante todo este 
tempo. Vanda, Alex, José Eduardo, Rodrigo, Cleiton, Rossana, Remo, Aldo, Franco, Gustavo e aos alunos de iniciação científica, importantes no desenvolvimento deste trabalho, Osmar, Júlio e Rafael.

Também tem aquele apoio que vem de fora do meio acadêmico. Aos meus pais Antonio Carlos e Natália e minha irmã Paula, agradeço pelo apoio fundamental no meu crescimento desde sempre. Mesmo quando nem sabia o que era vestibular já estavam me apoiando e torcendo para o meu sucesso. Tenho a sorte te ter o melhor exemplo de disciplina e honestidade dentro de casa.

Ao Lucas Albers Cuminato que se fez presente em um dos momentos mais importantes do doutorado. Agradeço o companheirismo, os bons momentos partilhados e todo carinho e compreensão que eu precisava durante esse período.

Depois de onze anos longe de casa, contruí uma família aqui, mais perto de mim. Chamo os integrantes desta família de amigos! Não ousarei citar um por um para não cometer uma injustiça, se por acaso esquecer de alguém. Foram vários amigos que passaram por minha vida nestes anos. Alguns já se foram, alguns estão longe, outros permanecem mais perto. Mas a importância de cada um deles na minha trajetória aqui em São Carlos permanece intacta e devo ser grata por ter conhecido tantas pessoas boas.

Agradeço também à empresa ROMI pela parceria com o Laboratório e empréstimo das máquinas e a agência FAPESP (Fundação de Amparo à Pesquisa do Estado de São Paulo) que foi responsável pelo apoio financeiro. 


\section{Resumo}

\section{NASCIMENTO, C.H. Estudo do erro de posicionamento do eixo $X$ em função da temperatura de um centro de usinagem. 2015, $126 \mathrm{f}$. Tese (Doutorado) -}

Escola de Engenharia de São Carlos, Universidade de São Paulo, São Paulo, 2015.

$\mathrm{Na}$ atual indústria de manufatura, destacam-se as empresas que sejam capazes de atender a demanda de produção de forma rápida e com produtos de qualidade. Durante a fabricação existem diversas fontes de erro que interferem na exatidão do processo de usinagem. Deste modo, torna-se importante o conhecimento destes erros para que técnicas de correção possam ser implementadas ao controle numérico da MF (máquinaferramenta) e assim, melhorar a exatidão do processo. Neste contexto, o objetivo principal do trabalho é desenvolver uma metodologia para corrigir os erros de posicionamento do eixo X levando em consideração a variação de temperatura medida experimentalmente em pontos específicos da MF. Primeiramente foi realizado um levantamento dos erros de posicionamento experimentais ao longo do eixo X da MF em três diferentes condições de trabalho e simultaneamente havia um sistema para medir a variação de temperatura. Os dados foram tratados e em seguida sintetizados utilizando a metodologia das matrizes homogêneas de transformação, onde foi possível armazenar todos os erros de posicionamento referentes à trajetória da mesa da MF ao longo do eixo X. Os elementos da matriz resultante são utilizados como dados de entrada para análise de regressão linear múltipla que através dos métodos dos mínimos quadrados, correlaciona as variáveis de temperatura e erros de posicionamento. Como resultado, as equações lineares obtidas no método de análise de regressão geram valores previstos para os erros de posicionamento que são utilizados para correção destes erros. Estas equações exigem 
baixo custo computacional e portanto, podem ser futuramente implementadas no controle numérico da MF para corrigir os erros de posicionamento devido às deformações térmicas. Os resultados finais mostraram que erros de $60 \mu \mathrm{m}$ foram reduzidos à $10 \mu \mathrm{m}$. Constatou-se a importância da sintetização dos erros de posicionamento nas matrizes homogêneas de transformação para aplica-los ao método de regressão.

Palavras-chave: erro de posicionamento, compensação térmica, regressão linear 
Abstract

NASCIMENTO, C.H. Study of the $X$ axis error positioning in the function
of the machining tool temperature. 2015, $126 \mathrm{f}$. Tese (Doutorado) - Escola de Engenharia de São Carlos, Universidade de São Paulo, São Paulo, 2015.

In today's manufacturing industry, companies stand out if they're able to meet a high production demand efficiently and with quality products. During manufacturing there are several sources of error that can affect the accuracy of the machining process. Thus, it becomes important to better understand these errors to allow correction techniques to be implemented into the numerical control of the machine tool (MT) and thus improve process accuracy. In this context, the main goal of this work is to develop a method for correcting positioning errors along the $\mathrm{X}$ axis taking into consideration the variation in temperature, measured experimentally in specific points of the MT. First we conducted a survey of experimental positioning errors along the $\mathrm{X}$ axis of the MT in three different working conditions and simultaneously collecting temperature variation data. Data were treated and then synthesized using the methodology of homogeneous transformation matrices, where it was possible to store all positioning errors related to the trajectory of the board of the MT along the $\mathrm{X}$ axis. The elements of the matrix resulting from the homogeneous transformation are used as input data for the multiple linear regression analysis by the methods of least squares, which correlates the temperature variables with the positioning errors. As a result, linear equations obtained from the regression analysis method generates predicted values for the positioning errors which are used to correct this errors. These equations require low computer processing and therefore can be further implemented into the numerical control of the MT to correct positioning errors due to thermal deformation. The final results showed 
that $60 \mu \mathrm{m}$ errors were reduced to $10 \mu \mathrm{m}$. It was noted the importance of synthesizing the positioning errors in homogeneous transformation matrices to apply them to the regression method.

Keywords: error positioning, thermal compensation, linear regression 


\section{Lista de Figuras}

2.1 Torno da ROMI DCE $480 \ldots \ldots \ldots \ldots$

2.2 Esquema de um sistema $\mathrm{CNC} \ldots \ldots \ldots \ldots \ldots$

2.3 Eixos principais de uma máquina-ferramenta CNC . . . . . . . . . 17

2.4 Movimento da ferramenta no plano $X$ e $Y \ldots \ldots \ldots$

2.5 Interpolação linear (Adaptado de [33]) . . . . . . . . . . . . . . 20

2.6 Interpolação circular (Adaptado de [33]) . . . . . . . . . . . . . 20

2.7 Interpolação NURBS (Adaptado de [33]) . . . . . . . . . . . . . . . . 21

2.8 Erro aleatório, sistemático e histerese (Adaptado de [45]) . . . . . . . . . 24

2.9 Fontes de erro de uma máquina-ferramenta (Adaptado de [2]) . . . . . . 25

2.10 Esquema de erro em uma MF com seis graus de liberdade (Adaptado de

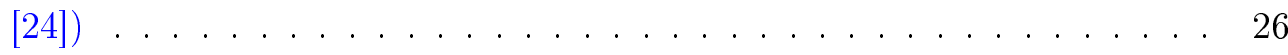

2.11 Peça hipotética . . . . . . . . . . . . . . . . . 26

2.12 Erros geométricos de uma máquina-ferramenta (Adaptado de [8]) . . . 27

2.13 Princípio de funcionamento de um encoder óptico (Adaptado de [25]) . 32

2.14 Princípios de Medição Linear - 1. Feixe de laser emergente do XL Laser;

2. Divisor de feixe; 3. Retroreflector; 4.Feixe de volta . . . . . . . . . . 33

3.1 Projeção ortogonal de $Y$ sobre $S(X): \hat{Y}=H Y$ (Adaptado de [7]) . . . . 45

3.2 Definição das somas dos quadrados da regressão linear através da projeção ortogonal de $Y$ sobre $S(X): \hat{Y}=H Y$ (Adaptado de [7]) . . . . . . 47 
4.1 Estrutura da máquina-ferramenta ROMI D800 - 1. Eixo-árvore; 2. Motorização; 3. Coluna; 4. Servomotores; 5. Base; 6. Mesa . . . . . . . . . 54

4.2 Esquema de montagem dos transmissores . . . . . . . . . . . 55

4.3 Termopar conectado ao transmissor de sinal Tx-Block . . . . . . . . . 56

4.4 Verificação do funcionamento do filtro de ruídos passa-baixa . . . . . . . 57

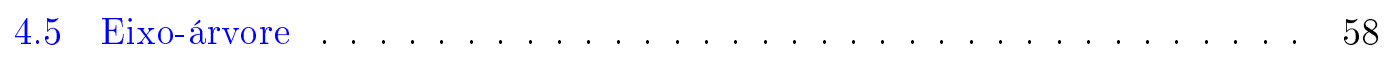

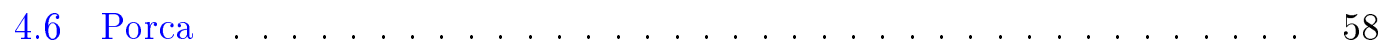

4.7 Mancal. . . . . . . . . . . . . . . . . . 58

4.8 Montagem do interferômetro na MF f . . . . . . . . . . 59

4.9 Alinhamento das lentes . . . . . . . . . . . . . . . . 60

4.10 Plataforma da medição dos dados experimentais (Adaptado de [46]) . . . 61

4.11 Curvas de temperatura no Caso $1(f=5.000 \mathrm{~mm} / \mathrm{min}) \ldots \ldots$. . . . . 64

4.12 Erros de posicionamento no Caso $1(f=5.000 \mathrm{~mm} / \mathrm{min}) \ldots \ldots$

5.1 Coordenadas virtuais no eixo $X$ da mesa de trabalho da MF $\ldots \ldots . .71$

5.2 Gráficos dos erros de posicionamento antes e depois da aplicação da equação de correção . . . . . . . . . . . . . . . 77

5.3 Gráficos dos erros de posicionamento antes e depois da aplicação da equação de correção . . . . . . . . . . . . . . . . . . . . . . 79

5.4 Gráficos dos erros de posicionamento antes e depois da aplicação da equação de correção . . . . . . . . . . . . . . . . 81

5.5 Gráficos dos erros de posicionamento antes e depois da aplicação da equação de correção . . . . . . . . . . . . . . . . . . . 83

A.1 Curvas de temperatura no Caso $1(f=30.000 \mathrm{~mm} / \mathrm{min}) \quad \ldots . \ldots . \quad 95$

A.2 Curvas de temperatura no Caso $1(f=5.000 \mathrm{~mm} / \mathrm{min}) \ldots . \ldots 96$

A.3 Curvas de temperatura no Caso $2(f=30.000 \mathrm{~mm} / \mathrm{min}) \quad \ldots \ldots . . .96$

A.4 Curvas de temperatura no Caso $2(f=5.000 \mathrm{~mm} / \mathrm{min}) \ldots \ldots 9$ 
A.5 Curvas de temperatura no Caso $3(6000 \mathrm{rpm}) \ldots \ldots . \ldots . \ldots 97$

A.6 Curvas de temperatura no Caso $3(12000 \mathrm{rpm}) \ldots \ldots$. . . . . . . . . 98 


\section{Lista de Tabelas}

2.1 Coordenada absoluta . . . . . . . . . . . . . . . . . . . . . 19

2.2 Coordenada incremental . . . . . . . . . . . . . . . . . 19

5.1 Tabela dos dados estatísticos (Caso $1-f=30.000 \mathrm{~mm} / \mathrm{min}$ ) . . . . 74

5.2 Tabela dos dados estatísticos (Caso $2-f=30 \mathrm{~m} / \mathrm{min}$ ) . . . . . . 74

5.3 Tabela dos dados estatísticos $($ Caso $3-n=12.000 \mathrm{rpm}) \ldots 75$ 


\title{
Nomenclatura
}

\author{
AIRBF artificial immune
}

ANSI American National Standards Institute

ARM Análise de Regressão Múltipla

CAD computer-aided design

CAM computer-aided manufacturing

CLP Controle Lógico Programável

CN controle numérico

CNC controle numérico computadorizado

FAA Força Aérea Americana

FEIMAFE Feira Internacional de Máquinas-Ferramenta e Sistemas Integrados de Manufatura

GUM Guide to the expression of uncertainty in measurement

IA Inteligência Artificial

Inmetro Instituto Nacional de Metrologia, Qualidade e Tecnologia

IRNN Integrated Recurrent Neural Network 
JCGM Comitê Conjunto para Guias em Metrologia

MEF Método dos Elementos Finitos

MF máquina-ferramenta

MMQ Método dos Mínimos Quadrados

MTH Matrizes de Transforamção Homogêneas

NURBS Non-Uniform Rational B-Spline

RBF Radical Basis Function

RN Redes Neurais

RNN Recurrent Neural Network

SPC Sistema de Produção em Células

TPM Total Preventive Maintenance 


\section{Sumário}

1 Introdução 1

1.1 Objetivos Gerais . . . . . . . . . . . . . 6

1.1.1 Objetivos Específicos . . . . . . . . . . . 6

1.2 Estrutura do Trabalho . . . . . . . . . . . . . . 6

2 Revisão da Literatura $\quad 9$

2.1 Evolução das máquinas-ferramenta com controle numérico . . . . . . . . 9

2.2 Análise estrutural de uma máquina-ferramenta . . . . . . . . . . . . . . 12

2.3 Controle Numérico Computadorizado - CNC . . . . . . . . . . . . . 16

2.4 Classificaçãos dos erros de medição . . . . . . . . . . . . . . . . . 22

2.4.1 Conceitos associados ao erro de medição . . . . . . . . . . . 22

2.5 Principais fontes de erro em máquinas-ferramenta . . . . . . . . . . . 24

2.5.1 Erros geométricos . . . . . . . . . . . . . . 25

2.5.2 Erros de posicionamento . . . . . . . . . . . . 27

2.5.3 Erros dinâmicos. . . . . . . . . . . . . . . . . 28

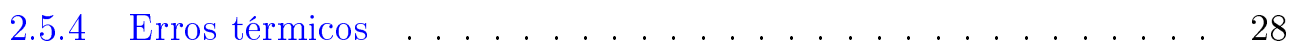

2.6 Sistemas de medição de erros de posicionamento em máquinas-ferramenta 31

2.6 .1 Encoder óptico . . . . . . . . . . . . . . . . . . . . 31

2.6 .2 Interferômetro a laser f . . . . . . . . . . . . . . . . . . 32

2.6.3 Alinhamento do laser . . . . . . . . . . . . . . . . . 34 
2.7 A compensação de erros . . . . . . . . . . . . . . . . . 35

3 Método proposto para compensação de erros térmicos em um centro $\begin{array}{ll}\text { de usinagem } & 39\end{array}$

3.1 Análise de Regressão . . . . . . . . . . . . . . . . . . . . . . . . 39

3.1.1 Modelo estatístico . . . . . . . . . . . . . . . . . . . 40

3.1.2 Método dos mínimos quadrados . . . . . . . . . . . . . . . . 40

3.1.3 Representação matricial do modelo de regressão linear múltipla 41

3.1.4 Estimação do coeficiente de determinação pela análise geométrica da regressão linear . . . . . . . . . . . . . . . . . 45

3.2 Matrizes de Transformação Homogênea . . . . . . . . . . . . . . . . . . . 48

4 Trabalho experimental $\quad 53$

4.1 Máquina-ferramenta ROMI D800 . . . . . . . . . . . . . . 53

4.2 Sistema de aquisição de temperatura . . . . . . . . . . . . . 54

4.3 Determinação da localização dos termopares . . . . . . . . . . . . . . . . 57

4.4 Sistema de aquisição dos erros de posicionamento . . . . . . . . . . . 59

4.5 Preparação da máquina . . . . . . . . . . . . . . . . . 61

4.6 Programação do CN para cada caso . . . . . . . . . . . . . . . . . . 62

4.7 Tratamento dos dados experimentais . . . . . . . . . . . . 64

4.8 Considerações sobre o modelo de compensação baseado na análise de regressão linear múltipla . . . . . . . . . . . . . . . . . . 67

$\begin{array}{lll}5 & \text { Resultados e discussão } & 69\end{array}$

5.1 Descrição da metodologia para compensação de erros . . . . . . . . . . . 69

5.1.1 Nomenclatura das variáveis utilizadas no modelo . . . . . . . . 70

5.1.2 Modelagem geométrica na MF para aplicação do modelo de Matrizes de Transformação Homogênea . . . . . . . . . . . . . 70 
5.1.3 Matriz que representa o movimento linear no eixo $X$ na MF . . . 72

5.2 Equação de regressão para o Caso $1 \ldots \ldots$. . . . . . . . 76

5.3 Equação de regressão para o Caso $2 \ldots \ldots \ldots$. . . . . . . 78

5.4 Equação de regressão para o Caso $3 \ldots \ldots$. . . . . . . . . . . 80

5.5 Modelo final de regressão . . . . . . . . . . . . . . . . . . . 82

6 Conclusões $\quad 85$

$\begin{array}{lll}7 & \text { Trabalhos futuros } & 87\end{array}$

$\begin{array}{lr}\text { Referências Bibliográficas } & 89\end{array}$

$\begin{array}{ll}\text { A Curvas de temperatura } & 95\end{array}$

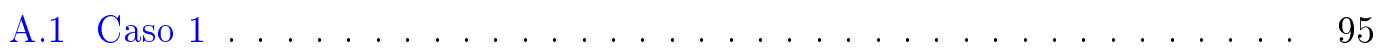

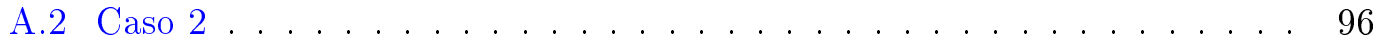

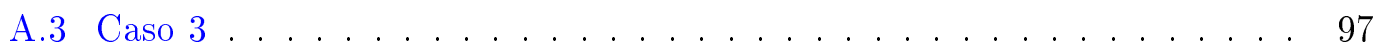

B Códigos $\quad 99$

B.1 Código I . . . . . . . . . . . . . . . . . . . . . . . . . . . . 99

B.2 Código II . . . . . . . . . . . . . . . . . . . . . . 102 


\section{Capítulo 1}

\section{Introdução}

Desde o início da revolução industrial quando surgiram as primeiras máquina-ferramenta (MF), até meados dos anos 70 do século XX, estas sempre evoluíram com base nas soluções puramente mecânicas, no máximo incorporando elementos eletrotécnicos e eletrônicos básicos. Na segunda metade do século XX, após a construção da primeira máquina numericamente controlada, o projeto para o desenvolvimento destas máquinas concentra-se, principalmente, em três objetivos: obter máxima flexibilidade de produção, máxima taxa de remoção de material e alta precisão e exatidão dimensional.

A introdução de novas metodologias de projeto de máquinas, voltadas à sistematização do conhecimento, orientações do desenvolvimento voltadas à fabricação, montagem, ajustagem, entre outras, permitiram uma racionalização e otimização do desenvolvimento de MFs [40].

Como principal equipamento do processo de usinagem, diversas otimizações têm sido pesquisadas e implementadas às MFs como forma de melhorar, dentre outros aspectos, a sua exatidão de trabalho. Muitas vezes, o controle numérico $(\mathrm{CN})$ das MFs não funciona dentro da precisão desejada e esta fica abaixo da solicitada pelo usuário. Isto ocorre porque sua precisão varia muito de acordo com o meio ambiente, configuração e histórico operacional que inclui as forças estáticas, forças de usinagem e calor gerado 
Capítulo 1. Introdução

pelas usinagens anteriores [18].

A qualidade final do produto usinado depende diretamente da precisão geométrica com que a MF opera. Por esta razão, uma MF é cuidadosamente projetada desde seu design inicial até a montagem. Contudo, alguns fatores que influenciam a precisão do processo de usinagem são difíceis de serem previstas e projetados no desenvolvimento inicial da MF. Como exemplo, tem-se o desgaste da MF, histórico operacional do controle numérico computadorizado (CNC), uso indevido da MF, falta de capacitação dos operadores e fatores ambientais, como mudanças climáticas, vibrações e as variações de temperatura que ocorrem interna e externamente.

Para um mapeamento das fontes de erro da MF e a subsequente compensação destes erros é necessário conhecer as fontes de erros e os efeitos que os erros geométricos causam nas MFs. Devido à mudança na geometria dos componentes estruturais da MF, a posição real da ferramenta em relação à peça difere da sua orientação e posição nominal, resultando em uma orientação relativa e erro de posicionamento. A magnitude deste erro de posicionamento e orientação dependem da sensibilidade estrutural da MF e das várias fontes de erro [34].

Estes erros eram observados pelos operadores da máquina e a correção, quando possível, era feita de forma manual. Nas últimas décadas com o avanço tecnológico, componentes eletroeletrônicos, controles numéricos, controladores lógicos programáveis e micro controladores foram instalados na MF com o objetivo de realizar tarefas de monitoramento e até mesmo compensação dos erros gerados durante o funcionamento da máquina. A implementação destas novas tecnologias, compõe a chamada automação industrial e auxilia no melhoramento da eficiência e precisão da produção. O monitoramento é realizado por meio de sensores capazes de detectar ruídos, mapear as deformações térmicas e mecânicas sobre a estrutura da MF.

Considerando o projeto de uma MF, os elementos deste são divididos em três grupos: estruturas, movimento (acionamento para a ferramenta, dispositivos de movimentação) 
e dispositivos de controle. O avanço tecnológico favoreceu o melhoramento no grupo de movimento e controle. O grupo das estruturas ainda é um grande desafio desta área e tema de estudo para diversos pesquisadores. Os problemas estruturais envolvem o comportamento estático e dinâmico. Erros estáticos consistem em erros geométricos, cinemáticos, força de gravidade, aceleração dos eixos, forças de corte, expansão térmica e erros de instrumentação. Os erros dinâmicos estão mais relacionados às condições de operação da máquina, tais como, vibração da estrutura, erros de controle, motores, transmissores e rolamentos. Estes erros são difíceis de predizer e compensar durante a fase do projeto da máquina.

Os erros que surgem nas MFs apresentam comportamento não-linear, o que dificulta a análise teórica e a modelagem de predição dos erros. Geralmente, o modelo de previsão quantitativa de erros é obtido por meios empíricos. Para a compensação de erro térmico, por exemplo, deve-se relacionar a variação de temperatura com o erro de posicionamento do eixo da MF. Existem trabalhos que fazem esta correlação obtendo primeiramente dados experimentais e em seguida os aplica em métodos numéricas tais como o Método dos Mínimos Quadrados (MMQ), Análise de Regressão Múltipla (ARM), teoria de Inteligência Artificial (IA), Redes Neurais (RN), lógica Fuzzy e algoritmo genético [11]. Os métodos mais utilizados na literatura atualmente são os métodos de regressão linear múltipla e redes neurais.

Aproximadamente $70 \%$ dos erros totais gerados na MF são causados por erros estáticos [6]. A determinação destes erros para que modelos de compensação possam ser desenvolvidos ainda é foco de diversos estudos que propõem modelos numéricos para previsão e compensação de erros. Uma vez que a análise analítica é difícil devido à complexidade das formas e acoplamentos entre os elementos da máquina, métodos numéricos de solução são aplicados a modelos simplificados com base na estrutura real da máquina.

A análise de regressão é aplicada para resolver os coeficientes do polinômio do mo- 
Capítulo 1. Introdução

delo de erro térmico. Este método possui as vantagens: simples aplicação e redução do tempo computacional. Por outro lado, o método de redes neurais também utilizado para prever erros de posicionamento, possui melhor precisão que o método de regressão, porém o tempo computacional não satisfaz as exigências de um sistema de compensação , principalmente quando o sistema exige compensação real-time [27].

A análise cinemática da estrutura de uma MF é um dos métodos mais utilizados para mapear os erros angulares e de posicionamento linear de uma MF. Slocum determina uma relação entre o erro de posicionamento da peça e da ferramenta utilizando matrizes de transformação [35]. Para um sistema de coordenadas $(X, Y, Z)$, define-se uma matriz $4 \times 4$ com seus respectivos pontos de referência $\left(X_{R}, Y_{R}, Z_{R}\right)$ e sabendo o valor do erro de posicionamento, calcula-se o valor da coordenada $\left(X_{1}, Y_{1}, Z_{1}\right)$ que representa a posição relativa entre a peça e a ferramenta considerando o erro de posicionamento. A desvantagem deste método é o custo computacional elevado para calcular as iterações entre as matrizes.

A análise estrutural em MFs utilizando o Método dos Elementos Fintitos (MEF) mostra-se como uma ferramenta importante para predizer como a mesma irá se comportar devido à disposição de seus componentes e da própria estrutura, podendo dessa forma avaliar a melhor configuração no que diz respeito à rigidez e deformações. Este método é usado para avaliar os erros térmicos por meio de deformação termoelástica e análise de transferência de calor da estrutura da máquina. Além disso, fazendo a simulação do comportamento estrutural e térmico da MF durante um processo de usinagem é possível obter a variação aproximada de temperatura de qualquer ponto da máquina. Porém, para a implementação do modelo em elementos finitos, é necessário o conhecimento prévio das propriedades físicas do material da máquina e do fluxo de calor gerado durante o processo. Tais dados não são facilmente obtidos experimentalmente e calculá-los algebricamente envolve modelos matemáticos complexos.

Tendo como referência trabalhos experimentais realizados anteriormente [19, 21], 
verifica-se a grande dificuldade em se medir temperatura em processo de usinagem. A utilização de termopares como sensores de temperatura mesmo sendo uma das técnicas mais viáveis e utilizadas atualmente, são insuficientes para descrever toda a geração e propagação de calor que ocorre no processo. O sensor capta somente a temperatura do ponto em que este está localizado em um determinado instante. O calor gerado pela máquina ocorre em seu interior (motor, spindle etc) mas até este fluxo de calor alcançar a superfície (carcaça), onde o termopar está localizado, houve dissipação de energia entre os outros componentes da máquina. Consequentemente, a variação de temperatura captada pelo sensor é bastante reduzida em relação à variação real.

Este trabalho utilizou o método de regressão linear múltipla para compensação de erros em que a variação de temperatura experimental seja suficiente para obter uma correlação com o erro de posicionamento do eixo $X$. Porém, antes da aplicação deste método foi necessário sintetizar os dados experimentais por meio de matrizes de transformação homogêneas (Homogeneous Transformation Matriz - HTM) em que são armazenadas os dados de erro de posicionamento linear do eixo $X$. A utilização de ambos os métodos visa o desenvolvimento de uma nova metodologia que possa ser aplicada à compensação de erros de posicionamento. Os trabalhos experimentais para aquisição da variação de temperatura foi realizada através de termopares do tipo $K$ inseridos na MF, enquanto que os erros de posicionamento foram medidos por meio de um interferômetro a laser XL-80 da marca Renishaw ${ }^{\circledR}$.

A metodologia desenvolvida neste trabalho foi baseada nos dados experimentais extraídos da MF ROMI D800, porém a metodologia aplicada pode ser empregada para variados tipos de MF. 
Capítulo 1. Introdução

\subsection{Objetivos Gerais}

Levando em consideração os erros de posicionamento no eixo $X$ da MF gerados devido à geração de calor durante o processo de usinagem, este trabalho tem como objetivo desenvolver uma metodologia baseada em dois métodos numéricos, análise de regressão linear múltipla e matrizes de transformação homogênea para compensar estes erros.

\subsubsection{Objetivos Específicos}

- Medir experimentalmente a variação de temperatura em alguns pontos específicos da MF;

- Medir experimentalmente os erros de posicionamento no eixo $X$ causados pela variação de temperatura;

- Estudar modelos matemáticos que descrevem os erros de posicionamento da MF;

- Desenvolver uma metodologia para compensar estes erros de posicionamento no eixo $X$.

\subsection{Estrutura do Trabalho}

Este trabalho divide-se em sete capítulos, brevemente descritos a seguir:

- Capítulo 1: Introdução e contextualização - Apresenta a motivação para o desenvolvimento deste trabalho, descrevendo o problema a ser tratado e a proposta de solução para o tema.

- Capítulo 2: Revisão da literatura - A interdisciplinaridade do trabalho exige que todos os conteúdos necessários para seu desenvolvimento sejam estudados e este capítulo mostra um levantamento com as referências mais importantes encontradas de cada tema envolvido. 
- Capítulo 3: Método a ser usado para compensação de erros térmicos em um centro de usinagem - Neste capítulo os modelos matemáticos utilizados no método desenvolvido são descritos.

- Capítulo 4: Trabalho experimental - Descreve-se cada etapa do procedimento experimental e os equipamentos utilizados em cada procedimento.

- Capítulo 5: Resultados e discussão - Após os ensaios experimentais e a aplicação do método matemático para compensação de erros são apresentados os resultados e um análise sobre eles é apresentada neste capítulo.

- Capítulo 6: Conclusões - São descritas as conclusões finais do trabalho.

- Capítulo 7: Trabalhos futuros - Sugestões para trabalhos futuros envolvendo o trabalho em questão. Algumas ideias de como desenvolver o trabalho de diferentes formas.

- Referências Bibliográficas: Contém todas as referências bibliográficas consultadas e citadas. 



\section{Capítulo 2}

\section{Revisão da Literatura}

\subsection{Evolução das máquinas-ferramenta com controle nu- mérico}

No início da década de 1800, o francês Joseph Marie Jacquard desenvolveu um tear com comando automático. Esta máquina de tecer possuía uma leitora automática de cartões perfurado que comandavam os movimentos da lançadeira.

O tear muito se difere das MFs e de computadores, porém o princípio utilizado na automatização do tear foi a base para a evolução de outras máquinas.

Quase um século mais tarde, o empresário norte americano Herman Hollerith fundador da empresa IBM, baseando-se na invenção do francês Jacquard, criou uma máquina para realizar operações de recenseamento da população para o governo dos Estados Unidos. A máquina armazenava dados nos cartões perfurados e assim Hollerith deu início ao conceito e aplicação de armazenamento e processamento de dados.

No mesmo século, M. Founeaux patenteou o piano automático, pianola, em que uma tira de papel perfurado comandava através de ar comprimido o acionamento mecânico da teclas e assim produziam as melodias.

Em 1947 uma empresa chamada Parsons Corporation fabricante de hélices e rotores 
de helicópteros, conectou uma máquina de usinagem convencional a um computador alimentado por dados de cartões perfurados. Em seguida, pela necessidade de produzir componentes aeronáuticos mais complexos e com maior precisão, a Força Aérea Americana (FAA) se uniu a esta empresa e patrocinou estudos para o desenvolvimento do controle numérico.

No ano de 1952, foi demostrado o protótipo da primeira MF controlada numericamente, a Cincinnati-Hydrotel. A unidade de controle controlava 3 eixos simultaneamente e obtinha seus dados por meio de fitas perfuradas em código binário. Um cinzeiro foi então fabricado a partir de uma chapa sem a intervenção de um operador. Em 1957 a FAA instala a primeira fresadora em sua oficina.

Na década de 1960 já existiam cartões perfurados com números em código indicando dimensões das peças. A década de 1970 foi marcada pela ampla utilização das MFs com controle numérico na indústria de manufatura. Em 1980, foi feita a primeira ligação entre os sistemas CAD (computer-aided design) e CAM (computer-aided manufacturing) e a transmissão destes programas para o controle numérico da máquina. O sistema CAD é empregado nas atividades de desenvolvimento de produtos (design industrial) e projeto. O CAD tem por objetivo auxiliar no desenho e modelamento de peças pela interação com o computador em que são definidas todas as informações geométricas necessária para a manufatura. A geometria CAD é utilizada pelo sistema CAM como base de cálculo das trajetórias da ferramenta. Após o cálculo, o percurso da ferramenta deverá ser simulado e posteriormente codificado em comandos, os quais possam ser interpretados e transformados pelo CNC em movimentos e acionamentos [36].

Paralelamente a este elevado desenvolvimento das MFs com controle numérico nas décadas de 1960 e 1970, a indústria de manufatura brasileira, que até o momento encontrava-se em defasagem, tenta alcançar o nível do padrão tecnológico internacional . Ao fim da década de 1970 o Brasil subiu para o $11^{\circ}$ no ranking mundial [17]. A primeira indústria brasileira que produziu uma MF com controle numérico foi a empresa ROMI. 
Este torno era um modelo DCE-480, que foi preparado para receber os servo motores e acionamentos para interfacear com o CN (Figura 2.1). Porém, a tecnologia em comando numérico ainda era dependente de fornecedores internacionais.

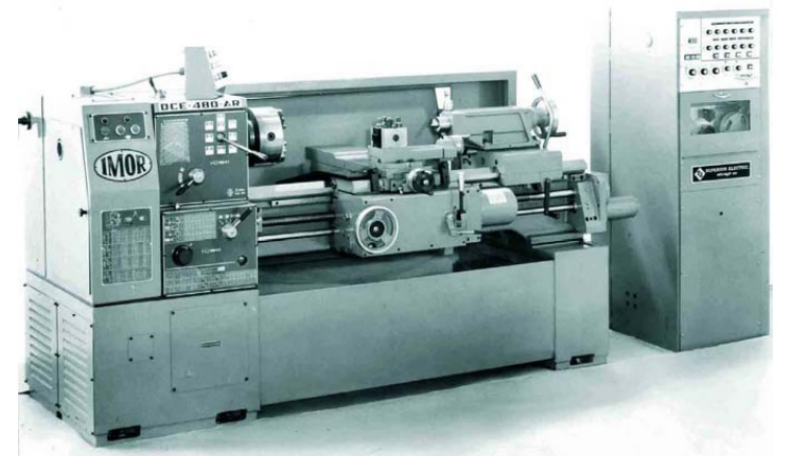

Figura 2.1: Torno da ROMI DCE 480

Em 1987, foi apresentada na FEIMAFE (Feira Internacional de Máquinas-Ferramenta e Sistemas Integrados de Manufatura) o torno ROMI Centur30 equipado com o CN 210 da MCS com tecnologia $100 \%$ nacional.

As décadas seguintes foram marcadas por um elevado desenvolvimento tecnológico em diversas áreas da indústria como automobilística, aeronáutica, metalúrgica. Como consequência, a demanda por uma produção otimizada em relação ao tempo e qualidade do produto cresceu de forma proporcional a este desenvolvimento. A automação se tornou uma necessidade e os controles numéricos já eram programados para manipulação de peças, sistemas de mudanças automática de ferramentas e compensação de erros.

A fabricação se tornou mais independente do operador, pois a maioria das tarefas executadas pelo operador são automatizadas pelo controle numérico. A vantagem é o aumento da produção e melhoria na qualidade e precisão das peças fabricadas. Por outro lado, o comportamento da indústria teve de ser diferenciada e novos padrões e estratégias de sistemas organizacionais e administrativos de produção foram aplicados. Entre eles pode-se citar Total Preventive Maintenance (TPM), Sistema de Produção em Células (SPC) e just-in-time [37]. Neste contexto, exige-se uma nova postura e 
qualificação dos profissionais. Elege-se como ideal o profissional que potencialize a comunicação, a interpretação de dados, a flexibilização, a integração funcional e a geração, absorção e troca de conhecimento. O novo profissional deve ser capaz de interpretar dados e sinais emitidos pelos novos sistemas autômatos, agindo pró-ativamente a partir desses dados, atuando como agente do processo de inovação [3].

\subsection{Análise estrutural de uma máquina-ferramenta}

Segundo Thyer, a estrutura de uma MF deve servir de apoio para todos os outros componentes funcionais da máquina. Esta estrutura necessita ter resistência suficiente para resistir ao conjunto de forças durante o processo de fabricação [42].

As forças resultantes da operação tem intensidades e sentidos variados. Portanto, a estrutura deve mover-se sem sofrer flexão e, assim, manter sua integridade estrutural, o alinhamento e posicionamento dos componentes que lhe estão associados.

Porém, as forças de inércia, vibrações, variações de velocidade, desgaste e aquecimento podem causar deformações e desequilíbrios na estrutura do material.

A estrutura de uma MF deve atender aos seguintes requisitos:

- rigidez estática;

- rigidez dinâmica;

- estabilidade térmica;

- estabilidade química;

- facilidade de manutenção;

- acessibilidade aos componentes internos.

A American National Standards Institute ANSI (1992) define looping estrutural a montagem de elementos mecânicos, os quais mantêm a posição relativa entre partes 
específicas. Em um caso típico de usinagem, a peça e a ferramenta são partes específicas da MF e o looping estrutural inclui o eixo-árvore, os mancais e o cabeçote, as guias, a estrutura, os acionamentos e a ferramenta com seu sistema de fixação.

A rigidez estática se caracteriza pelas deformações resultantes dos esforços aplicados sobre a MF, sendo as mais importantes, aquelas causadas por carregamentos flexivos e torcionais. Esses carregamentos são importantes, pois geralmente resultam em desalinhamentos e deslocamentos dos elementos guias, ocasionando assim inexatidões na máquina. A origem dessas deformações são principalmente decorrentes do peso das partes móveis, peso das peças de trabalho, forças de usinagem e gradientes térmicos [40].

Segundo Schellekens et al., o fato de as máquinas não serem estáticas, mas conter partes em aceleração significa que os efeitos dinâmicos podem exercer uma função em seu comportamento. Devido às forças de excitação dinâmica, o sistema MF é submetido à vibração [32].

O problema da rigidez dinâmica pode ser em parte atenuado com a escolha dos materiais que formarão a estrutura, com uso de dissipadores de energia e isoladores de vibrações [40].

A estabilidade térmica também é um fator importante a ser considerado durante a fabricação de uma MF. Toma-se o cuidado de se fazer uma estrutura simétrica e um sistema de refrigeração para evitar danos relativos ao aquecimento. Porém, a temperatura pode variar significativamente durante um processo que tenha elevada velocidade e força de avanço. Com esta variação pode haver uma dilatação na estrutura da máquina que prejudica na qualidade final da peça a ser usinada.

Ramesh et al. classificam três possíveis soluções para o problema de variação de temperatura na MF [29]:

- controle do fluxo de calor dentro do ambiente da MF; 
- reprojeto do sistema MF para estabilizar o fluxo de calor;

- a compensação dos desvios por meio do movimento controlado.

A estabilidade e rigidez de uma MF depende também dos materiais com que esta foi fabricada. O ferro fundido possui o módulo de elasticidade específico cerca de $65 \%$ menor que o valor do aço, tornando o uso e a distribuição do material como sendo um dos mais importantes parâmetros de projeto de estruturas inerciais carregadas [14]. Contudo, com o avanço da engenharia de materiais, novos materiais vem sendo desenvolvidos. Como exemplo, o concreto polimérico, também conhecido como granito sintético, possui baixo coeficiente de dilatação térmica, maior capacidade de amortecimento e menor peso [39].

Um dos elementos estruturais mais importantes da MF são as guias, pois são responsáveis pelo movimento efetuado por esta ao longo do eixo. Em guias lineares, geralmente o movimento ocorre em apenas uma direção restrita a um grau de liberdade [40]. Assim como as demais estruturas da MF, as guias devem ser fabricadas com rigidez (estática e dinâmica) suficiente para suportar as elevadas forças geradas durante o processo de usinagem.

Uma vez que as guias garantem o movimento linear relativo entre os elementos contituintes da MF, a estrutura que garante movimento rotativo é chamada de mancal. Ou seja, estes elementos servem de apoio fixo aos elementos (eixos e árvores) que possuem movimentos giratórios. Existem dois principais tipos de mancais: de deslizamento e de rolamento. Os mancais de deslizamento são todos os mancais cujo trabalho se baseia no deslizamento com elevado atrito dos elementos envolvidos. Os mancais de rolamento são os mais utilizados na indústria mecânica e definem-se como superfícies separadas por um elemento rolante, o qual pode ser esférico, cilíndrico, cônico, na forma de barril ou de agulha. Nestes, os carregamentos são absorvidos pela deformação elástica de contato dos elementos rolantes junto aos anéis [40]. 
A estrutura responsável pelo movimento rotativo da ferramenta em um centro de usinagem é o eixo-árvore. Para sua fabricação, deve-se estudar cuidadosamente sua estrutura e dimensionamento, pois grande parte dos esforços gerados pelo processo de usinagem (velocidade angular, torque e potência) são absorvidos pelos seus mancais [40]. Para velocidades baixa e média, o eixo-árvore é conectado ao motor elétrico via correia em formato "V"ou polias sincronizadas. Deve haver um redutor de engrenagens e um acoplamento entre o motor elétrico e o eixo-árvore. Para alta velocidade (maiores que $1.500 \mathrm{rpm}$ ), é possível construir motores elétricos dentro do eixo-árvore e, com isso, reduzir a inércia e o atrito produzidos pelo acoplamento entre o motor elétrico e o eixo-árvore [14].

Os comandos para os movimentos dos componentes móveis da MF são dados pelo sistema de controle. Este gerencia todas as informações relevantes da máquina, sendo que essas podem ser divididas em informações primárias e secundárias.

As informações primárias restringem-se ao controle dos movimentos principais da máquina, distribuídos entre a rotação da árvore e as translações dos eixos, incluindo direção, aceleração e velocidade de avanço e tamanho dos deslocamentos. As informações secundárias são gerenciadas por um CLP (Controle Lógico Programável) e representam as funções pertinentes ao controle dos sistemas auxiliares, tais como refrigeração, aspiração e transporte de cavaco, pressão nas linhas de ar comprimido e de fluido hidráulico, vácuo, temperatura e estado de deformação da estrutura, níveis de vibrações e potência consumida, provendo ao usuário informações gerais sobre o estado da máquina e o andamento do processo.

Os componentes do acionamento de avanço mecânico incluem todos os componentes estruturais que se encontram no fluxo de energia entre o servomotor e a ferramenta ou peça de trabalho. Além de um componente para converter rotação em movimento de translação, como um fuso de esferas, é necessário o mecanismo de avanço, os componentes para transmissão de potência (sistemas de fixação da peça e ferramenta, guias 
lineares e rolamentos) e o acoplamento [5].

As máquinas CNC têm servomotores e um computador equipado com unidade de emergência, controle e interface de operação. A velocidade de avanço e exatidão de posicionamento dos acionadores de avanço são dependentes do torque e da potência disponibilizados pelos servomotores e dos algoritmos dos servocontroladores do acionamento de avanço, executados no comando numérico da máquina [1].

\subsection{Controle Numérico Computadorizado - CNC}

Também chamado de comando numérico computadorizado, o CNC do inglês Computer Numeric Control, é um controlador numérico que permite o controle de máquinas, geralmente em tornos mecânicos e centros de usinagem.

Uma MF com CNC é composta de uma unidade de comando (computador que se encarrega de realizar todos os cálculos e as operações lógicas), a máquina e os acionamentos responsáveis pelos movimentos dos eixos (servomotores/servomecanismos).

Os comandos obedecem a uma lista de movimentos específicos programados em linguagem G (código G). Este sistema funciona como um sistema operacional, possibilitando a comunicação com o operador por meio de uma interface de controle, que atua sobre cada um dos controladores dos eixos e sobre o sistema de alimentação auxiliar de potência. O esquema de um sistema CNC é representado pela Figura 2.2.

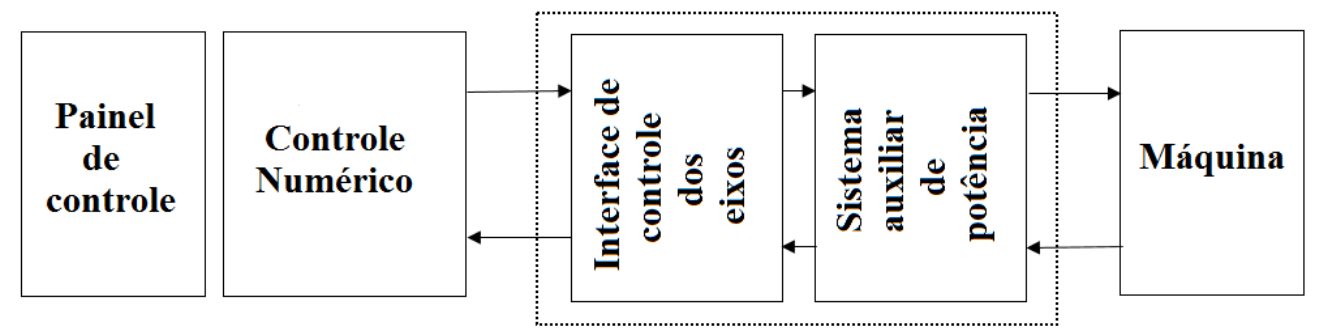

Figura 2.2: Esquema de um sistema CNC

Nos tornos, os movimentos são delimitados por dois eixos, o $Z$ (movimento lon- 
gitudinal) e $X$ (movimento transversal). Em uma fresadora, o movimento no eixo $Y$ (movimento transversal secundário) é adicionado. Estes três eixos $X, Y, Z$ compõem os eixos principais da MF.

O tipo de eixo e sua designação são normalizados para cada tipo de máquina. Atualmente é possível encontrar no mercado máquinas com cinco eixos ou mais, sendo os três eixos principais mais dois eixos complementares de rotação. A Figura 2.3a mostra a direção dos respectivos eixos.

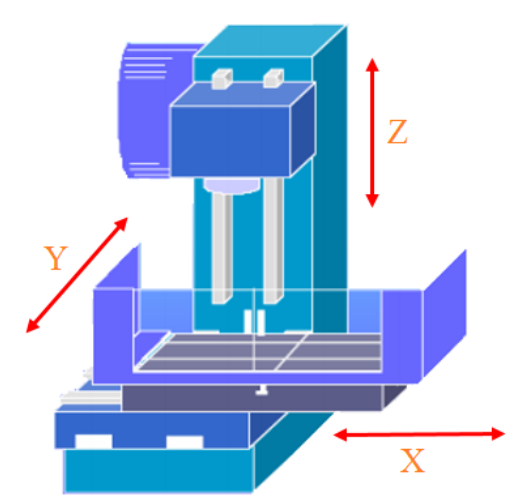

(a) Eixos de uma máquina CNC

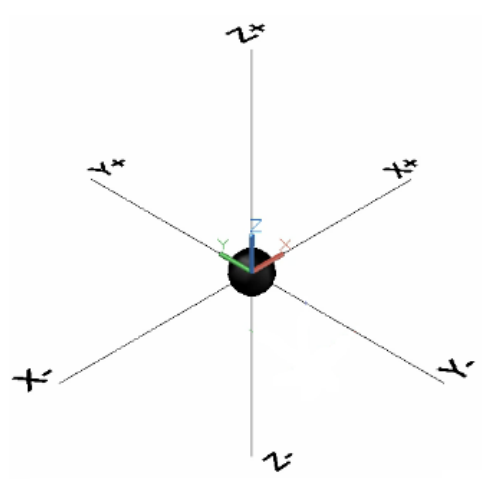

(b) Sistema de coordenadas

Figura 2.3: Eixos principais de uma máquina-ferramenta CNC

O operador da máquina deve controlar a ferramenta de forma precisa durante estes movimentos e para isto é definido um sistema de coordenadas que proporciona uma referenciação ao programador durante o desenvolvimento dos seus programas. Neste sistema de coordenadas são estabelecidos pontos de origem e de referência, de tal forma que a programação dos movimentos seja mais precisa.

Considera-se o ponto zero $(M)$ na MF onde os três eixos se interceptam, que também é chamado de ponto de origem do sistema de coordenadas $(0,0,0)$, conforme a Figura $2.3 \mathrm{~b}$.

O ponto zero é definido pelo fabricante da MF e é utilizado como ponto inicial para todos os outros sistemas de coordenadas e pontos de referência.

O ponto de referência da máquina $(\mathrm{R})$, também conhecido como grid de zeragem ou 
home position é utilizado na aferição e controle do sistema de medição dos movimentos da máquina. Ao ligar a máquina, desloca-se o carro até este ponto antes de iniciar a usinagem. Este procedimento define ao comando a posição do carro em relação ao zero da máquina, quando o carro aciona um sensor que envia um impulso ao comando determinando sua localização.

O ponto zero da peça é determinado pelo programador e usado para definir as coordenadas durante a elaboração do programa. Geralmente, define-se o sistema de coordenadas da peça em relação ao ponto zero da máquina, de tal forma que se possam transformar facilmente as medidas do desenho da peça em valores de coordenadas. Isto permite que o programador especifique movimentos a partir de um lugar comum.

As definições dos pontos de referência são seguidos da programação da trajetória da ferramenta, que é composta por uma sequência de comandos em códigos interpretados pela máquina CNC e por coordenadas. Estas coordenadas podem ser absolutas ou incrementais.

As coordenadas absolutas são representadas pelo código G90 e as posições são medidas em relação à posição zero da peça. No modo de programação em coordenadas incrementais, as posições dos eixos são medidas a partir da posição anteriormente estabelecida e é representada pela função G91 na linguagem CNC. Este último método é mais vunerável a erros. Se houver um erro em uma trajetória, consequentemente todos os outros movimentos subsequentes também estarão errados, uma vez que o movimento da ferramenta é baseada no ponto atual da peça e não no ponto zero. Por outro lado, quando o método das coordenadas absolutas é utilizado, a probabilidade de ocorrer este acumulo de erros é significativamente menor. Além disso, o ponto de referência é sempre o mesmo (o ponto zero), sendo menor a possibilidade de ocorrer algum engano por parte do operador.

A Figura 2.4 sugere uma trajetória para ferramenta no sistema de coordenadas no plano $X$ e $Y$. Em seguida tem-se duas tabelas referentes às coordenadas no modo 
absoluto e no modo incremental.

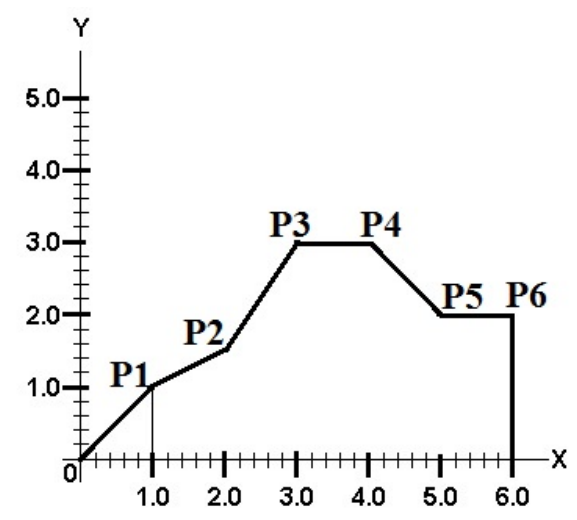

Figura 2.4: Movimento da ferramenta no plano $X$ e $Y$

Tabela 2.1: Coordenada absoluta

\begin{tabular}{ccc}
\hline & Eixo X & Eixo Y \\
\hline Ponto 1 & 1,0 & 1,0 \\
Ponto 2 & 2,0 & 1,5 \\
Ponto 3 & 3,0 & 3,0 \\
Ponto 4 & 4,0 & 3,0 \\
Ponto 5 & 5,0 & 2,0 \\
Ponto 6 & 6,0 & 2,0 \\
\hline
\end{tabular}

Tabela 2.2: Coordenada incremental

\begin{tabular}{ccc}
\hline & Eixo X & Eixo Y \\
\hline Ponto 1 & 1,0 & 1,0 \\
Ponto 2 & 1,0 & 0,5 \\
Ponto 3 & 1,0 & 1,5 \\
Ponto 4 & 1,0 & 0,0 \\
Ponto 5 & 1,0 & $-1,0$ \\
Ponto 6 & 1,0 & 0,0 \\
\hline
\end{tabular}

Neste exemplo, o ponto incial de referência é a coordenada $(0,0)$. Para que a ferramenta se mova até o ponto $P 1=(1 ; 1)$, o comando deve ser X1, Y1. A mudança no comando ocorre a partir do ponto P2. No modo absoluto, o comando é X2 e Y1,5. Para o modo incremental, o comando para a ferramenta se mover até $P 2$ é X1 e Y0,5. Da mesma forma, calcula-se a trajetória para os demais pontos.

Para descrever o percurso que a ferramenta deve seguir, o CNC utiliza métodos de interpolação definidos pelos comandos G01, G02 e G03, cujas funções serão descritas a seguir:

- Comando G01 (Interpolção linear com avanço de trabalho): na interpolação linear a trajetória da ferramenta é descrita por segmentos de retas, confrome a Figura 
2.5 .

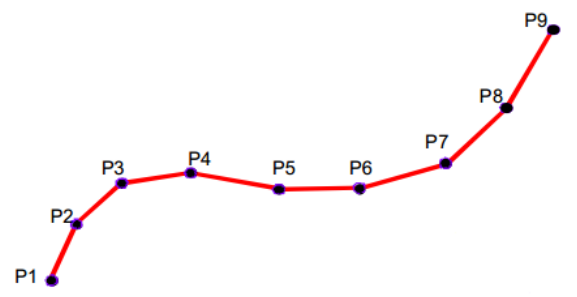

Figura 2.5: Interpolação linear (Adaptado de [33])

Os pontos cartesianos representam o início e o fim dos segmentos de retas. Este é o método de interpolação mais simples de ser utilizado, porém não é recomendado para usinagem de peças com superfícies complexas. Para representar um movimento circular com interpolação linear, haverá vários segmentos de retas que se aproximam do movimento desejado, aumentando a possibilidade de baixa qualidade e precisão.

- Comando G02 (Interpolação circular horária): A trajetória é feita de forma circular entre dois pontos, baseando-se na medida do raio imposto pelo operador da máquina. A Figura 2.6 mostra um exemplo em que é utilizado interpolação linear e circular.

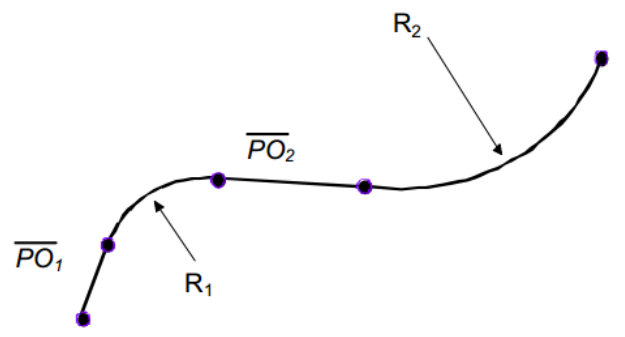

Figura 2.6: Interpolação circular (Adaptado de [33])

Os segmentos $P \bar{Q}_{1}$ e $P \bar{Q}_{2}$ representam segmentos de retas enquanto os movimentos circulares estão associados aos raios da circunferência por $R_{1}$ e $R_{2}$. As Figuras 2.5 e 2.6 representam geometrias parecidas realizadas por diferentes interpolações. Porém, na primeira foi necessário descrever nove pontos e na segunda 
apenas cinco. Em geometrias mais complexas, esta diferença pode ser maior e, consequentemente, há uma diminuição do número de movimentos a ser processado pelo CNC e é possível trabalhar com elevadas forças de avanço em segmentos de maior dimensão.

- Comando G03 (Interpolação circular anti-horária): movimento equivalente ao anterior com direção oposta.

Um método de interpolação mais recente visa o aumento da qualidade da superfície usinada e a redução no tempo de usinagem. O método de interpolação NURBS (Non-Uniform Rational B-Spline), é um método utilizado para descrever trajetórias em superfícies mais complexas utilizando um número menor de curvas. Uma vez que a interpolação é realizada por meio de funções Spline, é garantido que a curva complexa será representada por um polinômio de baixo grau.

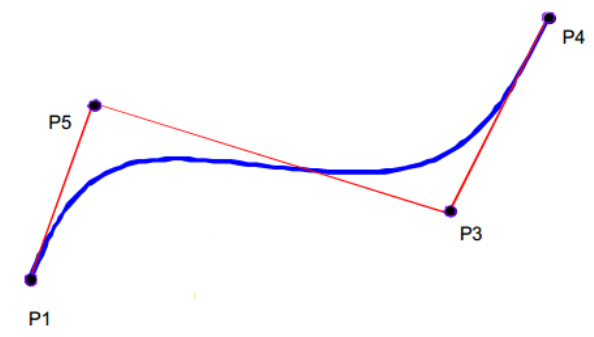

Figura 2.7: Interpolação NURBS (Adaptado de [33])

Para descrever a trajetória da ferramenta através da interpolação NURBS o programa utilizará um modelo matemático para interpolar o grupo de pontos. Contudo, neste método os movimentos não obedecem aos comandos tradicionais G01, G02 e G03 [9].

Matematicamente, as soluções de uma interpolação, calculadas pelo controle numérico da máquina, são precisas. O algoritmo desenvolvido para este tipo de problema não considera possíveis erros gerados durante o trabalho da MF. Desta maneira, quando o comando da trajetória for acionado, a posição final da ferramenta, calculada pelo mé- 
todo de interpolação pode não ser a mesma da posição real da ferramenta.

\subsection{Classificaçãos dos erros de medição}

Todo trabalho que depende de valores mensurados lida com diversos conceitos de erro que muitas vezes podem ser confundidos ou até mesmo podem ser definidos de diferentes formas em cada um deles. Para evitar este tipo de conflito, serão consideradas as definições do Guia para a expressão de incerteza de medição, uma tradução do GUM 2008 ("Guide to the expression of uncertainty in measurement") realizada por seis pesquisadores do Inmetro (Instituto Nacional de Metrologia, Qualidade e Tecnologia).

\subsubsection{Conceitos associados ao erro de medição}

Mensurar uma grandeza pode não ser uma tarefa tão simples. Para cada tipo de grandeza existe uma ou várias técnicas de medir que devem ser cuidadosamente analisadas e aplicadas para que as imperfeições da medição sejam as menores possíveis. Essas imperfeições estão diretamente relacionadas com um erro no resultado da medição.

Segundo o JCGM (Comitê Conjunto para Guias em Metrologia), o erro é contituído por dois componentes: um componente aleatório e um componente sistemático. Estes conceitos são definidos a seguir:

- Erro de medição: valor medido de uma grandeza menos o valor verdadeiro.

- Erro aleatório: componente de erro de medição que, em medições repetidas, varia de forma imprevisível. Desta maneira, um erro aleatório não pode ser compensado, porém ele pode geralmente ser reduzido aumentado-se o número de observações. Sua esperança ou valor esperado é zero.

- Erro sistemático: são devidos a causas identificáveis e, portanto, o efeito que causa o erro pode ser quantificado e, se for significativo com relação à exatidão 
requerida da medição, uma correção ou um fator de correção pode ser aplicado para compensar o efeito.

Os erros sistemáticos ainda podem ser subdivididos em três categorias: erros cíclicos, erros progressivos e erros de histerese [13]. O erro cíclico é um tipo de erro cujo comportamento se repete pelo menos uma vez ao longo do eixo da máquina. O erro progressivo pode ser crescente ou decrescente. A histerese pode ser observada para cada posição da medida e seu valor é definido pela máxima diferença entre a medição no avanço e no retorno.

Weck (1984) propõe uma classificação dos erros quanto ao comportamento [45]. A histerese $U_{i}$ é definida pela equação:

$$
U_{i}=\mid \bar{x}_{i} \text { avanço }-\bar{x}_{i} \text { retorno } \mid
$$

O erro de histerese é definido como sendo um erro de natureza sistemática e pode ser observado quando os erros nos sentidos de ida e de volta são avaliados em cada um dos pontos de medição.

A equação do erro sistemático é dada por:

$$
\overline{\bar{X}}=\frac{\bar{x}_{i} \text { avanço }-\bar{x}_{i} \text { retorno }}{2}
$$

e a equação do erro aleatório é:

$$
P_{S i}=4 \bar{S}_{i}
$$

onde

$$
\bar{S}_{i}=\frac{\bar{s}_{i} \text { avanço }+\bar{s}_{i} \text { retorno }}{2}
$$

Weck (1984) representa as curvas de erros pela Figura 2.8 [45]: 


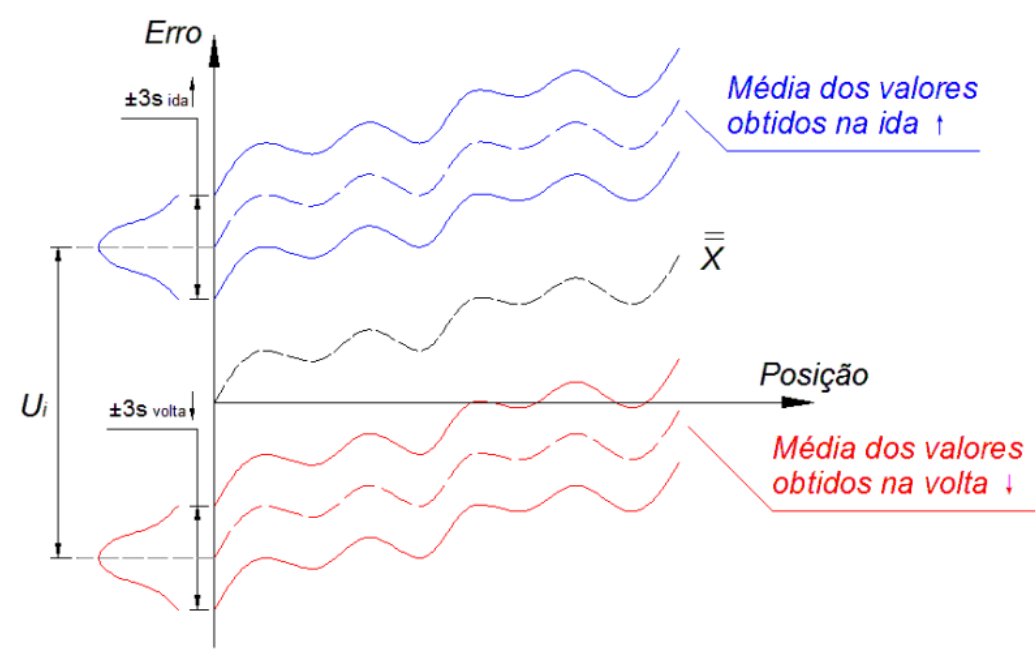

Figura 2.8: Erro aleatório, sistemático e histerese (Adaptado de [45])

As curvas de erros mostradas nesta figura representam os resultados de uma calibração hipotética para um dos erros geométricos. Para cada posição observada nas duas direções de movimento, tem-se um erro aleatório definido como \pm 2 vezes o desvio padrão da média dos dados observados nessa posição.

Os conceitos de erro definidos são idealizados, sendo praticamente impossível conhecer seu verdadeiro valor. Daí surge o termo estatístico "incerteza". A incerteza é definida como o parâmetro associado ao resultado da medição, que caracteriza a dispersão de valores que podem ser atribuídos ao mensurando.

O resultado de uma medição, após correção dos efeitos sistemáticos reconhecidos, é ainda e tão somente uma estimativa do valor do mensurando oriunda da incerteza proveniente dos efeitos aleatórios e da correção imperfeita do resultado para efeitos sistemáticos [4].

\subsection{Principais fontes de erro em máquinas-ferramenta}

Diversos fatores influenciam no posicionamento da ferramenta em relação à peça. Entre eles, os principais fatores que influenciam este erro relativo são os erros geométricos da 
MF e os efeitos térmicos sobre os eixos. Outras fontes de erros são a precisão do sistema de medição linear, deformação elástica dos componentes de acionamentos, forças de gravidade, sistemas de controle, forças de corte e vibrações. A Figura 2.9 agrupa estes erros em erros sistemáticos e aleatórios.

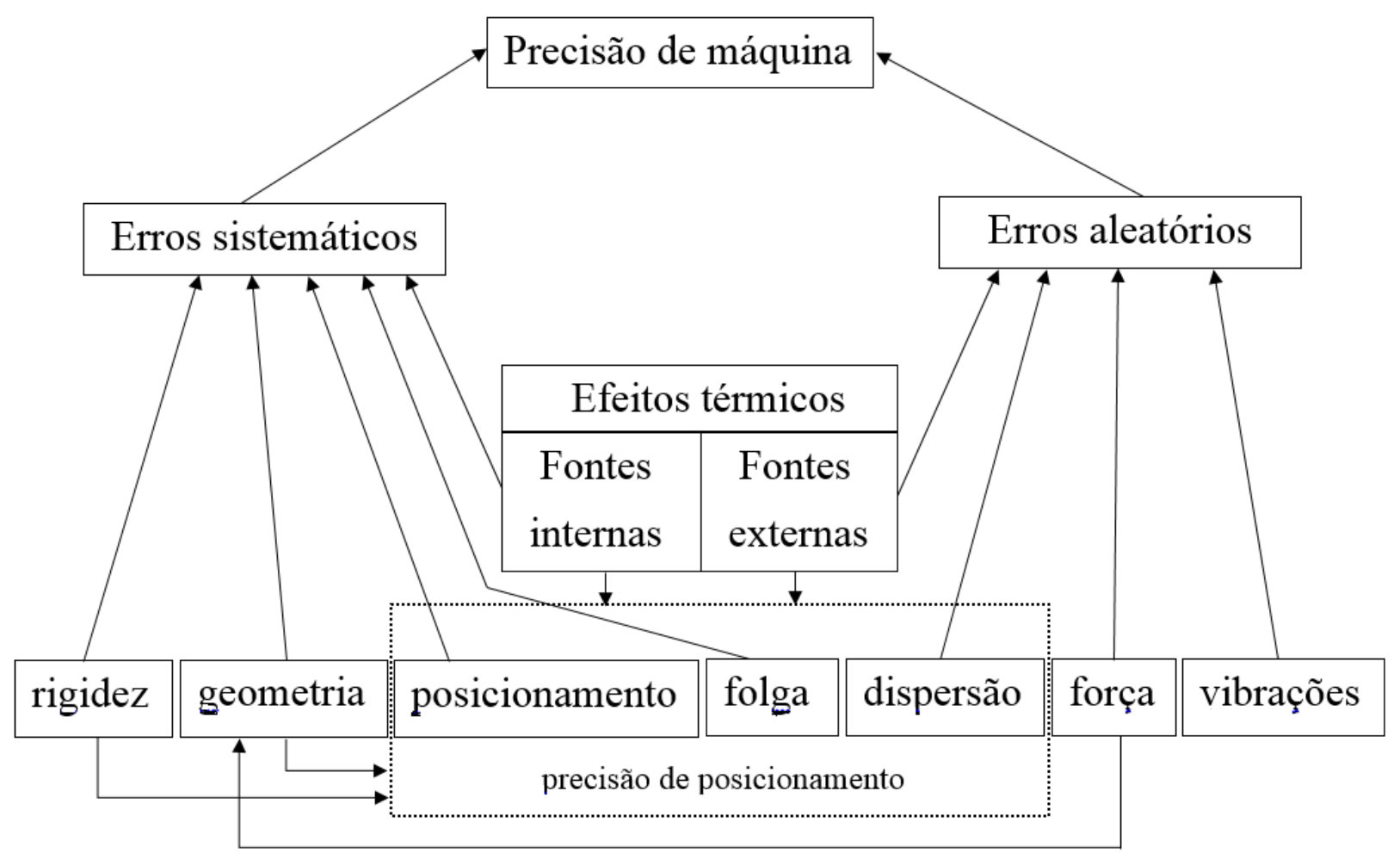

Figura 2.9: Fontes de erro de uma máquina-ferramenta (Adaptado de [2])

\subsubsection{Erros geométricos}

Os erros geométricos ocorrem em todos os eixos e são compostos por três eixos de translação e três eixos de rotação. Estes erros são provenientes de imperfeições mecânicas nas estruturas das MFs e de desalinhamentos dos componentes. Como resultado, obtém-se a falta de paralelismos e de perpendicularismos nos movimentos dos diversos componentes, ocasionando erros de posição e forma [35].

A Figura 2.10 mostra os seis componentes de erro em uma MF, onde $O X Y Z$ re- 
presenta o ponto de referência do sistema de coordenadas, $O_{1} X_{1} Y_{1} Z_{1}$ o sistema de coordenadas a ser movimentado, $X$ a direção desejada de movimento, $\epsilon_{x}(x)$ é o erro de rotação em torno do eixo $X$ (rolamento), $\epsilon_{y}(x)$ é o erro de rotação em torno do eixo $Y$ (tombamento), $\epsilon_{z}(x)$ é o erro de rotação em torno do eixo $Z$ (guiamento), $\delta_{x}(x)$ é o erro de translação ao longo do eixo $X, \delta_{y}(x)$ é o erro de translação ao longo do eixo $Y$ (linearidade horizontal) e $\delta_{z}(x)$ é o erro de translação ao longo do eixo $Z$ (linearidade vertical).

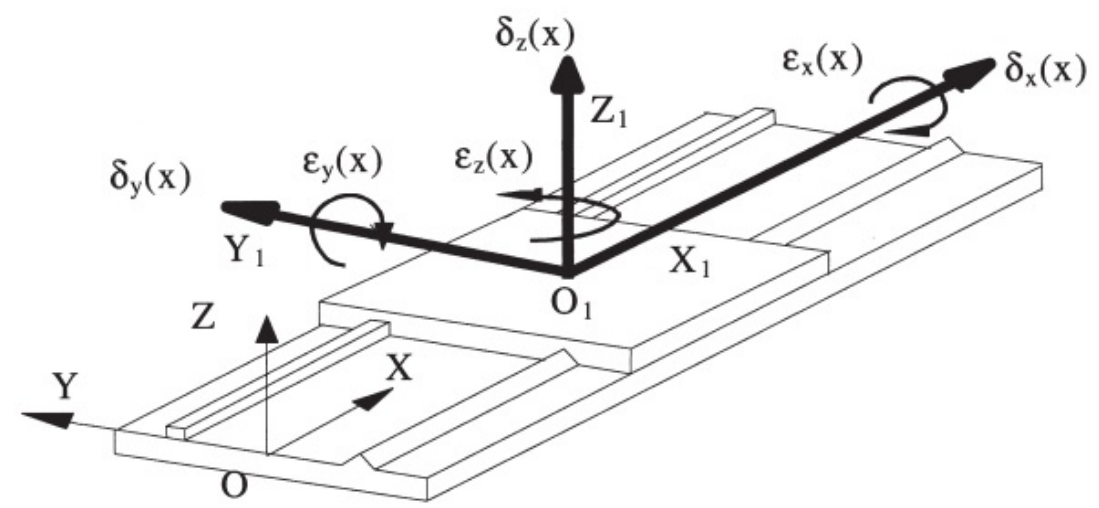

Figura 2.10: Esquema de erro em uma MF com seis graus de liberdade (Adaptado de [24])

Segundo Okafor e Ertekin, existem 21 erros geométricos em um centro de usinagem de três eixos. São eles: 3 erros lineares de posição, 6 erros de retilineidade, 9 erros angulares e 3 erros de ortogonalidade dos eixos da MF (perpendicularidade) [24]. A Figura 2.11 mostra uma peça com a geometria desejada. Em seguida são mostrados na Figura 2.12 a influência dos principais erros geométricos nesta peça hipotética.

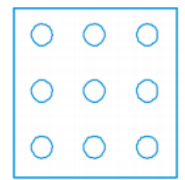

Figura 2.11: Peça hipotética

Esforços mecânicos estáticos e dinâmicos causados pelo próprio peso da máquina, 


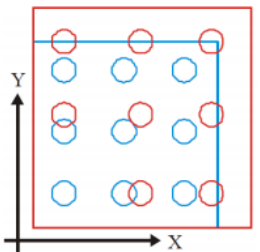

(a) Erro de posicionamento

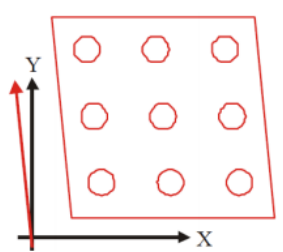

(b) Erro de perpendicularidade

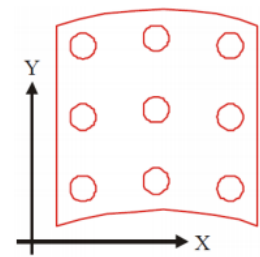

(c) Erro de retilineidade em X

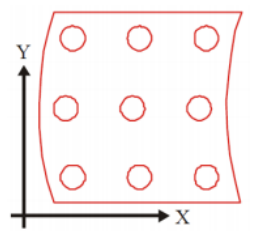

(d) Erro de retilineidade em Y

Figura 2.12: Erros geométricos de uma máquina-ferramenta (Adaptado de [8])

pelo peso da peça e pelos esforços do processo de usinagem podem afetar o comportamento geométrico das MFs, na medida em que causam deformações elásticas que podem modificar a posição correta entre a peça e a ferramenta [45].

Segundo Fagali, um dos fatores que influencia os erros geométricos da peça usinada é a velocidade de processamento do CNC [9]. Esta, deve ser alta para que não haja sobrecarga do cálculo que retarde ou cause oscilações no avanço da ferramenta.

\subsubsection{Erros de posicionamento}

O erro de posicionamento é definido como o desvio entre a posição real e teórica de um determinado elemento. Alguns fatores que geram este tipo de erro são: rugosidade e dureza superficiais das peças responsáveis pelas movimentações dos eixos, componentes de controle dos atuadores e pré-cargas em rolamentos.

A maioria das máquinas CNC possui um transdutor linear (converte movimento linear em sinal elétrico) conhecido como régua óptica, que efetua uma leitura direta da posição do eixo no qual está instalada e envia sinais relativos à posição do eixo CNC. Esta régua óptica é composta por uma placa com divisões que faz a função do disco no encoder. Ao se movimentar, a placa (régua), interrompe o feixe de luz que ilumina o fotossensor. Dessa forma uma sequência de pulsos é gerada. Novamente são usados dois conjuntos de fotossensores para gerar sinais defasados entre si que permitam distinguir o sentido do movimento. Assim, o erro de posicionamento é identificado e enviado ao 
CN da máquina para que a devida compensação possa ser realizada.

A principal desvantagem é o custo elevado do equipamento. Se a empresa opta por desenvolver uma MF mais precisa, será necessário um maior investimento, aumentando o preço da máquina.

Os resultados do trabalho de Okafor e Ertekin mostraram que motores de acionamento dos eixos são as principais fontes de calor [24]. A precisão da posição linear é melhor quando a máquina está fria e se deteriora com o aumento do tempo de operação da máquina nos três eixos. O maior erro de posicionamento encontrado foi no eixo $X$.

\subsubsection{Erros dinâmicos}

Os erros dinâmicos ocorrem devido a vibrações na MF. Algumas das fontes de vibrações são: compressores de ar, equipamentos de ventilação, vibração transmitida através do chão da fábrica, rotação mecânica dos componentes da MF, tais como motores e transmissores.

Estes erros fazem parte do conjunto de erros aleatório, ou seja, imprevisíveis. Vários são os fatores que alteram a dinâmica da máquina. [23] definem quantitativamente a componente variável de um erro dinâmico.

\subsubsection{Erros térmicos}

Os erros térmicos são aqueles que causam um deslocamento relativo entre a peça e a ferramenta, por conta da deformação ou expansão dos elementos da máquina, devido a um aumento em sua temperatura. O movimento relativo entre vários componentes da máquina gera calor nas zonas de contato e é esse calor que leva à deformação destes elementos [28].

Entre várias fontes que causam erros de posicionamento na MF, erros termicamente induzidos compõem 40-70\% do erro total, seguindo por erros geométricos causados por erros de fabricação [30]. Entretanto, problemas térmicos são mais complicados que 
problemas geométricos porque o campo de temperatura da MF muda constantemente de acordo com a complexidade da máquina, ciclos de trabalho e condições ambientais [6]. As fontes de calor geradas internamente e os gradientes externos de temperatura tornam complexas as distribuições de temperatura que atuam na MF.

As diversas fontes de calor geradas durante um processo de usinagem fazem com que a MF opere em uma condição instável termicamente. Qualquer mudança de temperatura nas estruturas da máquina pode causar deformações térmicas que afetam a precisão de trabalho. Fontes internas de calor são causadas, por exemplo, por transmissão dos motores elétricos, atrito entre os componentes e processo de corte. As fontes externas de calor são causadas pelo meio ambiente ou qualquer variação de temperatura que ocorre fora da MF [2].

Cinco principais fontes de influência térmica foram definidos por [6]:

- geração de calor pelo processo de usinagem;

- calor gerado pela máquina;

- resfriamento provocado pelos sistemas de arrefecimento;

- aquecimento ou resfriamento provocado pela influência do meio ambiente;

- memória térmica.

Para que a MF alcance o equilíbrio térmico, muitos operadores utilizam o método conhecido como warm up me que a máquina é ligada para funcionar durante um período de tempo, sem processamento de corte, até que a variação de temperatura se estabilize. Este método pode durar algumas horas, o que prejudica a eficiência de produção devido ao elevado tempo gasto [35].

Pesquisadores têm estudado ao longo das décadas maneiras para reduzir estes erros. Algumas técnicas sugeridas são: redução e realocação das fontes de calor [10], reorganizar a estrutura da máquina [38] e utilizar materiais que tenham maior rigidez [41]. 


\section{Capítulo 2. Revisão da Literatura}

O controle da temperatura ambiente também pode ajudar a reduzir as variações de temperatura, porém em grandes oficinas esta técnica se torna inviável.

As deformações em um ponto particular no tempo são dependentes do corpo naquele momento específico [43]. Logo, foi adotado pelos autores, o procedimento de calcular o perfil térmico no domínio de interesse e determinar a deformação resultante pela resolução das equações associadas à termoelasticidade usando o método de diferenças finitas. O MEF foi aplicado para obtenção das deformações, que foram usadas posteriormente para análise. Portanto, com a utilização do modelo de elementos finitos, a precisão da MF pode ser prevista pela medição de temperatura de pontos específicos da estrutura.

No trabalho de [15], foi apresentado um novo modelo para o comportamento térmico de uma MF baseado na determinação da perda de energia cinética dos componentes da máquina. Neste método, assume-se que a quantidade de energia dissipada em componentes específicos do sistema cinemático é função das condições operacionais. Assim, conhecendo-se as fontes de calor e os parâmetros operacionais, os valores de perda de energia em todos os componentes, as temperaturas e os deslocamentos térmicos, podem ser determinados automaticamente.

Os modelos de previsão de erros podem ser determinados usando a análise de elementos finitos para simular a distribuição de temperatura e deformações térmicas de MF considerando o fluxo de calor constante. No entanto, o modelo de elementos finitos deve ser simplificado, desprezando detalhes complexos como as condições de contorno, geometria e propriedades do material [16]. 
2.6. Sistemas de medição de erros de posicionamento em máquinas-ferramenta

\subsection{Sistemas de medição de erros de posicionamento em máquinas-ferramenta}

\subsubsection{Encoder óptico}

O encoder é um transdutor que converte um movimento linear ou angular em sinais digitais. Esses sinais digitais podem ser utilizados para determinar a posição, a direção, a velocidade e a aceleração do sistema ao qual o encoder está acoplado.

Os instrumentos de medição de posição são de extrema importância na precisão e qualidade do processo de usinagem. Existem dois tipos de encoder: linear e rotativo.

O encoder linear controla a posição real da mesa de trabalho e é considerado portanto, mais exato. No entanto, ocupa mais espaço e possui custo elevado [1].

Os instrumentos de medição rotativos são acoplados diretamente ao eixo de acionamento e permitem controlar tanto a velocidade angular como a posição angular do eixo.

Os encoders possuem internamente um ou mais discos perfurados. Os furos do disco ficam entre um feixe infravermelho gerado por um circuito eletrônico. Basicamente, os furos do disco ficam entre um emissor e um receptor de infravermelho, e quando o feixe do emissor chega até o receptor sem interrupção, é gerado um pulso.

O encoder óptico incremental possui apenas uma trilha com dentes igualmente espaçados. A posição é determinada pela contagem do número de pulsos fornecidos pelo encoder. A título de exemplo, a resolução do encoder incremental é dada por pulsos por revolução (normalmente chamado de PPR), isto é, o encoder gera certa quantidade de pulsos elétricos por uma revolução (no caso de um encoder rotativo). Para determinar a resolução basta dividir o número de pulsos por $360^{\circ}$. Por exemplo, um encoder fornecendo 1024 pulsos por revolução geraria um pulso elétrico a cada $0,35^{\circ}$ [25].

No caso de um sensor linear, em lugar de um disco com faixas, temos uma linha ou tira com faixas, que também pode operar no modo refletivo ou por transparência. 
Um esquema do encoder óptico rotativo e linear é apresentado na Figura 2.13.

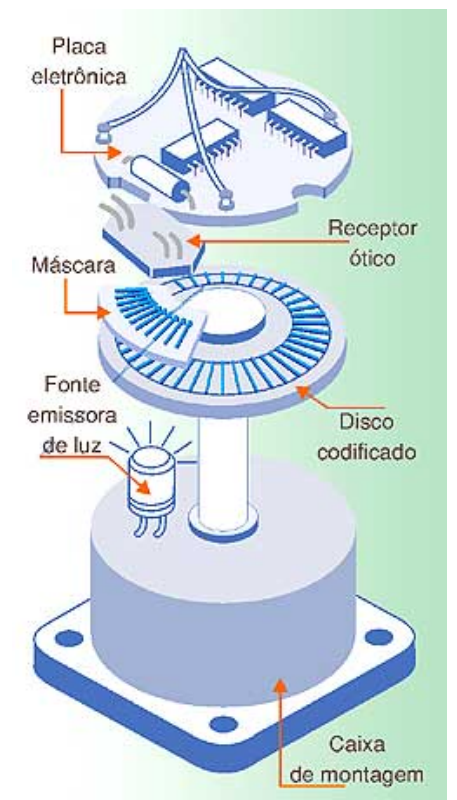

(a) Encoder óptico rotativo

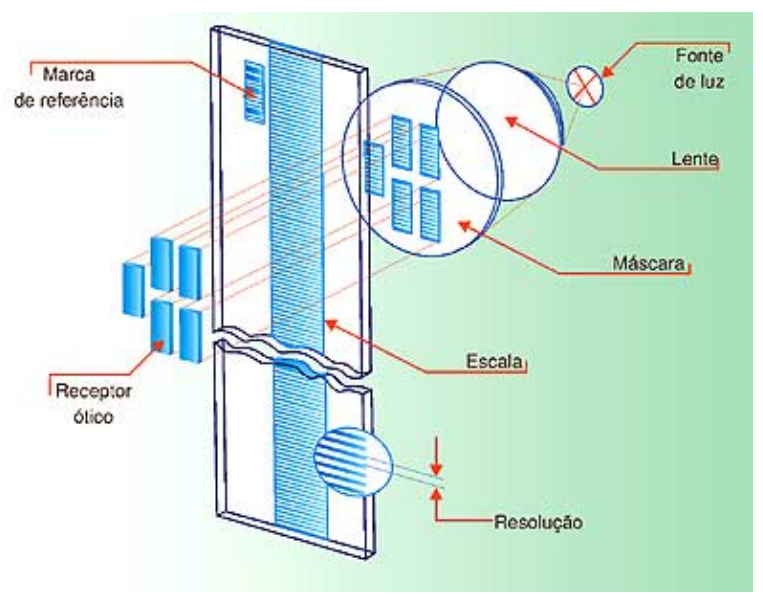

(b) Encoder óptico linear

Figura 2.13: Princípio de funcionamento de um encoder óptico (Adaptado de [25])

Estes tipos de encoders utilizam um ou mais pontos de referência, de localização conhecida, para calcular o deslocamento executado. Este cálculo é realizado a partir da contagem dos pulsos desde o ponto de referência, e posteriormente incrementados à posição de referência [44].

Contudo, quando há falha de energia no sistema, o encoder óptico incremental perde sua contagem, necessitando de se deslocar até um novo ponto de referência antes de iniciar nova sequência de movimentos [26].

\subsubsection{Interferômetro a laser}

Um dos principais padrões metrológicos na área de metrologia dimensional é o sistema de medição linear por interferometria laser, ou simplesmente sistema laser de medição, que é muito utilizado para avaliação de MF devido a sua versatilidade na medição de comprimento, o que pode ser feito com grande exatidão e rapidez. O interferômetro 
2.6. Sistemas de medição de erros de posicionamento em máquinas-ferramenta

produz uma diferença de caminho percorrido por dois feixes coerentes os quais são sobrepostos e, assim, provocam um padrão de interferência. A análise deste padrão permite a determinação do comprimento de onda da fonte de radiação.

Em MF, o interferômetro a laser é utilizado para medir posicionamento dos eixos. A dificuldade na realização e deste tipo de medição é que durante o processo de usinagem os fluidos refrigerantes e os cavacos podem interferir na medição. Além disso, este método não permite medir eixos rotativos (spindle) [28].

A interferometria utilizada por este sistema baseia-se no modelo de interferômetro de Michelson (Figura 2.14), em que um feixe de luz (1) atinge um bloco de vidro onde uma das superfícies é coberta com um filme refletor, que aumenta a refletividade da interface. Essa interface atua como um divisor de feixes (spliter) (2).

O feixe da fonte é dividido em dois na interface com a superfície refletora. Um dos raios sai em direção a $M 1$, é refletido sobre si mesmo e depois atravessa o bloco central. Outro raio vai na direção de $M 2$ (3), é refletido sobre si mesmo e é refletido no retrorrefletor. Na "volta"destes dois feixes (4), eles se encontram e ocorre então a interferência de ondas destes dois feixes. A diferença de fase entre os dois raios é causada pela diferença de caminho óptico percorrido e esta diferença de fase é o erro de posicionamento.

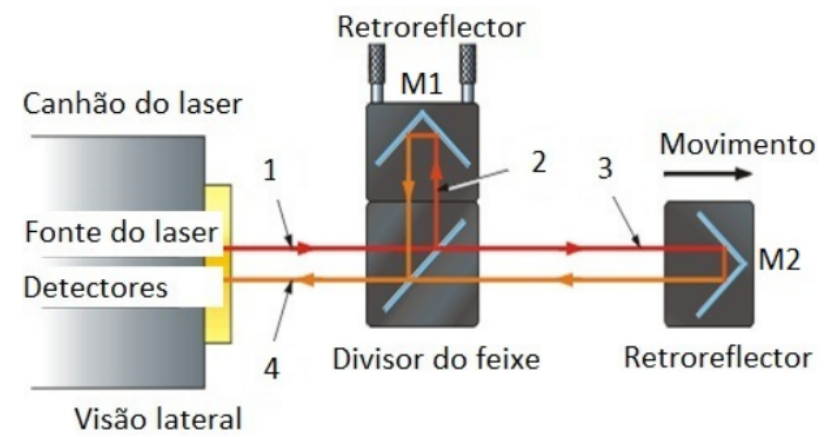

Figura 2.14: Princípios de Medição Linear - 1. Feixe de laser emergente do XL Laser; 2. Divisor de feixe; 3. Retroreflector; 4.Feixe de volta

Uma das maiores vantagens da interferometria é o seu alto grau de sensibilidade. 
Devido ao comprimento de onda do laser ser muito pequeno (da ordem de $650 \mathrm{~nm}$ ), variações na fase óptica podem ser mensuradas, mesmo sendo muito pequenas.

O sistema de interferometria a laser além de ser composto por lentes ópticas e eletrônicos, também é composto por sensores que monitoram a temperatura e umidade relativa do ar, a temperatura do objeto a calibrar e a pressão atmosférica. A finalidade dessa unidade é realizar correções dos desvios devido às variações das condições ambientais e da temperatura do objeto a calibrar, em relação às condições ambientais de referência.

\subsubsection{Alinhamento do laser}

No sistema de interferometria, a distância linear é realizada por dois cubos retrorrefletores e um cubo divisor de feixes, conforme foi apresentado na Figura 2.14. O fator mais importante neste tipo de medição é o alinhamento entre estes componentes. O mau alinhamento dos componentes compromete o resultado da medição.

Os dois feixes de laser devem incidir perpendicularmente sobre o divisor de feixe. Por ser um polarizador, o divisor de feixe transmite um feixe com polarização vertical ao cubo retrorrefletor móvel e o outro feixe é transmitido com polarização horizontal em direção ao cubo retrorrefletor fixo. O feixe de reflexão dos feixes deve voltar pelo mesmo caminho do feixe inicial. Além disso, os dois feixes, após a polarização, devem ser propagados ortogonalmente entre si pra que não exista interferência entre estes feixes.

Deve-se considerar também que a distribuição da intensidade luminosa do feixe de laser não é uniforme, mas sim Gaussiana, ou seja, mais intensa no centro do que nas bordas. Por isso a dificuldade em alinhar o feixe nas extremidades do eixo a ser medido. 


\subsection{A compensação de erros}

Existem dois métodos para redução dos erros que afetam a precisão da MF: evitar erros (error avoidance) e compensação de erros (error compensation). O método para evitar erros é aplicado durante a fabricação da máquina. Porém, é necessário elevado investimento e o custo da máquina pode subir exponencialmente com o nível de precisão envolvido. Por outro lado, no método de compensação térmica, nenhuma técnica é aplicada para evitar erros [47]. Os erros são medidos e compensados com custos mais baixos que na primeira técnica citada.

Não importa o quão bem uma máquina é projetada, a precisão das máquinas pode ser alterada quando submetidas à cargas térmicas e excessivas forças de corte. Portanto, é mais viável monitorar ou medir experimentalmente os erros e compensar através de mudanças na posição de coordenadas do CNC da MF [29].

A partir do momento em que um erro é estimado, geralmente é possível reduzir estes erros. Como já foi definido na seção 2.4, um erro sistemático pode ser identificado e quantificado. Se este erro for significativo em relação à exatidão requerida da medição, uma correção pode ser aplicada para compensar o erro. Porém, ainda é necessário lembrar que mesmo após a compensação, o erro ainda é uma estimativa do valor mensurado procedente do valor estimado na correção dos erros sistemáticos e da incerteza dos erros aleatórios.

Os erros que não podem ser evitados pelo refinamento da estrutura da MF durante sua construção podem ser medidos e compensados. O objetivo principal da compensação de erros não é eliminá-los completamente, mas reduzir seus efeitos sobre as dimensões finais do produto.

O processo de compensação de erros pode ser resumido envolvendo as seguintes atividades [28]:

- Determinar a melhor localização para a montagem dos termopares ou outros apa- 
relhos de medição de temperatura;

- Medição do erro de cada componente e da temperatura em diferentes condições da máquina;

- Criação do modelo de compensação de erros;

- Aplicação do modelo.

A compensação de erros também possui limitações. A precisão obtida por este método está diretamente relacionada ao grau de repetibilidade da própria máquina e ao método escolhido para relacionar as variáveis de erro medidas, ou seja, este último depende do modelo matemático desenvolvido para descrever o comportamento dos erros.

Por outro lado, esta técnica se destaca por ter custo reduzido e ser eficiente ao longo do tempo de uso da MF. A evolução da micro eletrônica e da computação é simultânea ao desenvolvimento das técnicas de compensação de erros. Esta compensação de erros é feita sempre se alterando a trajetória da ferramenta em relação à peça, de forma a compensar os erros da máquina. Como exemplo, pode-se citar a compensação de erros ocorridos com a dilatação térmica da máquina. Sensores de temperatura são instalados em alguns pontos da MF e através de modelos matemáticos, calcula-se a relação da variação de temperatura e erro de posicionamento, segundo um algoritmo interno implementado ao CNC. Com esta relação é possível prever o erro de posicionamento e alterar a trajetória dos eixos da máquina, atenuando os efeitos do erro sob o resultado final do produto.

Somente os erros sistemáticos podem ser compensados e segundo [31], a compensação deve satisfazer as seguintes condições:

- Os erros sistemáticos devem ser significativamente maiores que os erros aleatórios.

- Espera-se uma melhora significativa nos erros, pois a melhora na precisão da MF deve justificar os custos gastos na aplicação da compensação de erros. 
- A máquina deve ter um sistema de coordenadas absoluto.

- A execução do servomotor, assim como do computador (resolução, correção espacial da frequência, cálculo da velocidade) devem ser adequados.

- O modelo adequado da MF deve ser avaliado a partir de modelos matemáticos de erro para estabilidade do erro final da máquina. Os parâmetros para desenvolvimento do modelo devem ser obtidos por meio de ensaios experimentais.

No trabalho realizado por [46], foi desenvolvido um modelo de compensação térmica em tempo real usando análise de regressão múltipla baseada na variação de temperatura medida experimentalmente por seis sensores de temperatura PT-100. Neste modelo de compensação térmica, o erro de posicionamento no eixo $X$ foi reduzido de $20 \mu m$ para 3

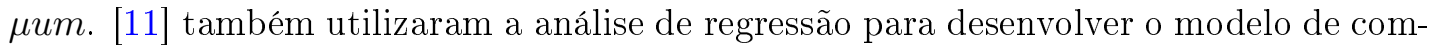
pensação térmica e afirmaram em seu trabalho que em mais de 100 centros de usinagem foi aplicado seu modelo de compensação térmica. Durante um ano em que a técnica foi aplicada, o modelo mostrou-se eficaz na redução do erro da máquina, mantendo durante todo o ano a precisão e removendo o ciclo improdutivo de aquecimento.

Alguns autores desenvolvem o método de compensação por meio da técnica de redes neurais, assim como [22] e [48]. Nie utilizou o método Radical Basis Function - RBF de redes neurais combinando ao sistema artificial immune - AIRBF, que tem como característica a auto-organização e estudo on-line da modelagem desenvolvida. Esta aplicação elimina o problema apresentado pela técnica tradicional de redes neurais, que não realiza a correção dinâmica e em tempo real do sistema. Na tentativa de corrigir este problema da técnica de RN, Yang também aplicou em seu trabalho uma variação deste método. Yang desenvolveu dois tipos de modelagem: Recurrent Neural Network - RNN e Integrated Recurrent Neural Network - IRNN, que são tipos de RN dinâmico, utilizados para controle em tempo real do sistema. Porém, o primeiro permite a modelagem de sistemas estacionários e o segundo descreve sistemas não-estacionários. 
Capítulo 2. Revisão da Literatura

Como a deformação térmica possui característica não estacionária, de natureza termo elástica, foi necessário a aplicação do IRNN.

A técnica de redes neurais baseia-se em algoritmos de aprendizado e adaptação, além de ser capaz de coordenar diversos graus de liberdade durante a execução de tarefas e trabalhar em ambientes desestruturados. São indicados para problemas em que os eventos ocorrem de forma não-linear. Porém, os algoritmos desenvolvidos para esta técnica, que simulam o cérebro humano, são bastante complexos e mesmo sendo um método eficiente, não são utilizadas quando precisa-se de um método de compensação em tempo real.

O principal objetivo a ser alcançado para um método de compensação em tempo real é a obtenção de modelos mais simples e com baixo custo computacional. 


\section{Capítulo 3}

\section{Método proposto para}

\section{compensação de erros térmicos em}

\section{um centro de usinagem}

Este capítulo tem como objetivo descrever os métodos teóricos aplicados no trabalho. A primeira seção mostra como desenvolver um modelo estatístico de regressão linear e como encontrar seus coeficientes de determinação. Na segunda seção, será definido um modelo de matrizes homogêneas de transformação.

\subsection{Análise de Regressão}

Regressão é um tipo de modelagem matemática que determina a relação entre duas ou mais variáveis, ou seja, verifica como o comportamento de uma variável pode mudar o comportamento de outra. A análise de regressão possibilita encontrar uma relação entre as variáveis de entrada e de saída por meio de relações empíricas. A utilização desta abordagem necessita de coleta de dados e do uso de métodos estatísticos de análise de regressão linear. A coleta de dados permite conhecer a natureza da relação entre 
Capítulo 3. Método proposto para compensação de erros térmicos em um centro de usinagem

as variáveis e realizar estudos capazes de acomodar situações inesperadas, como por exemplo, variabilidade na matéria prima, temperatura ambiente, máquina e operadores.

Neste trabalho, a utilização da análise de regressão tem como principal objetivo a predição dos valores de saída do modelo matemático. Uma vez que esperamos que grande parte da variação da variável de saída $(y(t)=$ erro de posicionamento) seja explicada pelas variáveis de entrada $(x(t)=$ variação de temperatura), podemos utilizar o modelo para obter valores de $y$ correspondentes a valores de $x$ que não estavam entre os dados.

\subsubsection{Modelo estatístico}

Os principais parâmetros envolvidos neste trabalho são variação de temperatura $(X)$ e erro de posicionamento $(Y)$. Dados n pares $\left(X_{1}, Y_{1}\right),\left(X_{2}, Y_{2}\right), \ldots,\left(X_{n}, Y_{n}\right)$, deve-se considerar que $Y$ é uma função linear de $X$. Admita-se que os valores esperados de $Y$ são dados por uma combinação linear das $n$ variáveis preditoras:

$$
E(Y / x)=\beta_{0}+\beta_{1} x_{1}+\beta_{2} x_{2}+\ldots+\beta_{n} x_{n}
$$

Admite-se que existem $k$ conjuntos de observações $\left\{x_{1 i}, x_{2 i}, \ldots, x_{k i}, y_{i}\right\}_{i=1}^{k}$ com base nas quais queremos estudar a relação entre a variável resposta e as variáveis preditoras.

O modelo de regressão linear múltipla parte da suposição que a variância $\sigma^{2}$ é desconhecida e que os erros tem distribuição normal, que podem ser simbolicamente representados por:

$$
\epsilon_{i} \approx N\left(0, \sigma^{2}\right)
$$

\subsubsection{Método dos mínimos quadrados}

O objetivo é minimizar a função: 
3.1. Análise de Regressão

$$
L=\sum_{i=1}^{n} \epsilon_{i}^{2}=\sum_{i=1}^{n}\left(Y_{i}-\beta_{0}-\beta_{1} x_{1 i}-\beta_{2} x_{2 i}-\ldots-\beta_{n} x_{k i}\right)^{2}
$$

Derivando $L$ em função dos $\beta$ 's tem-se:

$$
\begin{gathered}
\frac{\partial L}{\partial \beta_{0}}=-2 \sum_{i=1}^{n}\left[Y_{i}-\beta_{0}-\beta_{1} x_{1 i}-\beta_{2} x_{2 i}-\ldots-\beta_{n} x_{k i}\right] \\
\frac{\partial L}{\partial \beta_{j}}=-2 \sum_{i=1}^{n}\left[Y_{i}-\beta_{0}-\beta_{1} x_{1 i}-\beta_{2} x_{2 i}-\ldots-\beta_{n} x_{k i}\right] x_{i j} \quad j=1,2, \ldots, k
\end{gathered}
$$

Igualando as derivadas parciais a zero e substituindo $\beta_{0}, \beta_{1}, \beta_{2}, \ldots, \beta_{n}$ por $\hat{\beta}_{0}, \hat{\beta}_{1}$, $\hat{\beta}_{2}, \ldots, \hat{\beta_{n}}$, tem-se o sistema de equações:

$$
\left\{\begin{array}{l}
n \hat{\beta}_{0}+\hat{\beta}_{1} \sum_{i=1}^{n} x_{1 i}+\hat{\beta}_{2} \sum_{i=1}^{n} x_{2 i}+\ldots+\hat{\beta}_{k} \sum_{i=1}^{n} x_{k i}=\sum_{i=1}^{n} Y_{i} \\
\hat{\beta}_{0} \sum_{i=1}^{n} x_{1 i}+\hat{\beta}_{1} \sum_{i=1}^{n} x_{1 i}^{2}+\hat{\beta}_{2} \sum_{i=1}^{n} x_{1 i} x_{2 i}+\ldots+\hat{\beta}_{k} \sum_{i=1}^{n} x_{1 i} x_{k i}=\sum_{i=1}^{n} x_{x 1 i} Y_{i} \\
\hat{\beta}_{0} \sum_{i=1}^{n} x_{1 k}+\hat{\beta}_{1} \sum_{i=1}^{n} x_{k i} x_{1 i}+\hat{\beta}_{2} \sum_{i=1}^{n} x_{k i} x_{2 i}+\ldots+\hat{\beta}_{k} \sum_{i=1}^{n} x_{k i}^{2}=\sum_{i=1}^{n} x_{x k i} Y_{i}
\end{array}\right.
$$

Resolvendo este sistema, obtêm-se os estimadores de mínimos quadrados $\hat{\beta}_{0}, \hat{\beta}_{1}, \hat{\beta}_{2}$ $, \ldots, \hat{\beta_{n}}$ dos parâmetros do modelo em questão.

\subsubsection{Representação matricial do modelo de regressão linear múltipla}

Pode-se estabelecer uma relação de regressão linear cujo modelo estatístico é:

$$
Y_{i}=\beta_{0}+\beta_{1} x_{1 i}+\beta_{2} x_{2 i}+\ldots+\beta_{k} x_{k i}+\epsilon_{i} \quad i=1, \ldots, n
$$

onde $X_{i}$ foi substituído por $x_{k i}$ uma vez que $X_{i}$ é a variável determinística. $i$ representa o número de observações realizadas (tamanho da amostra) no experimento e $k$ o número 
Capítulo 3. Método proposto para compensação de erros térmicos em um centro de usinagem

de pontos em que a temperatura foi medida, ou seja, o número de termopares. Neste modelo, temos:

- $Y_{i}$ variável aleatória que representa o valor da variável resposta (variável dependente) na i-ésima observação;

- $x_{i}$ variável aleatória que representa a variação da temperatura;

- $\beta_{0}$ intercepto ou coeficiente linear que representa o ponto em que a reta regressora corta o eixo do y;

- $\beta_{1}, \ldots, \beta_{n}$ parâmetros de inclinação do modelo, que serão estimados e que definem a reta de regressão.

Considerando as $n$ observações da variável resposta $Y$, tem-se as equações:

$$
\begin{aligned}
Y_{1} & =\beta_{0}+\beta_{1} x_{11}+\beta_{2} x_{21}+\ldots+\beta_{k} x_{k 1}+\epsilon_{1} \\
Y_{2} & =\beta_{0}+\beta_{1} x_{12}+\beta_{2} x_{22}+\ldots+\beta_{k} x_{k 2}+\epsilon_{2} \\
Y_{3} & =\beta_{0}+\beta_{1} x_{13}+\beta_{2} x_{23}+\ldots+\beta_{k} x_{k 3}+\epsilon_{3} \\
\vdots & =\vdots \\
Y_{n} & =\beta_{0}+\beta_{1} x_{1 n}+\beta_{2} x_{2 n}+\ldots+\beta_{k} x_{k n}+\epsilon_{n}
\end{aligned}
$$

Para cada $i$ define-se um vetor $1 \times k, x_{t}=\left(1, x_{t 2}, \ldots, x_{t n}\right)$ e seja $\beta=\left(\beta_{0}, \beta_{1}, \ldots, \beta_{k}\right)^{\prime}$ o vetor $k \times 1$ de todos os parâmetros de inclinação e do intercepto. Pode-se então, escrever o modelo da seguinte forma:

$$
Y_{t}=X_{t} \beta+\epsilon_{t} \quad t=1,2, \ldots, k
$$

onde 


$$
X \equiv\left[\begin{array}{c}
X_{1} \\
X_{2} \\
\vdots \\
X_{n}
\end{array}\right]=\left[\begin{array}{cccc}
1 & x_{12} & \cdots & x_{i k} \\
1 & x_{22} & \cdots & x_{2 k} \\
\vdots & \vdots & \ddots & \vdots \\
1 & x_{n 2} & \cdots & x_{n k}
\end{array}\right]
$$

Escrevendo o modelo na forma matricial, tem-se que:

$$
\left[\begin{array}{c}
y_{1} \\
y_{2} \\
\vdots \\
y_{n}
\end{array}\right]=\left[\begin{array}{cccc}
1 & x_{12} & \cdots & x_{i k} \\
1 & x_{22} & \cdots & x_{2 k} \\
\vdots & \vdots & \ddots & \vdots \\
1 & x_{n 2} & \cdots & x_{n k}
\end{array}\right]\left[\begin{array}{c}
\beta_{0} \\
\beta_{2} \\
\vdots \\
\beta_{n-1}
\end{array}\right]+\left[\begin{array}{c}
\epsilon_{1} \\
\epsilon_{2} \\
\vdots \\
\epsilon_{n}
\end{array}\right]
$$

o que nos leva ao modelo:

$$
Y=X \beta+\epsilon
$$

em que:

- $Y$ vetor $n \times 1$ cujos componentes corresponde às $n$ respostas;

- $X$ matriz de dimensão $n \times(k+1)$ denominada matriz do modelo;

- $\epsilon$ vetor de dimensão $n \times 1$ cujos componentes são os erros;

- $\beta$ vetor de dimensão $n \times 1$ cujos elementos são os coeficientes de regressão.

O método de mínimos quadrados tem como objetivo encontrar o vetor $\hat{\beta}$ que minimiza: 
Capítulo 3. Método proposto para compensação de erros térmicos em um centro de usinagem

$$
\begin{aligned}
L & =\sum_{i=1}^{n} \epsilon_{i}^{2}=\epsilon^{\prime} \epsilon=(Y-X \beta)^{\prime}(Y-X \beta) \\
& =Y^{\prime} Y-Y^{\prime} X \beta-\beta^{\prime} X^{\prime} Y+\beta^{\prime} X^{\prime} X \beta \\
& =Y^{\prime} Y-2 \beta^{\prime} X^{\prime} Y+\beta^{\prime} X^{\prime} X \beta
\end{aligned}
$$

Sabendo que $Y^{\prime} X \beta=\beta^{\prime} X^{\prime} Y$, a notação $X^{\prime}$ representa a matriz transposta da matriz $X$ enquanto $Y^{\prime}$ e $\beta^{\prime}$ os vetores transpostos de $Y$ e $\beta$, respectivamente. Usando a técnica de derivação (em termos matriciais) obtemos:

$$
\frac{\partial L}{\partial \beta}=-2 X^{\prime} Y+2 X^{\prime} X \beta
$$

Igualando a zero e substituindo o vetor $\beta$ pelo vetor $\hat{\beta}$, temos:

$$
\left(X^{\prime} X\right) \hat{\beta}=X^{\prime} Y
$$

Pode-se dizer que a matriz $X^{\prime} X$ é irreversível, pois neste caso será diferente de zero, e portanto, não singular. Logo, os estimadores para os parâmetros $\beta_{j}, j=1, \ldots, k$ são dados pelo vetor:

$$
\hat{\beta}=X^{\prime} X^{-1} X^{\prime} Y
$$

Portanto, o modelo de regressão linear ajustado e o vetor de resíduos são respectivamente:

$$
\hat{Y}=X \hat{\beta}
$$

e 


$$
e=Y-\hat{Y}
$$

\subsubsection{Estimação do coeficiente de determinação pela análise geomé- trica da regressão linear}

O modelo de regressão linear assume que os vetores $Y$ e $\hat{Y}$ representam o vetor de erro de posicionamento obtido por meio de $n$ observações e erro de posicionamento previsto pelo modelo de regressão, respectivamente.

O método dos mínimos quadrados garante que o erro $e=Y-\hat{Y}$ seja o menor possível. Geometricamente, supõe-se que o vetor $\hat{Y}$ está contido em um subespaço $S(X): \hat{Y}=H Y$, sendo que $S(X) \subset \Re^{n}$. A Figura 3.1 mostra esta relação [7]:

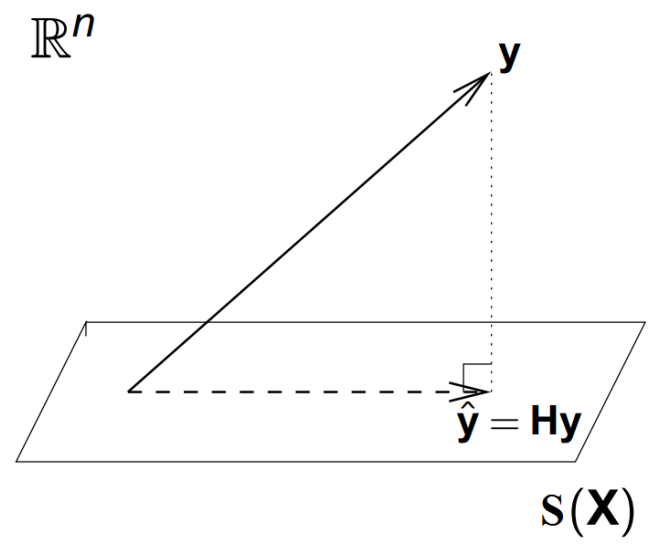

Figura 3.1: Projeção ortogonal de $Y$ sobre $S(X): \hat{Y}=H Y$ (Adaptado de [7])

Aplicando o método dos mínimos quadrados à geometria apresentada, encontrar a menor distância entre os vetores $Y$ e $\hat{Y}$ significa minimizar o quadrado dessa distância, dado por:

$$
\|Y-\hat{Y}\|^{2}=\sum_{i=1}^{n}\left(Y_{i}-\hat{Y}_{i}\right)^{2}
$$

A Equação 3.19 representa então, a soma dos quadrados dos resíduos (SQRE): 
Capítulo 3. Método proposto para compensação de erros térmicos em um centro de usinagem

$$
S Q R E=\sum_{i=1}^{n}\left(Y_{i}-\hat{Y}_{i}\right)^{2}
$$

Na regressão linear múltipla também são definidas a soma dos quadrados devido à regressão (SQR) e a soma de quadrados total (SQT). A SQR é dada por:

$$
S Q R=\sum_{i=1}^{n}\left(\hat{Y}_{i}-\bar{Y}\right)^{2}=\sum_{i=1}^{n} \hat{Y}_{i}^{2}-n \bar{Y}^{2}
$$

A SQT é dada por:

$$
S Q T=\sum_{i=1}^{n}\left(Y_{i}-\bar{Y}\right)^{2}=\sum_{i=1}^{n} Y_{i}^{2}-n \bar{Y}^{2}
$$

Aplicando o Teorema de Pitágoras ao triângulo retângulo da Figura 3.1, tem-se:

$$
\|Y\|^{2}=\|\hat{Y}\|^{2}+\|Y-\hat{Y}\|^{2}
$$

Substituindo pela soma dos quadrados, tem-se a relação:

$$
\sum_{i=1}^{n} Y_{i}^{2}=\sum_{i=1}^{n} \hat{Y}_{i}^{2}+\sum_{i=1}^{n}\left(Y_{i}-\hat{Y}_{i}\right)^{2}
$$

Substituindo o último termo da equação pela relação 3.20, pode-se escrever:

$$
\sum_{i=1}^{n} Y_{i}^{2}=\sum_{i=1}^{n} \hat{Y}_{i}^{2}+S Q R E
$$

Subtraindo $n \bar{Y}^{2}$ aos dois membros da equação, tem-se:

$$
\sum_{i=1}^{n} Y_{i}^{2}-n \bar{Y}^{2}=\sum_{i=1}^{n} \hat{Y}_{i}^{2} n \bar{Y}^{2}+S Q R E
$$

Agora, pode-se usar as relações apresentadas em 3.21 e 3.22 e, portanto: 
3.1. Análise de Regressão

$$
S Q T=S Q R+S Q R E
$$

Esta equação (3.27) é chamada de relação fundamental da regressão linear e como foi visto, é resultado da aplicação do Teorema de Pitágoras sobre a projeção ortogonal do vetor $Y$ sobre o subespaço $S(X)$ que contém o vetor $\hat{Y}$. As componentes da geometria mostrada na Figura 3.1 podem ser classificadas agora, segundo as somas dos quadrados:

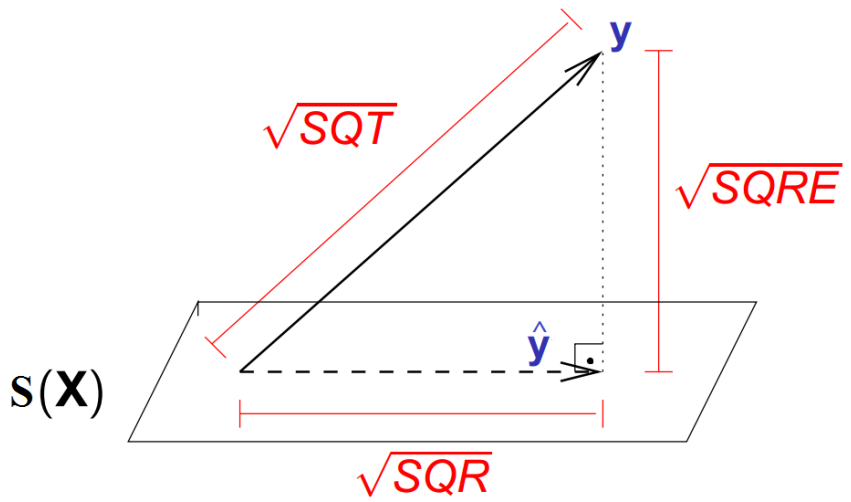

Figura 3.2: Definição das somas dos quadrados da regressão linear através da projeção ortogonal de $Y$ sobre $S(X): \hat{Y}=H Y$ (Adaptado de [7])

Supondo que exista um ângulo $\theta$ entre o vetor das observações da variável resposta, $Y$, e a sua projeção ortogonal sobre o subespaço $S(X)$ gerado pelas variáveis preditoras, tem-se:

$$
\cos (\theta)=\frac{\sqrt{S Q R}}{\sqrt{S Q T}}
$$

Elevando-se ambos os membros ao quadrado, encontra-se:

$$
\cos ^{2}(\theta)=\frac{S Q R}{S Q T}=R^{2}
$$

em que $R^{2}$ é o coeficiente de determinação associado à regressão, também conhecido como coeficiente de correlação de Pearson. 
Capítulo 3. Método proposto para compensação de erros térmicos em um centro de usinagem

Este é um importante coeficiente na análise da regressão, pois indica o grau de correlação entre as variáveis em questão. $\mathrm{O}$ valor do coeficiente deve estar entre $0<$ $R^{2}<1$. Quanto mais próximo de 1 , menor será o ângulo $\theta$ e portanto, menor será a distância entre o vetor $Y$ e $\hat{Y}$. Por outro lado, se $R^{2} \approx 0$, significa geometricamente que o vetor $Y$ é quase perpendicular ao vetor $\hat{Y}$ do subespaço $S(X)$. Logo, o resultado não é satisfatório [20].

\subsection{Matrizes de Transformação Homogênea}

As transformações homogêneas permitem descrever a localização relativa de corpos rígidos. Este tipo de formulação é amplamente utilizada em robótica, pois envolvem a determinação da localização relativa entre dois referenciais a partir do conhecimento da localização relativa destes em relação a um terceiro referencial.

Uma MF é constituída de elementos (corpos rígidos) unidos por articulações que fornecem movimento de translação ou rotação. Considerando dois sistemas de coordenadas representadas na máquina, é possível descrever matematicamente a relação entre estes sistemas por meio das matrizes homogêneas de transformação (Homogeneous Transformation Matrix - HTM).

Suponha que um ponto Q no espaço tridimensional é representado pelo vetor $\vec{v}$ :

$$
\vec{v}=a \vec{i}+b \vec{j}+c \vec{k}
$$

A partir deste vetor é possível obter as coordenadas cartesianas e homogêneas do ponto $P, \vec{i}, \vec{j}$ e $\vec{k}$ são vetores unitários na direção dos eixos $X, Y$ e $Z$, respectivamente. O ponto $P$ pode ser representado em coordenadas cartesianas pelo vetor $\vec{v}=[a, b, c]^{T} \mathrm{e}$ em coordenadas homogêneas pelo vetor $\vec{v}=[x, y, z, w]^{T}$, onde $a=\frac{x}{w}, b=\frac{y}{w}, c=\frac{z}{w} \mathrm{e}$ $w$ o fator de escala. Tomando como exemplo um vetor representado em coordenadas homogêneas $[1,2,3,1]$, pode-se dizer que o vetor $[2,4,6,2]$ é igual ao primeiro, com fator 
de escala $w=2$.

A representação de uma posição relativa de um sistema de coordenada tridimensional é feita por matrizes homogêneas de tamanho $4 \times 4$. Seja o sistema representado por $O X Y Z$ o ponto de referência e $O_{1} X_{1} Y_{1} Z_{1}$ o ponto do sistema de coordenadas a ser deslocado.

A translação de um ponto $P$ em coordenadas homogêneas, pode ser representado pela forma matricial:

$$
P^{\prime}=T P
$$

onde a matriz $T$ á dada por:

$$
T=\left[\begin{array}{cccc}
1 & 0 & 0 & \delta_{x} \\
0 & 1 & 0 & \delta_{y} \\
0 & 0 & 1 & \delta_{z} \\
0 & 0 & 0 & 1
\end{array}\right]
$$

Para transladar um objeto de $\left(\delta x_{1}, \delta y_{1}, \delta z_{1}\right)$ para $\left(\delta x_{2}, \delta y_{2}, \delta z_{2}\right)$, tem-se que $T 1 * T 2$ :

$$
\left[\begin{array}{cccc}
1 & 0 & 0 & \delta x_{1} \\
0 & 1 & 0 & \delta y_{1} \\
0 & 0 & 1 & \delta z_{1} \\
0 & 0 & 0 & 1
\end{array}\right] *\left[\begin{array}{cccc}
1 & 0 & 0 & \delta x_{2} \\
0 & 1 & 0 & \delta y_{2} \\
0 & 0 & 1 & \delta z_{2} \\
0 & 0 & 0 & 1
\end{array}\right]=\left[\begin{array}{cccc}
1 & 0 & 0 & \delta x_{1}+\delta x_{2} \\
0 & 1 & 0 & \delta y_{1}+\delta y_{2} \\
0 & 0 & 1 & \delta z_{1}+\delta z_{2} \\
0 & 0 & 0 & 1
\end{array}\right]
$$

De uma forma geral, segundo Slocum (1992), as estruturas da máquina podem ser decompostas em uma série de matrizes de transformação que descrevam a posição relativa de cada eixo e qualquer sistema de coordenada com relação ao sistema de coordenadas de referência [35]. 
Capítulo 3. Método proposto para compensação de erros térmicos em um centro de usinagem

$$
T_{N}^{R}=\prod_{m=1}^{N} T_{m}^{m-1}=T_{1}^{0} T_{2}^{1} T_{3}^{2} \ldots
$$

Slocum (1992), determina o erro relativo entre a peça e a ferramenta seguindo cinco passos [35]:

- Determinar a sequência de elementos da MF que descrevem o modelo cinemático e assim conhecer a matriz de transformação de cada ponto em relação ao ponto de referência.

- Os erros de posicionamento dos eixos que compõem a matriz de transformação podem ser gerados numericamente ou experimentalmente. Contudo, é importante que o modelo determinado no primeiro passo seja equivalente ao mapeamento para medição numérica ou experimental.

Em seguida o produtório (Equação 3.34) pode ser calculado. O erro de posicionamento relativo $E_{\text {rel }}$ e os erros entre a peça e a ferramenta podem ser determinados por $T_{\text {peça }}^{R}=T_{\text {ferramenta }}^{R} E_{\text {rel }}$, e então:

$$
E_{\text {rel }}=T_{\text {ferramenta }}^{R}-T_{\text {peça }}^{R}
$$

Para a implementação dos algoritmos de correção de erros no controle numérico da máquina, pode-se usar o vetor de correção $P_{\text {correção: }}^{R}$

$$
\left[\begin{array}{c}
P_{x} \\
P_{y} \\
P_{z}
\end{array}\right]_{\text {correção }}^{R}=\left[\begin{array}{c}
P_{x} \\
P_{y} \\
P_{z}
\end{array}\right]_{\text {peça }}^{R}-\left[\begin{array}{c}
P_{x} \\
P_{y} \\
P_{z}
\end{array}\right]_{\text {ferramenta }}^{R}
$$

- Para reduzir o custo computacional e os erros numéricos, o erros $\epsilon_{x}, \epsilon_{y}, \epsilon_{z}, \delta_{x}$, $\delta_{y}$ e $\delta_{z}$ de cada eixo podem ser calculados como multiplicação de todas as fontes 
de erro conhecidas que contribuem para cada componente de erro. Por exemplo, cada componente de erro é gerado por erro geométrico, erro térmico, erro de força etc. Então o produto destes erros em cada eixo será o valor das componentes citadas.

- Uma vez que todos os erros são conhecidos, é possível determinar o erro entre a peça e a ferramenta utilizando as Equações 3.34 e 3.35

- O sistema de matrizes de transformação homogêneas também pode ser usado para compensar os erros em tempo real. 



\section{Capítulo 4}

\section{Trabalho experimental}

Os principais equipamentos utilizados para a realização deste projeto são descritos neste capítulo. Entre eles estão o centro de usinagem CNC modelo ROMI D800, o sistema de aquisição de temperatura e o sistema de medição dos erros de posicionamento. As seções seguintes descrevem cada equipamento e como foram montados para os ensaios experimentais.

\subsection{Máquina-ferramenta ROMI D800}

Os ensaios experimentais foram realizados em um centro de usinagem vertical ROMI modelo Discovery 800. Esta MF possui três eixos, sendo que cada eixo possui um curso máximo distinto. O curso máximo da mesa superior (eixo $X$ ) é de $800 \mathrm{~mm}$, o curso máximo da mesa inferior (eixo $Y$ ) é de $530 \mathrm{~mm}$ e o curso máximo do cabeçote (eixo $Z$ ) é de $580 \mathrm{~mm}$. De acordo com as especificações técnicas da ROMI, o avanço rápido máximo em $X$ e $Y$ é de $40.000 \mathrm{~mm} / \mathrm{min}$ e em $Z 20.000 \mathrm{~mm} / \mathrm{min}$ possuindo um avanço máximo de corte programável de $20.000 \mathrm{~mm} / \mathrm{min}$. O eixo-árvore cone ISO 40 fornece 12,5 $\mathrm{kW}$ (30 min), com faixa de velocidade do cabeçote de 7 a $7.500 \mathrm{rpm}$. O CNC, comando numérico computadorizado, é GE Fanuc 21i-MB. O sistema de lubrificação 
Capítulo 4. Trabalho experimental

deste centro de usinagem é centralizado. A Figura 4.1 mostra a estrutura desta MF.

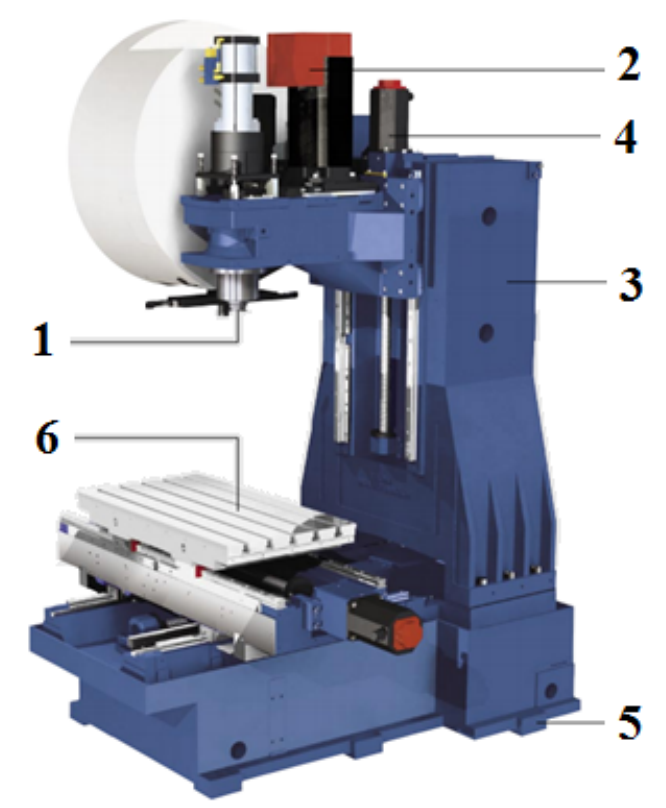

Figura 4.1: Estrutura da máquina-ferramenta ROMI D800 - 1. Eixo-árvore; 2. Motorização; 3. Coluna; 4. Servomotores; 5. Base; 6. Mesa

Pode-se observar nesta estrutura algumas das principais fontes de calor: os pontos 2 (motorização) e 4 (servomoteres) que geram, por exemplo, a movimetação do eixoárvore (1) e da mesa (6). Na parte superior da MF próxima aos servomoteores existe um sistema de refrigerção para garantir que a temperatura nesta região não ultrapasse $36{ }^{\circ} \mathrm{C}$.

\subsection{Sistema de aquisição de temperatura}

Os termopares utilizados foram do tipo K (Cromel/Alumel), que tem faixa de utilização de -270 a $1200{ }^{\circ} \mathrm{C}$. A soldagem da ponta do termopar é feita em atmosfera inerte com arco elétrico, assim, enrolam-se as pontas de dois fios (um de liga cromel e outro de liga alumel), que são ligados a um polo gerador. O outro polo é ligado a uma peça de tungstênio por onde passa um fluxo de argônio (gás inerte). A ponta dos fios é 
4.2. Sistema de aquisição de temperatura

aproximada da peça de tungstênio, efetuando a solda.

A composição química destas ligas é: cromel 90\% de níquel e 10\% de cromo; alumel 95,4\% de níquel, 1,8\% de manganês, 1,6\% de silício e 1,2\% de alumínio. Para aquisição das temperaturas, os termopares estavam ligados a amplificadores modelo Tx-Block da empresa Novus. Este equipamento faz aquisição de sinais de 0-50 $\mathrm{mV}$ de termopares, linearizando-se e transformando o sinal em 4-20 $\mathrm{mA}$. Com termopares, o erro de linearidade é de $0,3 \%$ da escala máxima. O dispositivo também tem compensação de junta fria para termopares. O sinal capturado dos termopares pelo sistema de aquisição deve corresponder à diferença de potencial elétrico entre o canal (AI) e o terra da placa, assim a montagem foi feita de modo que o lado negativo das resistências fossem aterrados juntamente com o terra da placa, e o lado positivo das resistências fossem ligados aos canais de aquisição. A montagem dos transmissores de temperatura segue conforme a Figura 4.2.

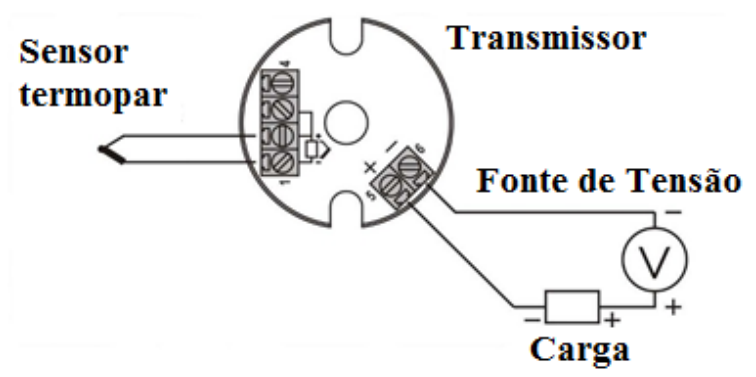

Figura 4.2: Esquema de montagem dos transmissores

Os polos postitivos e negativos do termopar foram testados por meio de um imã para serem instalados nos transmissores. Como este termopar é constituído por Cromel/Alumel, o polo positivo não é atraído pelo imã. Para garantir uma melhor comunicação entre os transmissores e o computador, foi instalada uma alimentação elétrica externa.

A Figura 4.3 mostra a instalação de um dos termopares na MF e conectado ao transmissor. O termopar é inserido primeiramente em uma placa de cobre com pasta 
Capítulo 4. Trabalho experimental

térmica para facilitar a transferência de calor. Em seguida, cobre-se a placa de cobre com isopor para minimizar a influência do meio ambiente na aquisição de temperatura.

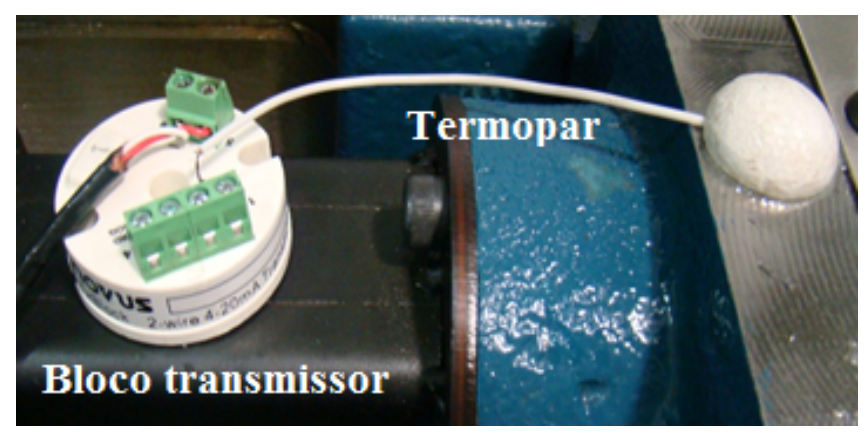

Figura 4.3: Termopar conectado ao transmissor de sinal Tx-Block

O fio do termopar foi cortado de forma que seu comprimento fosse o menor possível, pois quanto maior o fio, o termopar fica mais suscetível a ruídos. Além disso, este fio foi coberto com um espaguete termo retrátil.

A aquisição de queda de tensão na resistência será realizada ligando-se os terminais da mesma ao bloco conector SCB-68 da empresa National Instruments. Este é ligado à placa de aquisição PCI-6220 da mesma empresa, instalada em um microcomputador, por meio de um cabo SHC68-68-EPM. A leitura dos dados é feita com o software Labview $7.2^{\circledR}$.

Após a montagem, todos os transmissores foram configurados para termopares tipo $\mathrm{K}$ e a escala foi ajustada para $0-120^{\circ} \mathrm{C}$. Os termopares geram sinais da ordem de micro volts, logo foi feito um circuito eletrônico que permite a passagem de baixas frequências e atenua a amplitude das frequências maiores. Este circuito, chamado filtro passa-baixa evita que eventuais ruídos interfiram na leitura dos sinais. Entretanto, a placa de aquisição efetua medições sob forma de tensão. Portanto é necessário converter tal sinal novamente. Tal processo é feito com uso de um resistor de $250 \Omega$ montado junto ao filtro passa baixa. Desta forma, temos a tensão de entrada na placa variando de 1 a $5 V$.

O funcionamento do filtro passa-baixa foi validado por meio de um osciloscópio e 
um gerador de função. A Figura 4.4 mostra a forma como o sinal é atenuado e o ruído eliminado:

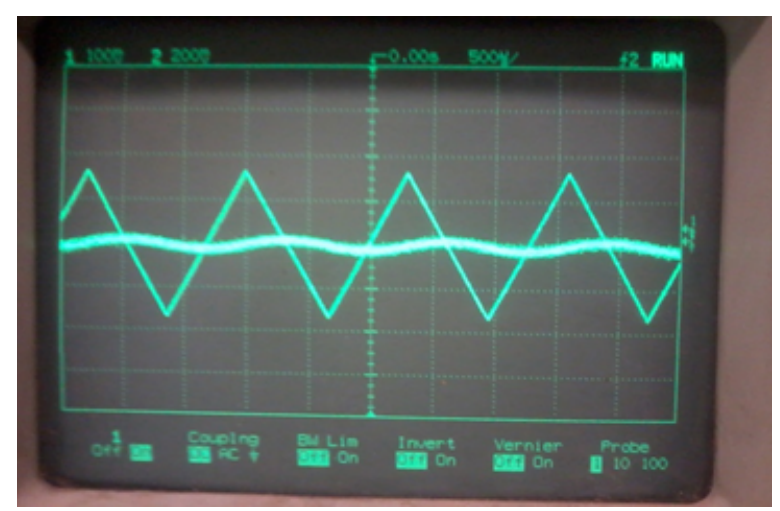

Figura 4.4: Verificação do funcionamento do filtro de ruídos passa-baixa

Os sinais obtidos pelos termopares serão enviados à placa de aquisição, ficando então, acessíveis ao software Labview 7.2 ${ }^{\circledR}$. Será necessário criar uma rotina de aquisição na qual o sinal é convertido no valor correspondente de temperatura, mostrado em um gráfico e armazenado em um arquivo.

\subsection{Determinação da localização dos termopares}

A localização dos termopares foi escolhida segundo um teste realizado na MF com o objetivo de conhecer os locais em que a variação de temperatura é maior. Tal teste, consiste em deixar a máquina sob funcionamento durante 1 hora com 'Z seco' (spindle desativado) e em seguida tirar algumas fotografias com a termocâmera ThermaCAM da empresa FLIR e verificar a dissipação de calor nos componentes da máquina.

Esta câmera captura a energia infravermelha (o calor) emitida pelo objeto enquadrado pelas lentes e converte esta energia em um sinal eletrônico. Este sinal é processado de forma a mostrar a imagem térmica no monitor da câmera ao mesmo tempo em que calcula a temperatura de cada pixel. A precisão de uma câmera infravermelha depende de vários componentes como as lentes, filtros, o detector, circuitos de leitura e 
Capítulo 4. Trabalho experimental

tratamento de sinal e programas de linearização e compensação [12].

As Figuras 4.5a, 4.5b, 4.6a, 4.6b, 4.7a e 4.7b mostram alguns destes testes. Para melhor reconhecimento da região a ser analisada, além das fotos térmicas foram tiradas fotos sem o efeito térmico e apresentadas lado a lado.

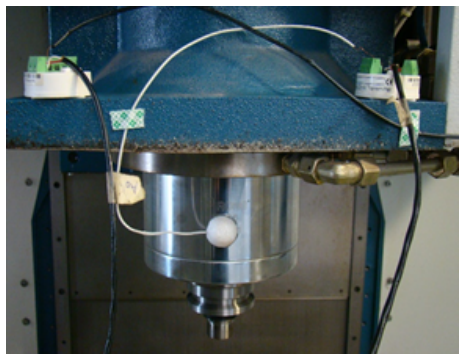

(a) Eixo-árvore

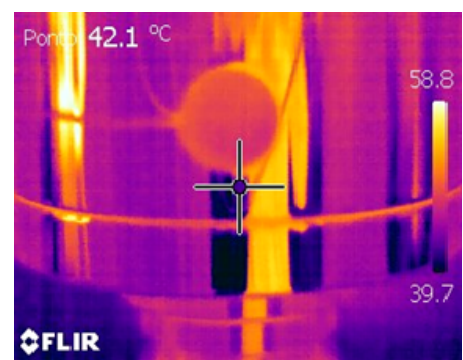

(b) Imagem térmica do eixoárvore

Figura 4.5: Eixo-árvore

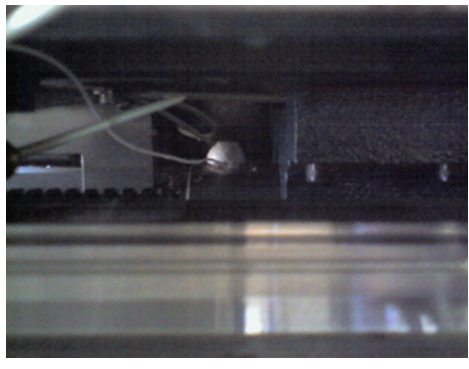

(a) Porca

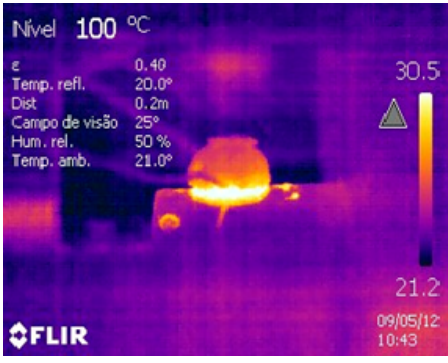

(b) Imagem térmica da porca

Figura 4.6: Porca

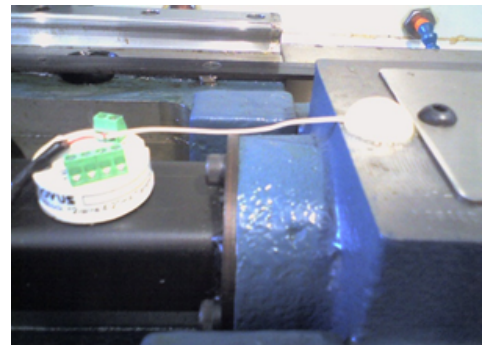

(a) Mancal direito

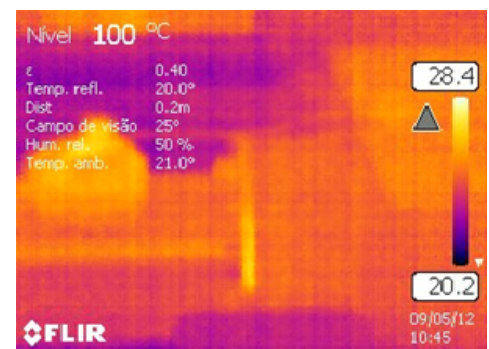

(b) Imagem térmica do mancal direito

Figura 4.7: Mancal

Constatou-se que após uma hora de funcionamento, a região do eixo-árvore alcançou 
4.4. Sistema de aquisição dos erros de posicionamento

a maior variação de temperatura, aproximadamente 20 graus. Na região dos mancais e das porcas, a termocâmera registrou veriaçãoes de aproximadamente 10 graus. Desta forma, os termopares foram instaldos em pontos próximos a estas regiões.

\subsection{Sistema de aquisição dos erros de posicionamento}

O equipamento utilizado para medição dos erros de posicionamento foi o interferômetro a laser XL-80 da marca Renishaw, conforme a Figura 4.8.

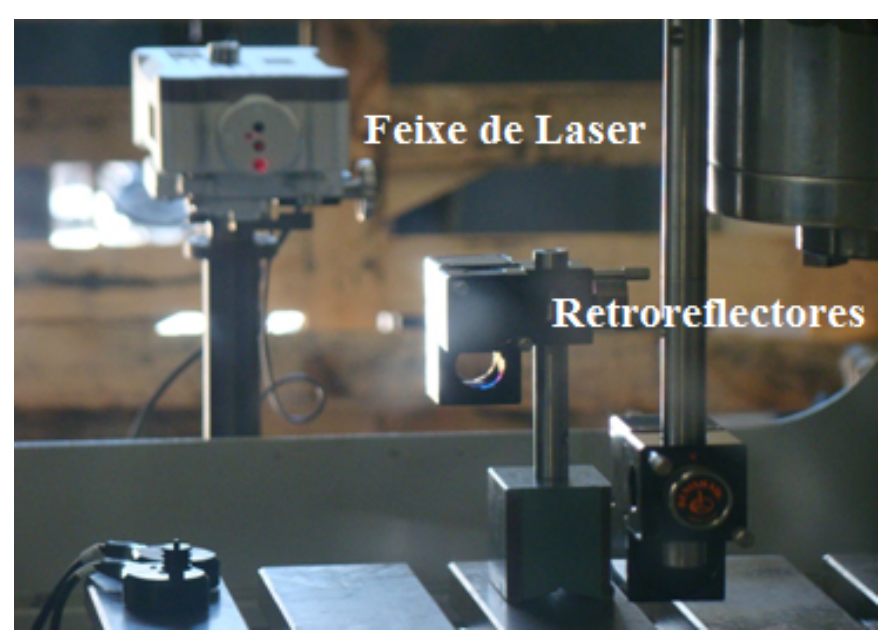

Figura 4.8: Montagem do interferômetro na MF

O feixe do laser foi posicionado na direção do eixo $X$, uma vez que os erros de posicinamento a serem tratados estão também nesta direção.

Neste equipamento, as leituras são realizadas a $50 \mathrm{kHz}$, com velocidade de medição linear máxima de $4 \mathrm{~m} / \mathrm{s}$ e resolução linear de $1 \mathrm{~nm}$, mesmo com velocidade máxima e há elevada exatidão de compensação ambiental da temperatura, pressão e umidade relativa do ar. O sistema também é integrado por um sistema de compensação ambiental XC80. Este compensador possui sensores que processam as leituras na fonte, medindo temperatura, pressão ambiente e umidade relativa. O valor nominal do comprimento de onda é então modificado para fornecer um valor real, utilizado nos cálculos, o que 
Capítulo 4. Trabalho experimental

virtualmente elimina quaisquer erros de medição resultantes dessa variação.

Para adaptação do sistema na máquina, o laser deve estar paralelo a uma das extremidades da mesa e à superfície, os retroreflectores devem estar alinhados com o interferômetro. Além disso, o laser, o interferômetro e os retroreflectores devem estar rigidamente apoiados para evitar vibrações. A Figura 4.9 mostra como as lentes devem estar alinhadas para a medição do posicionamento.

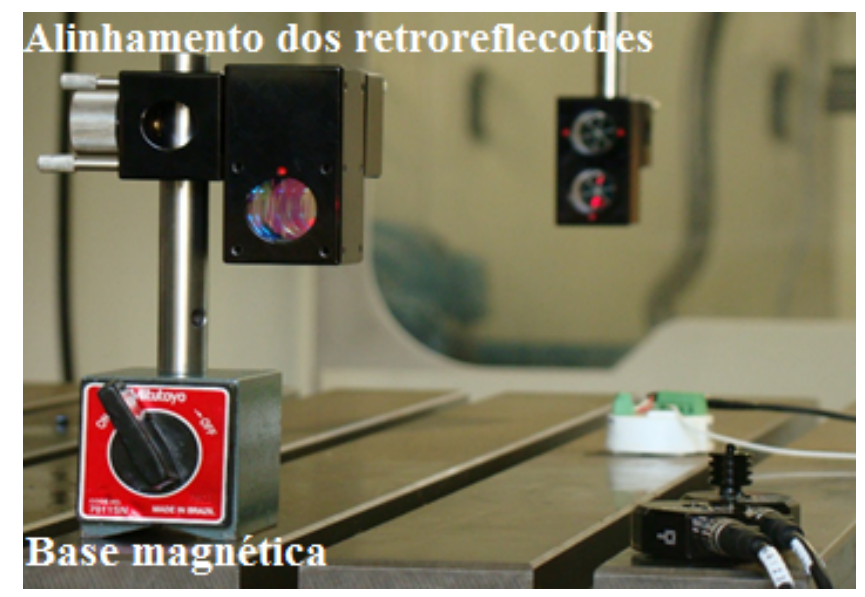

Figura 4.9: Alinhamento das lentes

O retroreflector do sistema é preso ao eixo-árvore da MF enquanto o splitter é fixado na mesa por um bloco magnético que se movimenta junto com a mesa. A aquisição dos dados obtidos pelo sistema foi realizada pelo software Renishaw Laser XL que contém um pacote FFT (Fast Fourier Transform) integrado pela análise de frequências. O software possui pacotes de compensação de erro em que os dados obtidos pela calibração podem ser utilizados para criar valores de compensação para uso no comando da máquina CNC.

O sistema XL-80 e XC-80 foram conectados a um computador através da porta USB. Processadores integrados analisam e processam a saída dos sensores de temperatura antes de transmitir valores digitais de temperatura para o compensador XC-80.

A Figura 4.10 mostra o esquema de como foi montado o sistema de aquisição de 60 
dados. A Parte I indicada na figura representa a aquisição dos dados de medição do posicionamento e a Parte II, a aquisição dos sinais de temperatura.

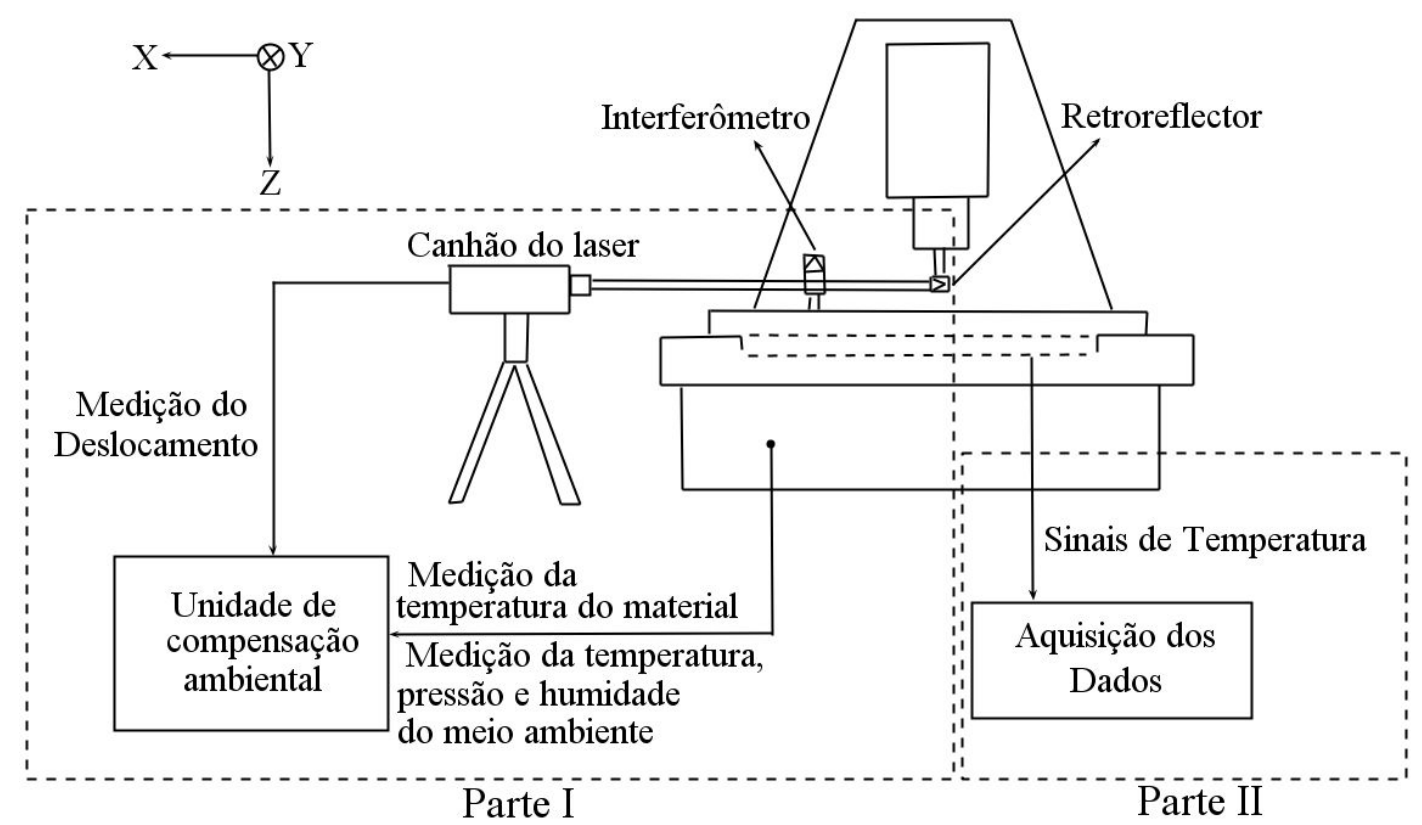

Figura 4.10: Plataforma da medição dos dados experimentais (Adaptado de [46])

Ambos sitemas foram preparados para funcionar simultanemante e a configuração do CN para o funcionamento da máquina foi realizado de acordo com cada experimento proposto neste trabalho. Tais experimentos serão descrito na seção a seguir.

\subsection{Preparação da máquina}

Há três diferentes casos de teste, os quais permitem definir as condições de funcionamento da máquina. Nos primeiros dois casos (movimento e aquecimento do eixo $X$ e do eixo $Y$, respectivamente), ocorre somente o movimento da mesa da MF, sendo necessário definir a velocidade de avanço, o percurso total do deslocamento da mesa e quantas paradas são feitas para que a medição de posicionamento com o laser possa ser feita. No terceiro caso, aquece-se o eixo $Z$ por meio da rotação do spindle. Em todos os casos, o erro de posicionamento é medido no eixo $X$, ou seja, deseja-se observar a 
Capítulo 4. Trabalho experimental

influência dos três eixos no erro de posicionamento do eixo $X$.

- Caso 1: O aquecimento neste primeiro caso ocorre no eixo $X$. Portanto, a localização dos termopares está nos mancais direito e esquerdo do eixo $X$ e na porca localizada em baixo da mesa de trabalho.

- Caso 2: Agora o aquecimento ocorre no eixo $Y$. O termopar localizado na porca do eixo $Y$ permanece, porém os termopares localizados nos mancais do eixo $X$ são realocados para os mancais no eixo $Y$.

- Caso 3: São instalados dois termopares no spindle da MF, pois o aquecimento é devido à rotação do eixo-árvore.

Em todos os casos apresentados, também haverá um termopar medindo a variação de temperatura no ambiente.

\subsection{Programação do CN para cada caso}

Nos ensaios, o CNC da máquina é programado de acordo com cada caso. Os dados de temperatura obtidos pelos termopares e os erros de posicionamento obtidos pelo interferômetro a laser são captados simultaneamente. O sistema de aquisição de temperatura coleta os dados com frequência de $5 \mathrm{~Hz}$ e para aquisição dos erros de posicionamento o CNC da MF foi programado para parar em quatro posições distintas com um curso pré-programado (por meio do código $\mathrm{G}$ implementado no $\mathrm{CN}$ da máquina).

O percurso total utilizado da mesa da máquina é de $585 \mathrm{~mm}$ e considerando que a distância entre cada posição é igual, tem-se que a sequência das posições no eixo $X$ medida pelo interferômetro a laser é: $X=-300 \mathrm{~mm}, X=-105 \mathrm{~mm}, X=90 \mathrm{~mm}, X=285$ $m m$. O interferômetro a laser captura a medida em cada posição desta sequência no avanço e no retorno do movimento da mesa, e cada parada tem a duração de 4 segundos que é o tempo suficiente para que o software do interferômetro capture a medida com 
precisão de quatro casas decimais. Nos ensaios dos três casos, a medição do erro de posicionamento obedece esta sequência.

A seguir serão detalhadas as condições de ensaio para o aquecimento nos eixos $X$, $Y$ e $Z$. Para cada caso, foram realizados dois ensaios com diferentes velocidades para aquecimento do eixo.

- Caso 1: O CNC foi programado para que a mesa se desloque no eixo $X$ com velocidade de avanço de $f=5.000 \mathrm{~mm} / \mathrm{min}$ no primeiro ensaio e $f=30.000$ $\mathrm{mm} / \min (\mathrm{G} 0)$ no segundo. Este processo foi repetido 57 vezes.

- Caso 2: No primeiro ensaio, a mesa da máquina foi programada para fazer 21 corridas em G0 no eixo $Y$. Depois do aquecimento no eixo $Y$, a mesa da máquina volta a movimentar-se no eixo $X$ para que a aquisição das medidas dos erros de posicionamento possa ser feita. O segundo ensaio seguiu este mesmo padrão e as mesmas velocidades de avanço do primeiro caso, porém o número de corridas no eixo $Y$ foi 41. Em cada ensaio este processo repetiu-se 12 vezes.

- Caso 3: O aquecimento neste caso, se dá pela rotação do eixo-árvore da MF. No primeiro ensaio, a rotação foi de $6.000 \mathrm{rpm}$ e no segundo $12.000 \mathrm{rpm}$ (velocidade máxima segundo as especificações da MF). Assim como no segundo caso, as medidas do erro de posicionamento foram feitas após o aquecimento. O processo se repetiu 10 vezes.

O número de repetições foi definido para cada um dos casos de acordo com o tempo de estabilidade da variação de temperatura. No eixo $X$ a variação da temperatura demorou mais para se estabilizar, logo foi preciso mais repetições. No eixo $Z$, devido ao sistema de refrigeração localizado próximo ao eixo-árvore, a variação de temperatura se estabilizou rapidamente, sendo necessário um menos número de repetições. 
Capítulo 4. Trabalho experimental

\subsection{Tratamento dos dados experimentais}

Após a aquisição dos dados experimentais, surge o problema de como adequá-los de tal maneira que possam ser aplicados ao desenvolvimento do modelo numérico de compensação de erros. Considerando a frequência de aquisição do sistema de temperatura, se forem habilitados 4 termopares para funcionar somente 10 minutos, o arquivo .txt gerado pelo software de aquisição Labview $7.2^{\circledR}$ terá 600 linhas e 4 colunas.

O tipo de gráfico gerado por esta matriz de dados de temperatura pode ser visto na Figura A.6.

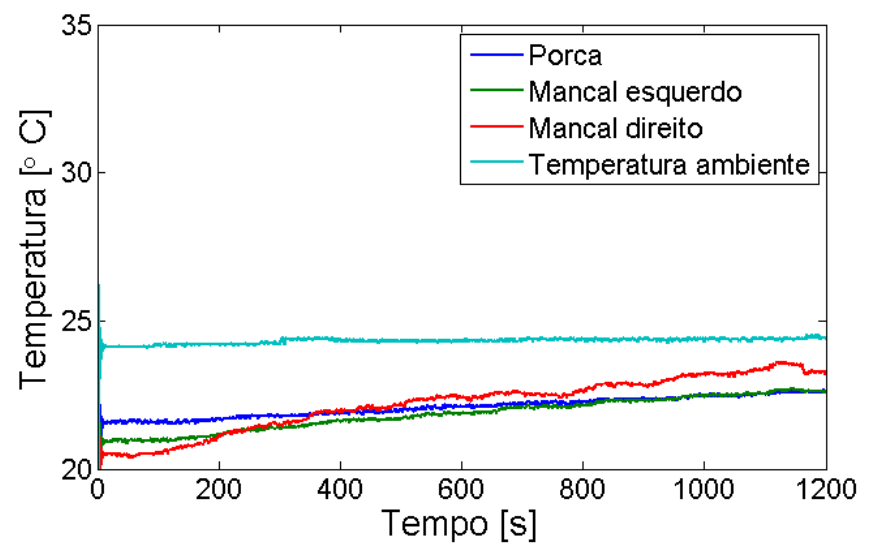

Figura 4.11: Curvas de temperatura no Caso $1(f=5.000 \mathrm{~mm} / \mathrm{min})$

Por outro lado, o sistema de aquisição dos dados de erro de posicionamento armazena um valor de erro em cada ponto do eixo $X$ determinado $(-300,-105,90$ e $285 \mathrm{~mm})$ no movimento de avanço e no movimento de retorno da mesa da máquina. Um exemplo de gráfico gerado pelo software de aquisição da Renishaw é dado pela Figura 4.12:

Neste caso, por exemplo, se forem realizadas 10 repetições no experimento (também chamadas de corridas), o arquivo .txt gerado por este software é de 80 linhas, 40 erros no movimento de avanço (referentes as 10 repetições para cada ponto) e 40 erros de movimento de retorno.

O algoritmo para regressão linear múltipla exige que a matriz de temperatura e o 
4.7. Tratamento dos dados experimentais

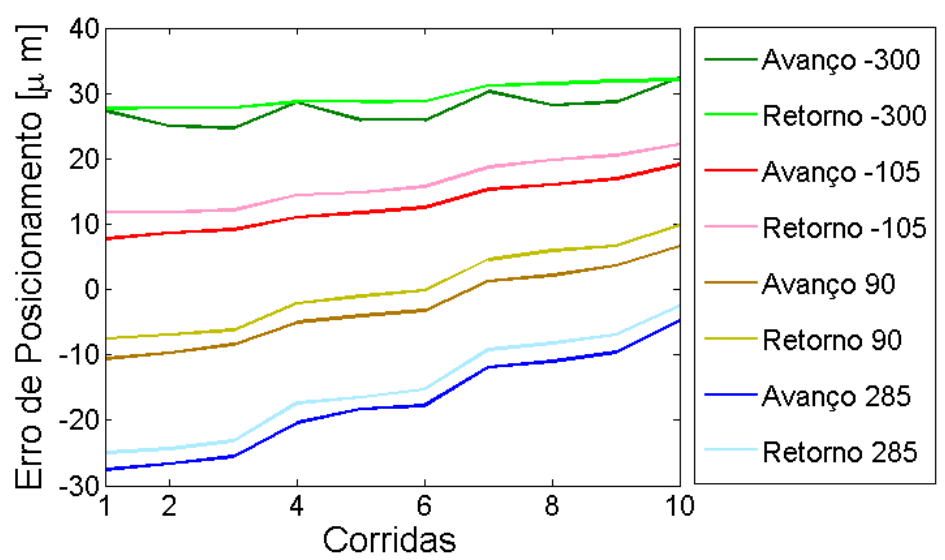

Figura 4.12: Erros de posicionamento no Caso $1(f=5.000 \mathrm{~mm} / \mathrm{min})$

vetor de erro possuam o mesmo número de linhas. Caso contrário, o sistema torna-se indeterminado.

Portanto, é preciso tratar os dados experimentais de ambos os sistemas de aquisição para que estes estejam de acordo com as exigências do algoritmo.

Duas soluções foram consideradas:

- Reduzir o número de linhas da matriz temperatura, de forma que esta alcance o mesmo número de linhas do vetor de erros de posicionamento;

- Aumentar o número de linhas do vetor de erros de posicionamento até que seja igual ao número de linhas da matriz de temperatura.

O método utilizado na primeira solução seria a função resample do software $M a t L a b{ }^{\circledR}$, que consiste em re-amostrar uma matriz de $n$ linhas em $p / q$ vezes (caso $p / q$ tenha um valor fracionário, é utilizado o arredondamento para cima) utilizando uma implementação polifásica. Sendo assim, a taxa de amostragem da temperatura ajusta-se à dimensão do vetor de erros de posicionamento.

Esta função resample é usada somente para casos em que o número de linhas da matriz deve ser reduzida. Portanto, se a segunda solução for escolhida, deve-se pensar 
Capítulo 4. Trabalho experimental

em um método que seja possível a contrução de um vetor de erros de posicionamento com um maior número de linhas.

Pode-se pensar que o erro de posicionamento medido experimentalmente é uma função dependente do tempo e que, inicialmente, esta função é dita discreta por ter resultados somente nos pontos especificados do eixo $X$. Os erros de posicionamento nos intervalos, como por exemplo, entre $X=-300$ e $X=-105 \mathrm{~mm}$ são desconhecidos. Este tipo de problema é comumente resolvido por métodos numéricos chamados de interpolação linear. Logo, uma função linear é construída a partir dos pontos já conhecidos, de forma que a função torne-se contínua e, assim, possa ser calculado o erro de posicionamento para qualquer ponto do eixo $X$. A partir do momento em que esta função contínua é conhecida, pode-se calcular o erro de posicionamento de quantos pontos forem necessários.

Partindo da premissa de que quanto maior o número de pontos forem analisados para desenvolver o método de regressão linear, maior será a precisão da resposta, decidiu-se utilizar a segunda solução para igualar o número de linhas da matriz de temperatura e do vetor de erros de posicionamento.

A rotina em $M a t L a b^{\circledR}$ para o tratamento de dados segue os seguintes passos:

- Lê os arquivos .txt obtidos dos ensaios experimentais da aquisição de temperatura e da aquisição do erro de posicionamento;

- Retorna a dimensão da matriz de temperatura e do vetor de erro;

- Aplica o método de interpolação linear baseado nos valores do vetor erro e gera a função linear contínua aproximada que descreve o comportamento dos erros de posicionamento ao longo do eixo $X$;

- A partir desta função, calcula-se um vetor de erro de posicionamento com $n$ linhas (mesmo número de linhas que a matriz temperatura). Este novo vetor é usado no desenvolvimento do método de regressão linear múltipla. 
4.8. Considerações sobre o modelo de compensação baseado na análise de regressão linear múltipla

\subsection{Considerações sobre o modelo de compensação baseado na análise de regressão linear múltipla}

No Capítulo 3, foi definido o modelo de regressão múltipla. Seguindo o modelo já apresentado, precisam-se contruir as matrizes relacionadas às variáveis variação de temperatura e erros de posicionamento.

Mesmo com o tratamento de dados realizado na seção anterior, ainda é necessário adequá-los para aplicação do modelo de regressão. Uma das considerações feitas já foi citada na seção anteiror no desenvolvimento da matriz de coordenada homogênea: foram considerados os ensaios em cada caso com a maior variação de temperatura. As outras considerações foram:

- O número de termopares deve ser otimizado para a construção da matriz de temperatura. Considerando o ensaio com a maior variação de temperatura em cada caso, foram obtidas 12 curvas de temperatura, pois cada ensaio contém quatro termopares. A idéia inicial foi tornar possível a compensação com apenas um termopar. Porém, analisou-se que o modelo seria pouco preciso. Logo, decidiuse utilizar a maior curva de temperatura em cada caso na matriz de temperatura do modelo de regressão e, então foi necessário três termopares, um medindo a variação de temperatura no eixo $X$, outro no eixo $Y$ e o terceiro no eixo $Z$. As curvas de temperatura selecionadas foram: a variação de temperatura no mancal direito no caso 1 , no mancal da frente no caso 2 e no spindle no caso 3 . Cada coluna da matriz de temperatura é representada pelas respectivas curvas de temperatura. Além de obter uma maior precisão, um mesmo modelo pode descrever a influência da variação de temperatura dos três eixos no erro de posicionamento do eixo $X$.

- Pela matriz apresentada na Equação 3.8, sabe-se que a primeira coluna da matriz $X$ deve ser composta por 1 , e então um vetor $n \times 1$ contendo valores iguais a 1 
Capítulo 4. Trabalho experimental

foi adicionado à matriz temperatura.

$$
X=\left[\begin{array}{llll}
1 & X 1 & X 2 & X 3
\end{array}\right]_{n \times 4}
$$

- Formados a matriz temperatura $X$ e o vetor erro de posicionamento $Y$, pode-se calcular os parâmetros $\beta$ pela Equação 3.16. Como a matrix $M$ possui quatro colunas, o resultado desta equação é um vetor com quatro linhas que correspondem aos parâmetros $\beta_{0}, \beta_{1}, \beta_{2}, \beta_{3}$.

$$
\hat{\beta}=\left[\begin{array}{l}
\beta_{0} \\
\beta_{1} \\
\beta_{2} \\
\beta_{3}
\end{array}\right]
$$

- A partir da matriz temperatura e do vetor $\hat{\beta}$ é calculado o vetor $\hat{Y}$ que representa o valor dos erros de posicionamento previstos pelo modelo, conforme a Equação 3.17 . 


\section{Capítulo 5}

\section{Resultados e discussão}

\subsection{Descrição da metodologia para compensação de erros}

O desenvolvimento do modelo para compensação de erros baseia-se em todo o estudo teórico e experimental descrito nas seções anteriores. O modelo de matrizes de transformação homogênea foi aplicado ao movimento da mesa da MF no eixo $X$ sob influência das variações de temperaturas dos eixos $X, Y$ e $Z$. Foram desconsiderados os erros angulares e os erros lineares dos eixos $Y$ e $Z$. Porém, o modelo desenvolvido pode ser utilizado futuramente aplicando esses erros.

Após a construção das matrizes de transformação homogênea, foi aplicada, individualmente, a análise de regressão para cada caso apresentado (Casos 1, 2 e 3). Em outras palavras, foi desenvolvida uma equação de regressão descritiva da relação entre a variação de temperatura individual dos eixos $X, Y$ e $Z$, e os erros de posicionamento nos pontos determinados do eixo $X$ (-300, -105, 90 e $285 \mathrm{~mm})$.

Em seguida, uma equação geral de regressão foi desenvolvida para corrigir os erros de posicionamento em cada ponto do eixo $X$, considerando a influência das variações de temperatura dos três eixos simultaneamente. Para essa equação, foram utilizados os valores do erro de posicionamento encontrados por meio da matriz de transfomação 
Capítulo 5. Resultados e discussão

homogênea $\left(\delta\left(x_{1}\right) x, \delta\left(x_{2}\right) x, \delta\left(x_{3}\right) x\right)$.

\subsubsection{Nomenclatura das variáveis utilizadas no modelo}

Os erros medidos foram classificados da seguinte forma:

- $\delta\left(x_{i}\right) x$ : erro de posição na direção $X$ devido ao movimento na direção $X$;

- $\delta\left(x_{i}\right) y$ : erro de posição na direção $X$ devido ao movimento na direção $Y$;

- $\delta\left(x_{i}\right) z$ : erro de posição na direção $X$ devido ao movimento na direção $Z$;

- $\delta\left(U_{i}\right) x$ : histerese na direção $X$ devido ao movimento na direção $X$;

- $\delta\left(U_{i}\right) y$ : histerese na direção $X$ devido ao movimento na direção $Y$;

- $\delta\left(U_{i}\right) z$ : histerese na direção $X$ devido ao movimento na direção $Z$;

em que $i=0,1,2,3$ correspondem aos pontos em que foram realizadas as medições do erro de posicionamento pelo interferômetro.

\subsubsection{Modelagem geométrica na MF para aplicação do modelo de Matrizes de Transformação Homogênea}

O objetivo do trabalho é medir a influência das variações térmicas que ocorrem nos eixos $X, Y$ e $Z$ no erro de posicionamento do eixo $X$. Experimentalmente, foram medidos os erros de posicionamento em quatro pontos distintos do eixo $X(-300,-105,90$ e $285 \mathrm{~mm}$ ). Portanto, foram construídas quatro coordenadas virtuais no eixo $X$ nestes pontos medidos e a coordenada de referência foi definida como sendo o ponto 0 do eixo $X$.

Para facilitar os cálculos, o ponto de referência foi definido como o primeiro ponto de medição, $X=-300 \mathrm{~mm}$. Os pontos seguintes foram definidos como:

- Ponto 0: localizado em $X=-300 \mathrm{~mm}$; 
5.1. Descrição da metodologia para compensação de erros

- Ponto 1: localizado em $X=-105 \mathrm{~mm}$;

- Ponto 2: localizado em $X=90 \mathrm{~mm}$;

- Ponto 3: localizado em $X=285 \mathrm{~mm}$;

A Figura 5.1 mostra como foram criadas as coordenadas a partir destes pontos:

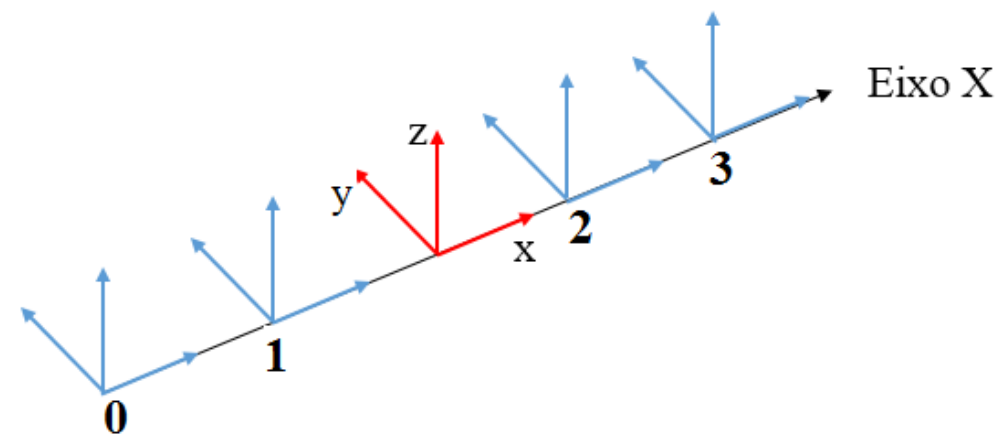

Figura 5.1: Coordenadas virtuais no eixo $X$ da mesa de trabalho da MF

A coordenada $(0,0,0)$ foi adicionada à figura apenas como ponto de referência.

De acordo com este esquema, foi construído o sistema de matrizes de transformação homogêneas considerando as componentes das translações sem erro e ao se conhecer a presença de cada componente de erro, foram adicionados estes componentes nas matrizes conforme a teoria das transformações homogêneas.

Inicialmente foram determinadas as matrizes correspondentes ao movimento ideal $(M)$ e a matriz contendo o erro de posicionamento no eixo $X(E)$ em relação à coordenada de referência.

As matrizes que definem o movimento ideal de cada trajetória são:

$$
M_{0}=\left[\begin{array}{llll}
1 & 0 & 0 & 0 \\
0 & 1 & 0 & 0 \\
0 & 0 & 1 & 0 \\
0 & 0 & 0 & 1
\end{array}\right]
$$


Capítulo 5. Resultados e discussão

$$
M_{1}=M_{2}=M_{3}=\left[\begin{array}{cccc}
1 & 0 & 0 & 195 \\
0 & 1 & 0 & 0 \\
0 & 0 & 1 & 0 \\
0 & 0 & 0 & 1
\end{array}\right]
$$

O deslocamento de translação total da mesa da MF em cada intervalo de deslocamento é de $195 \mathrm{~mm}$, ou seja, a mesa moveu-se $195 \mathrm{~mm}$ do ponto 0 ao ponto 1 , do ponto 1 ao ponto 2 e finalmente do ponto 2 ao ponto 3 .

\subsubsection{Matriz que representa o movimento linear no eixo $X$ na $\mathrm{MF}$}

De acordo com este esquema foi construído o sistema de matrizes de transformações homogêneas considerando as componentes das translações sem erro e ao se conhecer a presença de cada componente de erro foram adicionados estes componentes nas matrizes conforme a teoria das transformações homogêneas.

Para encontrar a matriz que representa a trajetória com erro da mesa, multiplica-se a matriz de cada sistema, conforme a Equação 3.34:

$$
{ }^{R} T_{N}={ }^{0}[T]_{1}^{1}[T]_{2}^{2}[T]_{3}
$$

As montagens das matrizes foram feitas a partir dos trajetos que unem os sistemas de coordenadas estabelecidos.

No trajeto que une o sistema de coordenadas no ponto 0 e o sistemas de coordenadas no ponto 1 , há a presença de uma translação ${ }^{0} M_{1}$ e há também presença de erros de posição ${ }^{0} E_{1}$. Portanto,

$$
{ }^{0}[T]_{1}={ }^{0} M_{1}^{0} E_{1}
$$

Da mesma forma estão conectados os sistemas de coordenadas ${ }^{1}[T]_{2}$ e ${ }^{2}[T]_{3}$. 
5.1. Descrição da metodologia para compensação de erros

$$
\begin{gathered}
{ }^{1}[T]_{2}={ }^{1} M_{2}{ }^{1} E_{2} \\
{ }^{2}[T]_{3}={ }^{2} M_{3}{ }^{2} E_{3}
\end{gathered}
$$

Como os erros angulares e os erros lineares nos eixos $Y$ e $Z$ serão desconsiderados, a matriz que corresponte ao erro em cada ponto é dada por:

$$
{ }^{i-1} E_{i}=\left[\begin{array}{cccc}
1 & 0 & 0 & \delta\left(x_{i}\right) \\
0 & 1 & 0 & 0 \\
0 & 0 & 1 & 0 \\
0 & 0 & 0 & 1
\end{array}\right]
$$

em que $i=1,2,3$ e os valores de $\delta\left(x_{i}\right) x$ são dados por:

$$
\begin{gathered}
\delta\left(x_{0}\right)=\delta\left(x_{0}\right) x+\delta\left(x_{0}\right) y+\delta\left(x_{0}\right) z+U\left(x_{0}\right) x+U\left(x_{0}\right) y+U\left(x_{0}\right) z \\
\delta\left(x_{1}\right)=\delta\left(x_{1}\right) x+\delta\left(x_{1}\right) y+\delta\left(x_{1}\right) z+U\left(x_{1}\right) x+U\left(x_{1}\right) y+U\left(x_{1}\right) z \\
\delta\left(x_{2}\right)=\delta\left(x_{2}\right) x+\delta\left(x_{2}\right) y+\delta\left(x_{2}\right) z+U\left(x_{2}\right) x+U\left(x_{2}\right) y+U\left(x_{2}\right) z \\
\delta\left(x_{3}\right)=\delta\left(x_{3}\right) x+\delta\left(x_{3}\right) y+\delta\left(x_{3}\right) z+U\left(x_{3}\right) x+U\left(x_{3}\right) y+U\left(x_{3}\right) z
\end{gathered}
$$

A matriz resultante ${ }^{R} T_{N}$ que representa a trajetória final da mesa da MF, é: 
Capítulo 5. Resultados e discussão

$$
{ }^{R} T_{N}=\left[\begin{array}{cccc}
1 & 0 & 0 & 585+\delta\left(x_{3}\right)+\delta\left(x_{2}\right)+\delta\left(x_{1}\right)+\delta\left(x_{0}\right) \\
0 & 1 & 0 & 0 \\
0 & 0 & 1 & 0 \\
0 & 0 & 0 & 1
\end{array}\right]
$$

As variáveis representadas pelas Equações 5.8, 5.9, 5.10, 5.11 são calculadas com os dados das Tabelas 5.1, 5.2, 5.3. Decidiu-se por usar os dados dos ensaios em que houve maior variação de temperatura, uma vez que estas variáveis serão aplicadas no modelo de regressão linear múltipla, quanto maior for a relação entre as variáveis de temperatura e os erros de posicionamento, melhor será a precisão do modelo.

Tabela 5.1: Tabela dos dados estatísticos (Caso $1-f=30.000 \mathrm{~mm} / \mathrm{min}$ )

\begin{tabular}{|l|r|r|r|r|}
\hline Valores Estatísticos $[\mu \mathrm{m}]$ & -300 & -105 & 90 & 285 \\
\hline Média (avanço) & 22,510 & 19,000 & 12,910 & 7,790 \\
Média (retorno) & 25,810 & 22,030 & 15,750 & 10,080 \\
Máximo (avanço) & 28,700 & 30,400 & 29,300 & 28,500 \\
Máximo (retorno) & 31,800 & 33,300 & 32,200 & 30,900 \\
Mínimo (avanço) & 12,200 & 4,200 & $-6,000$ & $-14,400$ \\
Mínimo (retorno) & 15,600 & 7,500 & $-3,100$ & $-11,800$ \\
\hline
\end{tabular}

Tabela 5.2: Tabela dos dados estatísticos (Caso $2-f=30 \mathrm{~m} / \mathrm{min}$ )

\begin{tabular}{|l|r|r|r|r|}
\hline Valores Estatísticos $[\mu \mathrm{m}]$ & -300 & -105 & 90 & 285 \\
\hline Média (avanço) & 17,200 & 5,920 & $-2,800$ & $-16,820$ \\
Média (retorno) & 20,280 & 8,900 & 0,230 & $-14,370$ \\
Máximo (avanço) & 17,600 & 6,300 & $-2,300$ & $-15,900$ \\
Máximo (retorno) & 20,900 & 9,100 & 0,800 & $-13,500$ \\
Minimo (avanço) & 16,500 & 5,600 & $-3,100$ & $-17,700$ \\
Minimo (retorno) & 19,900 & 8,500 & $-0,100$ & $-15,600$ \\
\hline
\end{tabular}

Para cada ponto no eixo $X$, foi medido o erro de posicionamento no movimento de avanço e retorno da mesa. Logo, o erro de posicionamento será representado pela média desses erros. A histerese, por definição, foi calculada como o módulo da diferença entre 
5.1. Descrição da metodologia para compensação de erros

Tabela 5.3: Tabela dos dados estatísticos (Caso $3-n=12.000 \mathrm{rpm}$ )

\begin{tabular}{|l|r|r|r|r|}
\hline Valores Estatísticos $[\mu \mathrm{m}]$ & -300 & -105 & 90 & 285 \\
\hline Média (avanço) & 3,810 & 4,190 & 8,900 & 7,700 \\
Média (retorno) & 6,510 & 7,170 & 11,600 & 10,400 \\
Máximo (avanço) & 6,000 & 7,500 & 8,900 & 7,500 \\
Máximo (retorno) & 9,400 & 10,400 & 11,600 & 10,400 \\
Minimo (avanço) & 0,300 & $-0,900$ & $-0,300$ & 1,900 \\
Minimo (retorno) & 2,700 & 2,900 & 3,100 & 4,300 \\
\hline
\end{tabular}

os valores máximo no sentido de avanço e no retorno. Assim, as variáveis 5.8, 5.9, 5.10, 5.11 terão como resultado:

$$
\begin{aligned}
\delta\left(x_{0}\right) & =\left(\frac{22,51+25,81}{2}\right)+\left(\frac{17,20+20,28}{2}\right)+\left(\frac{3,81+6,51}{2}\right)+ \\
& +|28,70-31,80|+|17,60-20,90|+|6,00-9,40|=57,71 \\
\delta\left(x_{1}\right) & =\left(\frac{19,00+22,03}{2}\right)+\left(\frac{5,92+8,90}{2}\right)+\left(\frac{4,19+7,17}{2}\right)+ \\
& +|30,40-33,30|+|6,30-9,10|+|7,50-10,40|=42,22 \\
\delta\left(x_{2}\right)= & \left(\frac{12,91+15,75}{2}\right)+\left(\frac{-2,80+0,23}{2}\right)+\left(\frac{8,90+11,60}{2}\right)+ \\
& +|20,30-32,2|+|-2,30-0,80|+|8,90-11,60|=34,78 \\
\delta\left(x_{3}\right)= & \left(\frac{7,79+10,08}{2}\right)+\left(\frac{-16,82+(-14,37)}{2}\right)+\left(\frac{7,70+10,40}{2}\right)+ \\
+ & |28,50-30,90|+|-15,90-(-13,50)|+|7,50-10,40|=56,88
\end{aligned}
$$

Os termos apresentados são dados de entrada para o modelo de regressão que descreve o erro de posicionamento do eixo $X$ sob influência da variação de temperatura 
Capítulo 5. Resultados e discussão

dos três eixos coordenados da MF $X, Y$ e $Z$.

\subsection{Equação de regressão para o Caso 1}

Através da análise de regressão múltipla construiu-se uma equação com coeficientes $\hat{\beta}$ para cada ponto de parada do eixo $X$. O número de coeficientes estava diretamente relacionado ao número de termopares utilizados para medir a variação de temperatura. Como no primeiro caso, foram utilizados quatro termopares, a matriz de temperatura $X$ tem 5 colunas (sendo que a primeira coluna é um vetor com valores 1 ), e portanto a equação possui cinco coeficientes $\hat{\beta}$.

Sabendo o valor dos coeficientes $\hat{\beta}$, a equação de regressão em cada posição foi dada por:

- Posição $X=\mathbf{- 3 0 0}$

$$
\hat{Y}=1451,471+2,108 x_{1}+1,365 x_{2}-73,998 x_{3}-6,359 x_{4}+u
$$

Coeficiente de determinação: 0,995

- Posição $X=-105$

$$
\hat{Y}=1852,859+3,059 x_{1}+8,788 x_{2}-59,022 x_{3}-55,246 x_{4}+u
$$

Coeficiente de determinação: 0,998

- Posição $X=90$

$$
\hat{Y}=3125,200+3,760 x_{1}+15,509 x_{2}-98,870 x_{3}-92,481 x_{4}+u
$$

Coeficiente de determinação: 0,998

76 
5.2. Equação de regressão para o Caso 1

- Posição $X=285$

$$
\hat{Y}=3685,571+4,844 x_{1}+22,088 x_{2}-98,674 x_{3}-133,512 x_{4}+u
$$

Coeficiente de determinação: 0,998

Os coeficientes de determinação mostraram-se satisfatórios segundo a teoria apresentada na Seção 3.1. O resultado confirmou a forte relação entre a variação de temperatura no eixo $X$ e o erro de posicionamento do mesmo eixo.

O resultado das equações acima levaram à predição dos erros de posicionamento nos pontos especificados do eixo $X$ dada a variação de temperatura da MF. O gráfico a seguir (Figura 5.2) relaciona a variação de temperatura com o erro de posicionamento antes e depois da aplicação da equação de correção.

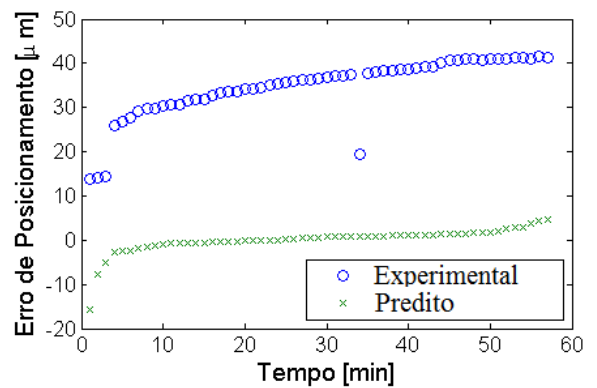

(a) Posição $\mathrm{X}=-300$

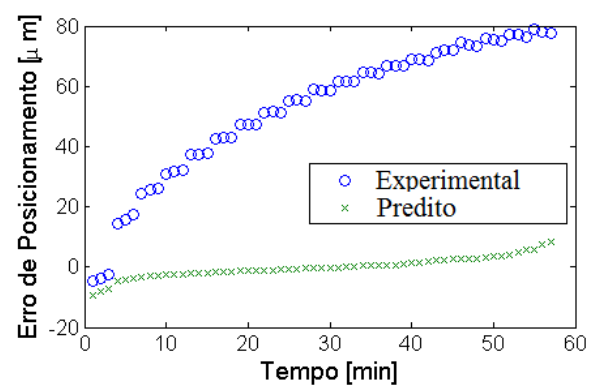

(c) Posição $\mathrm{X}=90$

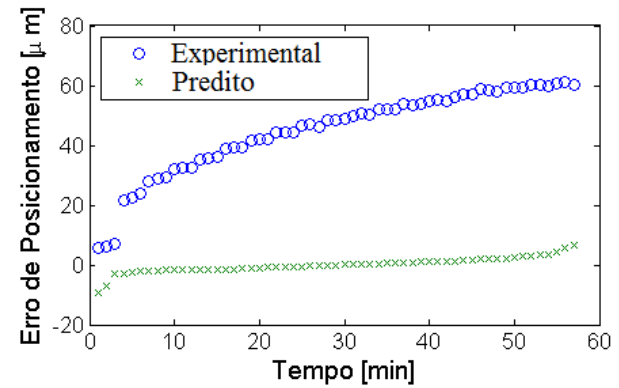

(b) Posição $\mathrm{X}=-105$

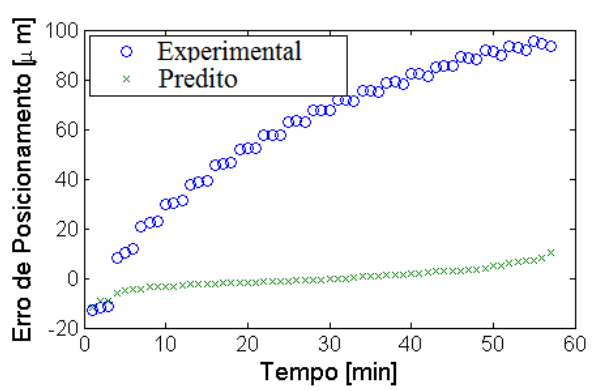

(d) Posição $\mathrm{X}=285$

Figura 5.2: Gráficos dos erros de posicionamento antes e depois da aplicação da equação de correção 
Capítulo 5. Resultados e discussão

O erro de posicionamento sem correção varia aproximadamente entre 0,02 a 0,1 $\mathrm{mm}$. Aplicando as equações de regressão, os erros passam a variar entre 0,02 a 0,1 $\mathrm{mm}$. Uma redução significativa para o trabalho proposto.

\subsection{Equação de regressão para o Caso 2}

As equações de regressão para o caso 2 foram desenvolvidas da mesma forma que a anterior. O número de termopares também foi o mesmo, logo cada equação de regressão para cada posição $X$ possui quatro coeficientes, apresentados a seguir:

- Posição $X=\mathbf{- 3 0 0}$

$$
\hat{Y}=189,487+0,641 x_{1}-0,079 x_{2}-0,298 x_{3}-7,295 x_{4}+u
$$

Coeficiente de determinação: 0,994

- Posição $X=-105$

$$
\hat{Y}=52,530+0,009 x_{1}-0,002 x_{2}-0,079 x_{3}-1,772 x_{4}+u
$$

Coeficiente de determinação: 0,992

- Posição $X=90$

$$
\hat{Y}=102,429+0,641 x_{1}-0,066 x_{2}-0,155 x_{3}-4,721 x_{4}+u
$$

Coeficiente de determinação: 0,776

- Posição $X=285$ 
5.3. Equação de regressão para o Caso 2

$$
\hat{Y}=111,430+0,736 x_{1}+0,062 x_{2}-0,337 x_{3}-5,732 x_{4}+u
$$

\section{Coeficiente de determinação: 0,988}

Observou-se uma pequena redução nos coeficientes de determinação, para cada ponto de medição do erro de posicionamento, em relação aos coeficientes do primeiro caso. Tal resultado indicou que a influência do aquecimento dos pontos de medição no eixo $Y$ podem ter menor influência nos erros de posicionamento do eixo $X$.

O gráfico correspondente aos erros de posicionamento antes e depois da aplicação da equação de correção é mostrado na Figura 5.3 a seguir:

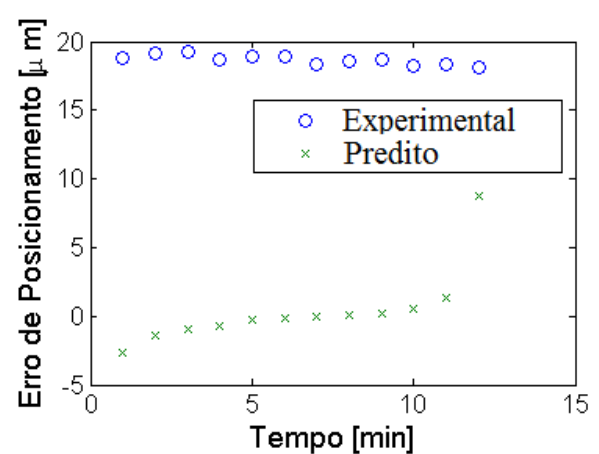

(a) Posição $\mathrm{X}=-300$

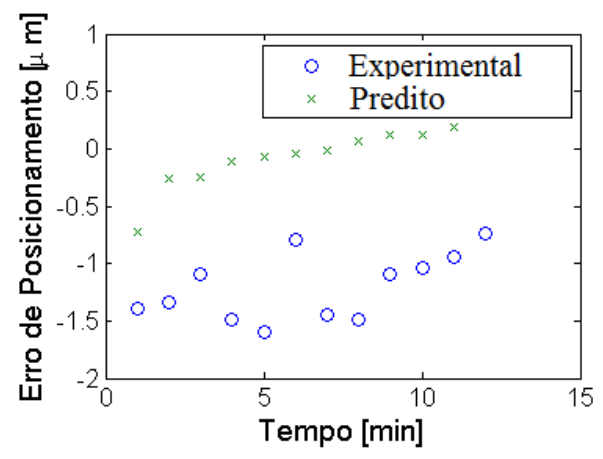

(c) Posição $\mathrm{X}=90$

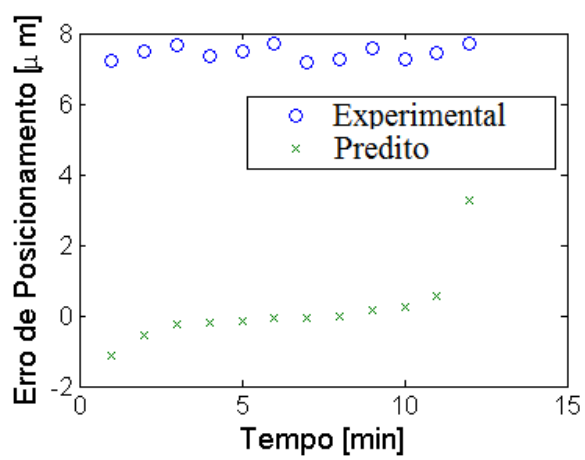

(b) Posição $\mathrm{X}=-105$

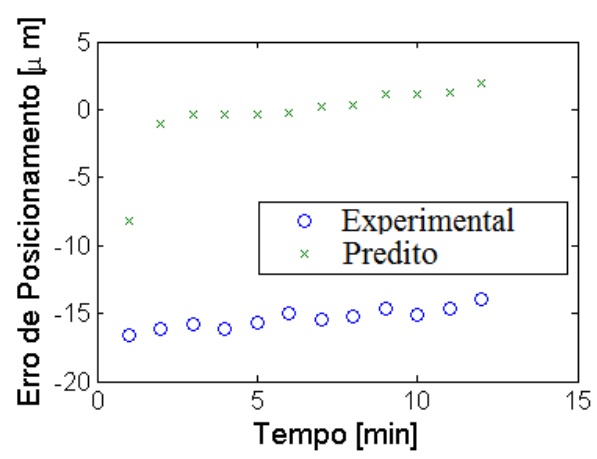

(d) Posição $\mathrm{X}=285$

Figura 5.3: Gráficos dos erros de posicionamento antes e depois da aplicação da equação de correção 
Capítulo 5. Resultados e discussão

Apesar da pequena redução do valor dos coeficientes de determinação, estes ainda são viáveis para aplicação no sistema de compensação. Os gráficos apresentados mostram que os resultados das equações de regressão geram valores reduzidos em relação aos erros de posicionamento medidos experimentalmente.

\subsection{Equação de regressão para o Caso 3}

No terceiro caso, em que foram utilizados três termopares, existem quatro coeficientes $\beta$ em cada equação. Tais equações de regressão para os pontos -300 mm,-105 mm, 90 $m m$ e $285 \mathrm{~mm}$ são dadas por:

- Posição $X=\mathbf{- 3 0 0}$

$$
\hat{Y}=-277,995-1,771 x_{1}+0,101 x_{2}+12,343 x_{3}+u
$$

Coeficiente de determinação: 0,798

- Posição $X=-105$

$$
\hat{Y}=-425,105-2,686 x_{1}+0,214 x_{2}+18,694 x_{3}+u
$$

Coeficiente de determinação: 0,645

- Posição $X=90$

$$
\hat{Y}=-576,735-3,618 x_{1}+0,331 x_{2}+25,233 x_{3}+u
$$

Coeficiente de determinação: 0,519

- Posição $X=285$ 


$$
\hat{Y}=-732,164-4,601 x_{1}+0,431 x_{2}+32,057 x_{3}+u
$$

\section{Coeficiente de determinação: 0,602}

Ao comparar os coeficientes de determinação deste caso com os outros casos já apresentados, pode-se verificar que estes são os menores coeficientes encontrados. A influência da variação de temperatura do eixo $Z$ não é tão significativa sobre erros de posicionamento do eixo $X$, quanto à variação de temperatura nos eixos $X$ e $Y$. Porém, ainda são mais próximos de 1 do que de 0 e podem ser consideradas relevantes na equação final da equação de regressão para compensação dos erros de posicionamento.

A Figura 5.4 mostra os gráficos do erro de posicionameno em relação à variação de temperatura antes e depois da correção.

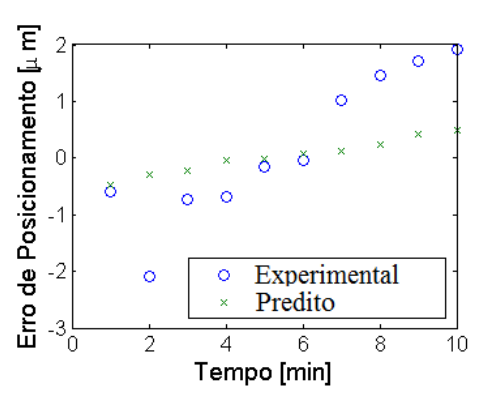

(a) Posição $\mathrm{X}=-300$

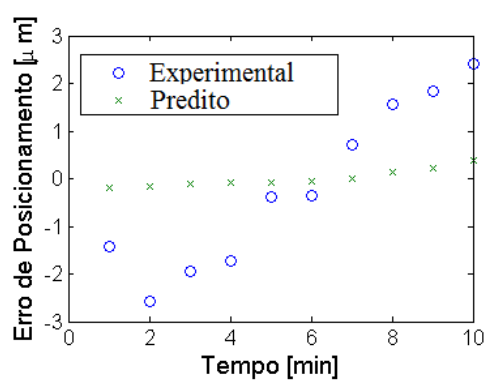

(c) Posição $\mathrm{X}=90$

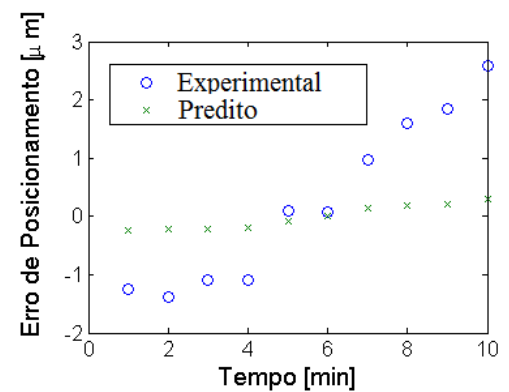

(b) Posição $\mathrm{X}=-105$

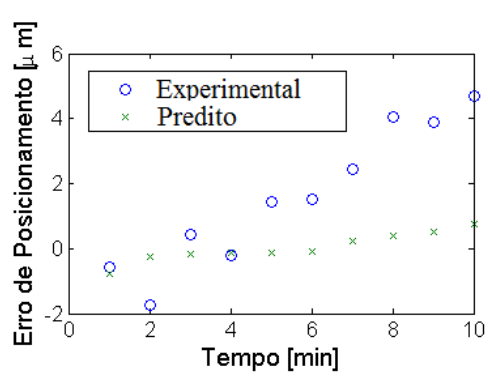

(d) Posição $\mathrm{X}=285$

Figura 5.4: Gráficos dos erros de posicionamento antes e depois da aplicação da equação de correção 
Capítulo 5. Resultados e discussão

Neste caso, os erros de posicionamento experimentais variaram entre -3 e $5 \mu m$, após a aplicação da equação de regressão, o erro passou a variar de -1 a $1 \mu m$.

\subsection{Modelo final de regressão}

O modelo final de compensação usando a análise de regressão é o modelo descrito na Seção 4.8. As colunas da matriz $X$ foram os vetores que representaram os termopares com maior variação de temperatura em cada caso experimental. Abaixo são apresentadas as equações finais para cada posição avaliada:

- Posição $X=\mathbf{- 3 0 0}$

$$
\hat{Y}=55,845+0,307 x_{1}-0,676 x_{2}+0,436 x_{3}
$$

Coeficiente de determinação: 0,998

- Posição $X=-105$

$$
\hat{Y}=52,903+0,094 x_{1}-1,647 x_{2}+0,463 x_{3}
$$

Coeficiente de determinação: 0,997

- Posição $X=90$

$$
\hat{Y}=40,390+0,055 x_{1}+0,214 x_{2}+0,387 x_{3}
$$

Coeficiente de determinação: 0,995

- Posição $X=285$ 


$$
\hat{Y}=45,258+0,039 x_{1}+0,349 x_{2}+0,309 x_{3}
$$

\section{Coeficiente de determinação: 0,990}

O gráfico da Figura 5.5 mostra o erro de posicionamento do vetor de observações $Y$ redimensionalizado, sem a aplicação da equação de regressão e o vetor $\hat{Y}$ com os valores do erro de posicionamento usando as equações acima.

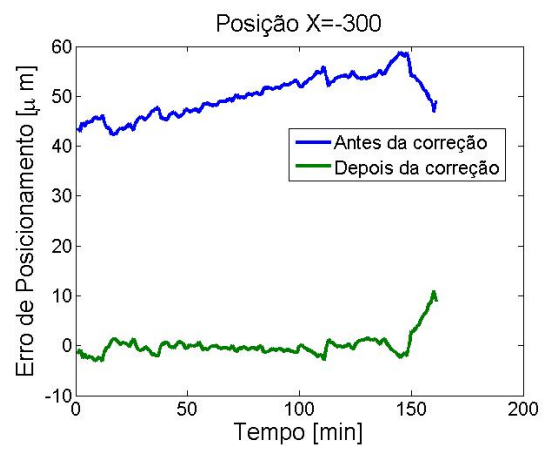

(a) Posição $\mathrm{X}=-300$

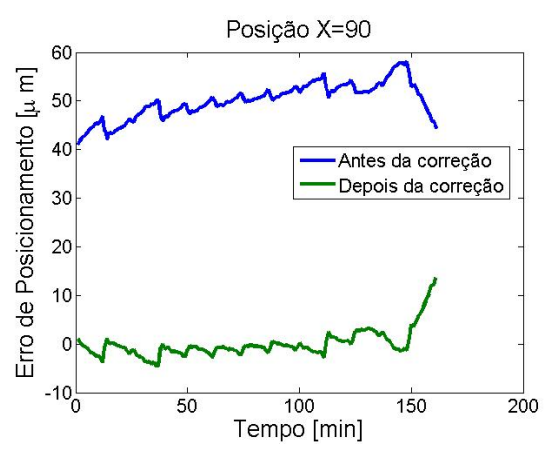

(c) Posição $\mathrm{X}=90$

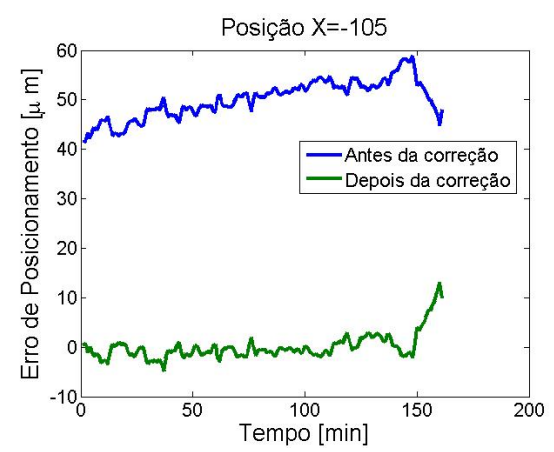

(b) Posição $\mathrm{X}=-105$

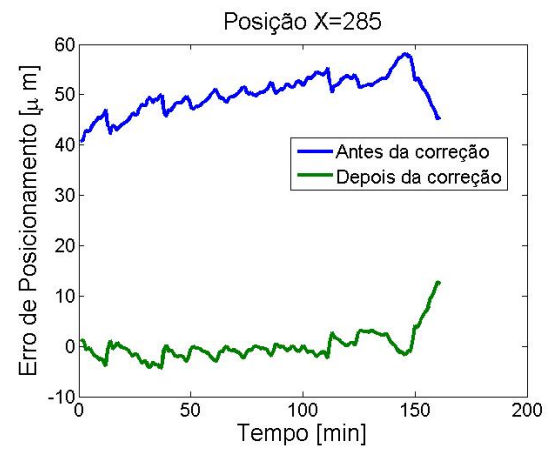

(d) Posição $\mathrm{X}=285$

Figura 5.5: Gráficos dos erros de posicionamento antes e depois da aplicação da equação de correção

Este modelo tem por finalidade reunir as influências da variação de temperatura em todos os eixos para predição e correção dos erros de posicionamento. O fator de correlação $R^{2}=0,995$ foi a maior correlação obtida dentre todos os casos individuais 
Capítulo 5. Resultados e discussão

analisados. Este fator mostra que a utlização de um termopar em cada eixo no desenvolvimento do modelo de regressão pode ser tão vantasojo quanto utilizar três ou mais termopares em cada eixo. Basta especificar um local para instalação do termopar em que a variação de temperatura seja suficiente para se obter uma boa correlação no modelo de regressão linear. 


\section{Capítulo 6}

\section{Conclusões}

A pesquisa desenvolvida neste trabalho resultou no desenvolvimento de modelos matemáticos que possibilitam a implementação de um compensador térmico para erros de posicionamento. Os ensaios experimentais, tais como medição de erros de posicionamento por meio de um interferômetro a laser, garantem uma boa qualidade metrológica nos dados de entrada do modelo. A técnica de medição pelo interferômetro a laser, como mede o posicionamento na direção de avanço e no retorno, torna possível estimar a histerese.

No modelo final de compesação baseado na análise de regressão, foi obtida uma redução significativa nos erros de posicionamento. Observou-se erros de quase $60 \mu \mathrm{m}$ antes da aplicação da equação. Após a correção, os erros variaram entre -5 e $5 \mu \mathrm{m}$. Estes resultados levam em consideração a influência somente dos erros lineares e da histerese no eixo $X$. O modelo de matrizes de transformações homogêneas torna possível a aplicação de erros lineares nos demais eixos e dos erros angulares. Aumentando-se a quantidade de erros a serem considerados, aumenta-se também a precisão do modelo. Porém, os erros angulares, por exemplo, não são tão significativos quanto os erros lineares e sua aquisição demanda um alto grau de dificuldade e tempo.

Além disso, as medições de erros angulares podem gerar elevados desvios padrão. 


\section{Capítulo 6. Conclusões}

Portanto, considera-se neste trabalho, que a medição dos erros lineares e histerese tornam o modelo de regressão linear múltipla um método preciso para compensação de erros. O rápido processamento torna possível a implementação do modelo para compensação em tempo real no $\mathrm{CN}$ da $\mathrm{MF}$.

Partindo do mesmo princípio de desenvolvimento de um modelo de correção para o eixo $X$, é possível fazer um modelo para correção de erros de posicionamento para os eixos $Y$ e $Z$. Para tanto, será necessário posicionar as lentes e os retroreflectores do interferômetro a laser de modo que seja possível fazer a medição linear desses eixos. A aquisição dos dados de temperatura permanecem inalterados desde que também se queira medir a influência da variação de temperatura dos três eixos.

Outra vantagem deste trabalho é a possibilidade de construir MF sem régua óptica e compensar os erros somente pelo modelo apresentado. O custo da máquina seria reduzido e conforme a necessidade, os coeficientes do modelo podem ser adequados a novas situações em que a MF é exposta. Como exemplo, pode-se citar o desgaste da máquina com o tempo. Se forem realizados novos ensaios com as novas condições da máquina, o modelo das matrizes de transformação homogêneas mostrará os erros de posicinamento partindo de um novo ponto de referência.

O presente trabalho entra em consenso com outros trabalhos deste tema, no que diz repseito à redução dos erros, porém utiliza dois importantes métodos, matrizes de transformação homogêneas e análise de regressão linear. O primeiro permite a modelagem dos erros de posicionamento experimentais conforme os dados que são obtidos. O modelo de regressão utliza esses dados para definir os coeficientes da equação. 


\section{Capítulo 7}

\section{Trabalhos futuros}

O próximo passo será aplicar este modelo ao CN da máquina e analisar experimentalmente a redução dos erros de posicionamento. Espera-se resultados com boa precisão, assim como nos reultados obtidos neste trabalho implementados no software Matlab ${ }^{\circledR}$.

Um dos maiores desafios deste trabalho foi encontrar métodos para compensação que precisassem somente dos dados que foram possíveis de se obter experimentalmente: variação de temperatura e erros de posicionamento em pontos específicos do eixo $X$. A falta de algumas informações como o valor do fluxo de calor gerado durante o funcionamento da MF diretamente das fontes de geração de calor (motores e acionamentos), impediram de desenvolver um modelo em elementos finitos no software ABAQUS, ideia inicial do projeto.

Durante o doutorado sanduíche na Universidade McMaster, no Canadá, foi iniciado um estudo para adquirir estes dados de fluxo de calor pelo problema inverso de transferência de calor (IHTP - Inverse Heat Transfer Problem). Esta técnica permite resolver problemas indiretos, em que não há conhecimento de certas propriedades do modelo nem condições de contorno. Por meio de um histórico de informações sobre um ponto específico, deve ser possível estimar estas propriedades ou condições de contorno. Ou seja, esta técnica faz o processo inverso de um modelo de transferência de calor direto. 
Capítulo 7. Trabalhos futuros

Conhecendo estas propriedades, pode-se modelar o desempenho da MF no software ABAQUS sob influência das propriedades estimadas pelo IHTP. 


\section{Referências Bibliográficas}

[1] Altintas, Y. (2000). Manufacture Automations. Cambridge University.

[2] Anderson, P. (1992). Methodology for evaluating the production accuracy of the machine tools. Tampere Technical University.

[3] Arruda, M. d. C. C., Marteleto, R. M., and Souza, D. B. (2007). Educação, trabalho e o deliniamento de novos perfis profissionais: o bibliotecário em questão. Ciência da Informação, 29(3):14-24.

[4] Baratto, A. C., Damanesco, J. C., Alves, J. A. P., Filho, J. T., Couto, P. R. G., and Olideira, S. P. (2008). Avaliação de dados de medição - Guia para a expressão de incerteza de medição. JCGM Comitê Conjunto para Guias em Metrologia.

[5] Brecher, C. and Gerrath, T. (2005). Machine tools i - lecture 11: Measuring instruments, geometric and kinematic behavior of machine tools. WZL/IPT.RWTHAACHEN.

[6] Bryan, J. (1990). International status of thermal error research. Annals of the CIRP, 2(39):645-656.

[7] Cadima, J. and Valente, F. (2010). Estatística e Deliniamento. Departamento de Matemática, Instituto Superior de Agronomia (ISA). 
Referências Bibliográficas

[8] de Sousa, A. R. (2000). Padrões corporificados e a tecnologia de mediçẫo por coordenadas inovando a qualificação geométrica de centros de usinagem. $\mathrm{PhD}$ thesis, Universidade Federal de Santa Catarina.

[9] de Souza, A. F. (2001). Análise das interpolações de trajetórias de ferramenta na usinagem hsc (high speed cutting) em superfícies complexas. Master's thesis, Universidade Metodista de Piracicaba.

[10] Donaldson, R. and Thompson, D. (1986). Design and performance of a small precision cnc turning machine. Annals of the CIRP, 35(1):373-376.

[11] Du, Z., Yang, J., and Xue, B. (2002). Modeling approach of regression orthogonal experiment design for the thermal error compensation of a cnc turning center. Journal of Materials Processing Technology, 129:619-623.

[12] FLIR (2015 (acessado em 22 de outubro de 2015)). FLIR Instruments. http: //www.flir.com/thermography/americas/br/view/?id=55706.

[13] Giacomo Di, B., Nakazato, K., and Arencibia, V. (2005). Estudo inicial dos erros cíclicos de máquina de medir a três coordenadas. Revista Iberoamericana de Ingenieria Mecânica, 9(3):103-109.

[14] Hale, L. (1999). Principles and techniques for designing precision machines. PhD thesis, Massachusetts Institute of Technology.

[15] Jedrzejewshi, J. and Kaczmarek, W. (1992). A new approach to modeling thermal behaviour of a machine tool under service conditions. Annals of the CIRP, pages $455-458$.

[16] Kang, Y., Chang, C.-W., Huang, Y., Hsu, C.-L., and Nieh, I.-F. (2007). Modification of a neural network utilizing hybrid filters for the compensation of thermal 
deformation in machine tools. International Journal of Machine Tools and Manufacture, $47(2): 376-387$.

[17] Laplane, M. F. (1990). Diagnóstico da Indústria Brasileira de Máquinasferramenta. IPT FECAMP.

[18] Lee, E.-S., Suh, S.-H., and Shon, J.-W. (1998). A comprehensive method for calibration of volumetric positioning accuracy of cnc-machines. The International Journal of Advanced Manufacturing Technology, 14:43-49.

[19] Luchesi, V. M. (2011). Estudo teórico da condução de calor e desenvolvimento de um sistema para a avaliação de fluidos de corte em usinagem.

[20] Montegomery, D., Peck, E., and Vining, G. (2006). Introduction to linear regression analysis. John Wiley (New York, N.Y.).

[21] Nascimento, C. H. (2011). Estudo da distribuição de temperatura na região de formação de cavacos usando método dos elementos finitos. Master's thesis, Universidade de São Paulo.

[22] Nie, X. (2011). Application of neural network for thermal error compensation in cnc machine tool. In Computing, Control and Industrial Engineering (CCIE), 2011 IEEE 2nd International Conference on, volume 1, pages 211 -215.

[23] Okafor, A. C. and Ertekin, Y. M. (1989). The practice of dynamic pressure measurement. Measurement \& Control, 22(10):258 - 301.

[24] Okafor, A. C. and Ertekin, Y. M. (2000). Vertical machining center accuracy characterization using laser interferometer: Part 1. linear positional errors. Journal of Materials Processing Technology, 105(3):394 - 406.

[25] Oliveira, A. (2007). Encoder. Instituto Federal de Educação Tecnológica do Mato Grosso - IFMG. 
Referências Bibliográficas

[26] Parr, A. (1998). Industrial Control Handbook. Industrial Press Inc.

[27] Qianjian, G. and Jianguo, Y. (2011). Application of projection pursuit regression to thermal error modeling of a cnc machine tool. The International Journal of Advanced Manufacturing Technology, 55:623-629.

[28] Ramesh, R., Mannan, M., and Poo, A. (2000a). Error compensation in machine tools - a review: Part i: geometric, cutting-force induced and fixture dependent errors. International Journal of Machine Tools and Manufacture, 40(9):1235 - 1256.

[29] Ramesh, R., Mannan, M., and Poo, A. (2000b). Error compensation in machine tools - a review: Part ii: thermal errors. International Journal of Machine Tools and Manufacture, 40(9):1257 - 1284.

[30] Rui, Shijie, D., Youglu, Z., Xinye, W., and Yinbiao, G. (2008). Thermal error analysis and error prediction modeling on a machine tool. In IEEE, editor, Proceedings of 2008 IEEE, pages 2056-2060.

[31] Sartori, S. and Zhang, G. (1995). Geometric error measurement and compensation of machines. \{CIRP\} Annals - Manufacturing Technology, 44(2):599 - 609 .

[32] Schellekens, P., Rosielle, N., Vermeulen, H., Vermeulen, M., Wetzels, S., and Pril, W. (1998). Design for precision: Current status and trends. \{CIRP\} Annals Manufacturing Technology, 47(2):557 - 586.

[33] Schutzer, K. and Souza, A. (2000). Concepção do produto e fabricação utilizando a tecnologia de usiangem em altíssima velocidade de corte. In: Anais do VI Congresso Nacional de Mecânica Aplicada e Computacional, pages 635 - 644. Aveiro, Portugal.

[34] Schwenke, H., Knapp, W., Haitjema, H., Weckenmann, A., Schmitt, R., and Delbressine, F. (2008). Geometric error measurement and compensation of machines-an update. CIRP Annals - Manufacturing Technology, 57(2):660 - 675. 
[35] Slocum, A. (1992). Precision Machine Design. Society of Manufacturing Engineers.

[36] Souza, A. F. d. and Ulbrich, C. B. L. (2009). Engenharia Integrada por Computador e Sistemas $C A D / C A M / C N C$ - Princípios e Aplicações. São Paulo, Artliber.

[37] Souza, D. B. (2002). Complexificação e simplificação do trabalho em face do processo de reestruturação produtiva na indústria brasileira: Formação ou educação para o trabalho? Revista Electrónica de Geografia y Ciencias Sociales, 86(119).

[38] Spur, G., Hoffman, E., Paluncic, Z., Benzinger, K., and Nymoen, H. (1988). Thermal behavior optimization of machine tools. Annals of the CIRP, 37(1):401-405.

[39] Stoeterau, R. (2009). Introdução ao projeto de máquinas-ferramenta modernas. Escola Politécnica de São Paulo.

[40] Stoeterau, R. L. (2004). Introdução ao Projeto de Máquinas-Ferramentas Modernas. Universidade Federal de Santa Catarina.

[41] Suh, S. and Lee, E. (2000). Contourning performance measurement and evaluation of nc machine controller for virtual machining cam system. Internatinal Journal of Advanced Manufacturing Technology, 16(4):271-276.

[42] Thyer, E. G. (1993). Computer numerical control of machine tools. Industrial Pres Inc.

[43] Venugopal, R. and Barash, M. (1986). Thermal effects in the accuracy of numerically controlled machine tools. Annals of the CIRP, pages 255-258.

[44] Webster, J. (1999). The Measurement, Instrumentation and Sensors: Handbook. Springer.

[45] Weck, M. (1984). Handbook of Machine Tools, Construction and Mathematical Analysis. John Wiley \& Sons. 
Referências Bibliográficas

[46] Wu, C.-W., Tang, C.-H., Chang, C.-F., and Shiao, Y.-S. (2012). Thermal error compensation method for machine center. The International Journal of Advanced Manufacturing Technology, 59:681-689.

[47] Wu, S. and Ni, J. (1989). Precision machining without precise machinery. Annals of the CIRP, 1(38):533-536.

[48] Yang, H. and Ni, J. (2005). Dynamic neural network modeling for nonlinear, nonstationary machine tool thermally induced error. International Journal of Machine Tools and Manufacture, 45(4-5):455 - 465. 


\section{Apêndice A}

\section{Curvas de temperatura}

Este apêndice mostra os gráficos das curvas de temperatura obtidas nos ensaios exmperimentais antes do tratamento de dados.

\section{A.1 Caso 1}

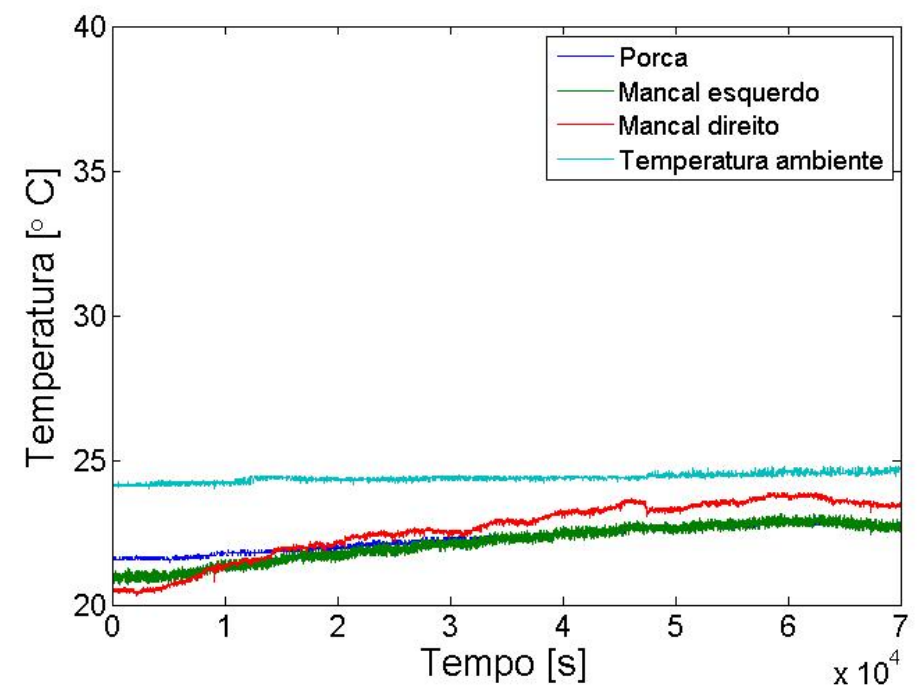

Figura A.1: Curvas de temperatura no Caso $1(f=30.000 \mathrm{~mm} / \mathrm{min})$ 
Apêndice A. Curvas de temperatura

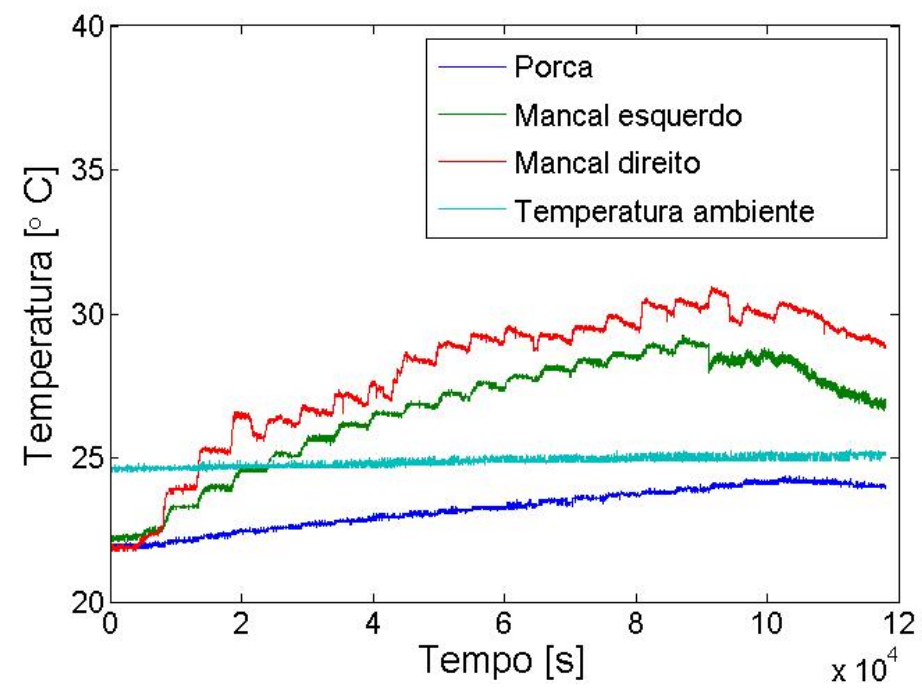

Figura A.2: Curvas de temperatura no Caso $1(f=5.000 \mathrm{~mm} / \mathrm{min})$

\section{A.2 Caso 2}

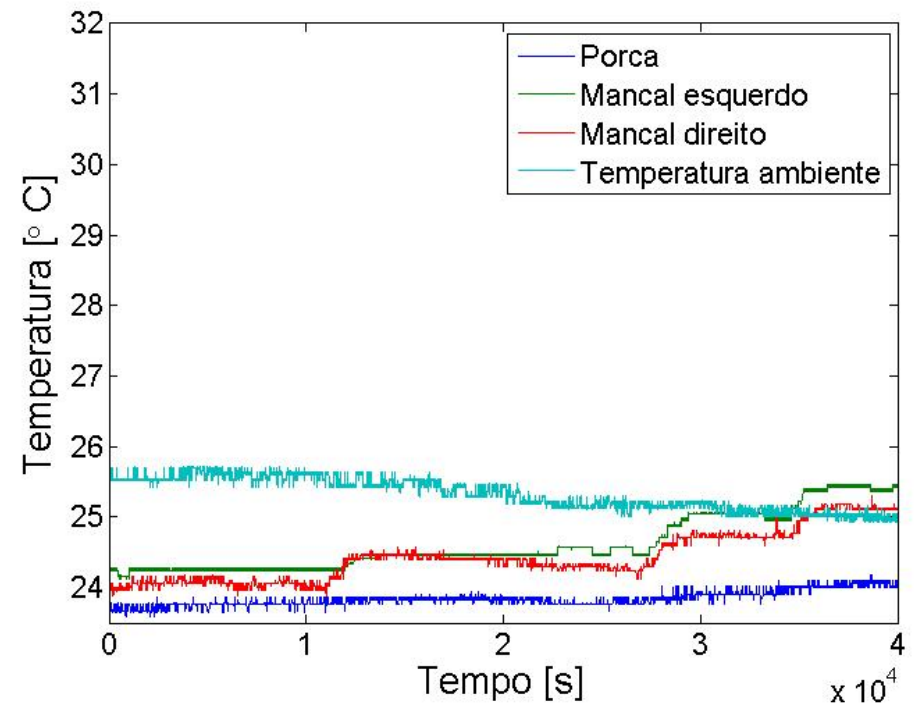

Figura A.3: Curvas de temperatura no Caso $2(f=30.000 \mathrm{~mm} / \mathrm{min})$ 
A.3. Caso 3

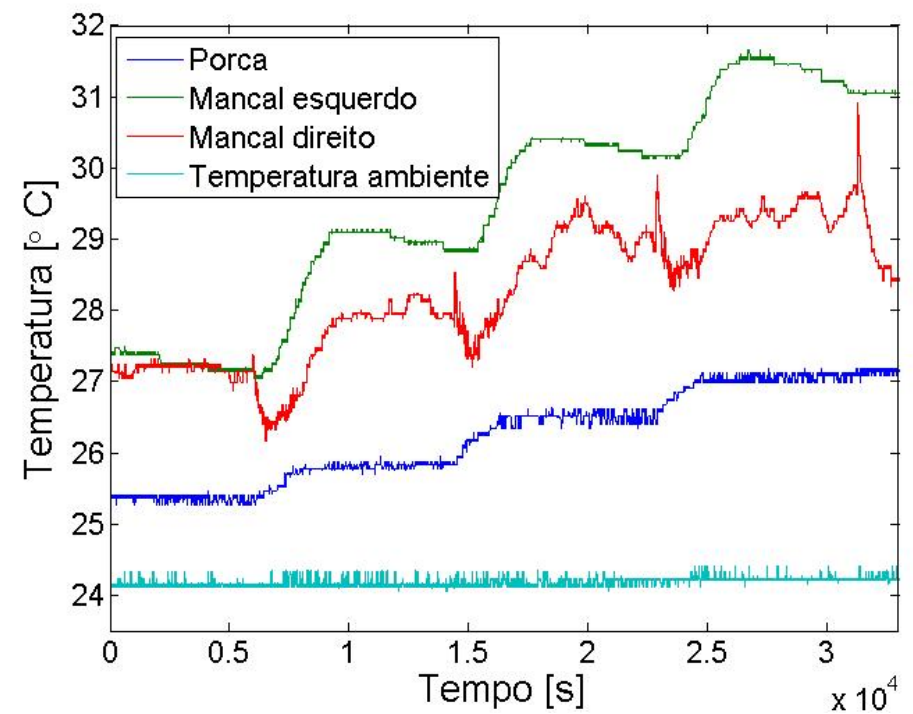

Figura A.4: Curvas de temperatura no Caso $2(f=5.000 \mathrm{~mm} / \mathrm{min})$

\section{A.3 Caso 3}

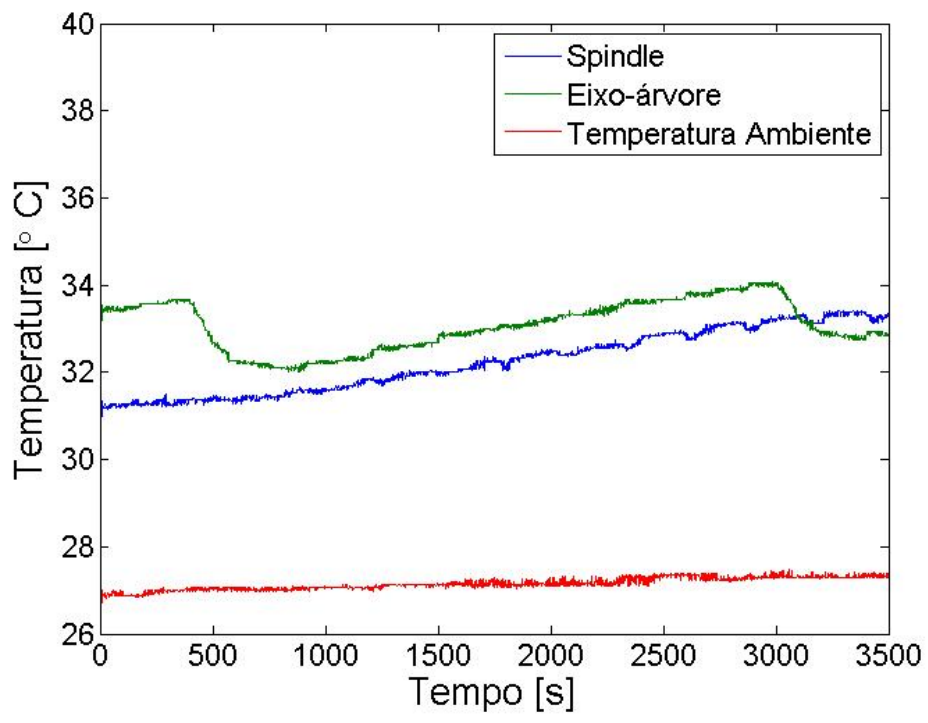

Figura A.5: Curvas de temperatura no Caso 3 (6000 rpm) 
Apêndice A. Curvas de temperatura

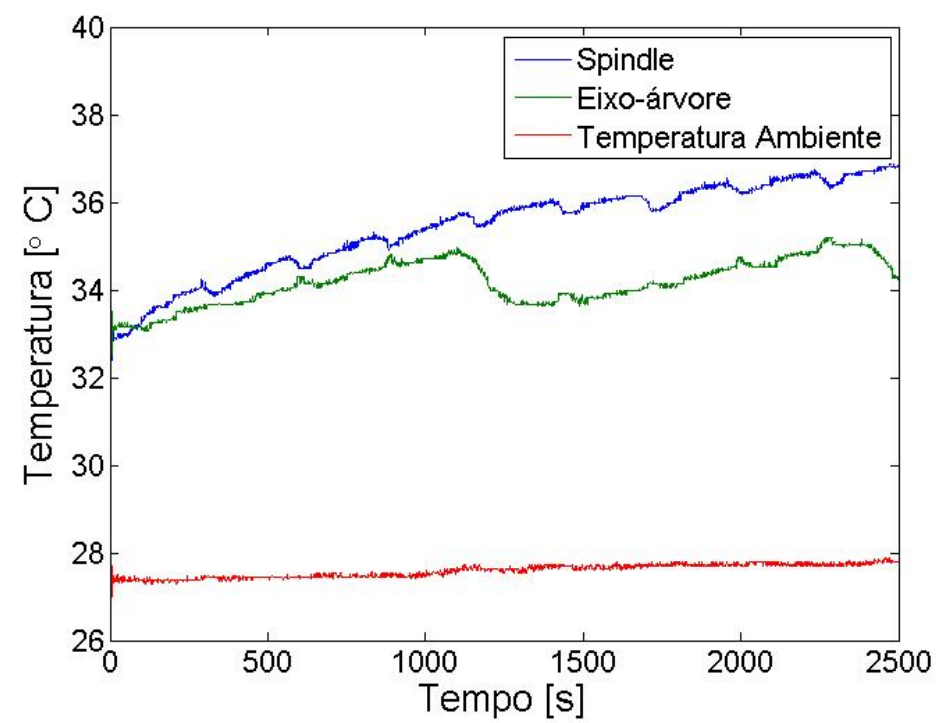

Figura A.6: Curvas de temperatura no Caso 3 (12000 rpm) 


\section{Apêndice B}

\section{Códigos}

primeiro código, desenvolvido em MATLAB ${ }^{\circledR}$, foi utilizado para leitura dos dados iniciais para gerar os coeficientes do modelo de análise de regressão. Neste programa os novos dados são gravados em um arquivo .txt que será o arquivo de entrada para o segundo código que calcula os valores numéricos do erro geométrico.

\section{B.1 Código I}

\% Compensa Tica utilizando o Mdo de Regressltipla

clear all;

clc;

$\% \% \% \% \% \% \% \% \% \% \% \% \% \%$

\%er os dados do arquivo

$\%$ Vetor entrada de temperatura

X_temp $=\operatorname{load}($ 'temp.txt')

size (X_temp);

\%\% \% \% \% \% \% \% \% \% \% \% \% \% \% \% 
Apêndice B. Códigos

\% Vetor entrada de errro de posicionamento - valores observados da experiia

Y_rtl = load ('erros.txt');

$Y=\operatorname{sort}\left(Y_{-}\right.$rtt $\left.(:, 3)\right)$;

$\operatorname{size}(\mathrm{Y})$;

$\% \% \% \% \% \% \% \% \% \% \% \% \% \% \% \%$

$\%$ Definir as matrizes e suas repectivas dimenses para utilizar no Mdo de Regressltipla $\mathrm{n}=$ length $\left(\mathrm{X}_{-}\right.$temp $\left.(:, 1)\right) ; \%$ nmero de linhas do vetor temperatura

$\mathrm{m}=$ length(Y_rtl $(:, 3)) ; \%$ nmero de linhas do vetor erro de posicionamento

$\mathrm{X}_{\text {_ones }}=$ ones $(\mathrm{n}, 1) ; \%$ constr vetor com $\mathrm{n}$ linhas e uma coluna apenas com numero 1

$\mathrm{X}_{-} 1=\left[\mathrm{X}_{-}\right.$ones $\mathrm{X}_{-}$temp $] ; \%$ constratriz de temperatura

$\mathbf{z}=\operatorname{ceil}(\mathrm{n} / \mathrm{m})-1 ; \%$ arredonda para cima a divisntre $\mathrm{n} / \mathrm{m}$

$\mathrm{X}=\operatorname{resample}\left(\mathrm{X}_{-} 1, \mathrm{~m}, \mathrm{n}\right) ; \%$ redimensionaliza a matriz $\mathrm{X}_{-} 1$ para que $\mathrm{X}_{-} 1$ e $\mathrm{Y}$ tenham

o mesmo tamanho

$\% \% \% \% \% \% \% \% \% \% \% \% \% \% \% \% \% \%$

\% Encontrar os valores dos coeficientes da equa

$\mathrm{A}=\mathrm{X}, * \mathrm{X}$

$\mathrm{B}=\mathrm{X}, * \mathrm{Y}$

Beta $=\operatorname{inv}(\mathrm{A}) * \mathrm{~B} ; \%$ forma matricial do Mdo dos Mmos Quadrados

$c=$ length(Beta); $\%$ nmero de coeficientes

Y_estimated $=\mathrm{X} *$ Beta; $\%$ estimar os valores do erro de posicionamento

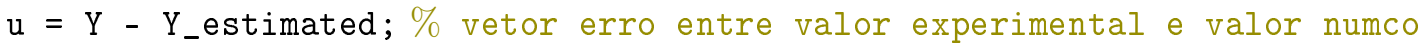

SQ_res $=u, * u ; \%$ soma dos resos quadrados

SQ_total $=\operatorname{sum}(Y .2)-((\operatorname{sum}(Y)) .2) / z ; \%$ soma total dos desvios quadrcos

$\mathrm{SQ}_{-} r e g=\operatorname{Beta}^{\prime} * \mathrm{X}, * \mathrm{Y}-((\operatorname{sum}(\mathrm{Y})) .2) / z ; \%$ soma total dos desvios quadrcos

r_2 = SQ_reg /SQ_total; \% coeficiente de determina (ajustado)

100 
B.1. Código I

MQ_reg = SQ_reg / z; \% desvio quadrco mo de regress

MQ_res $=$ SQ_reg / $(\mathrm{m}-\mathrm{n}-1) ; \%$ desvio quadrco mo residual

$\mathrm{F}=$ MQ_reg / MQ_res; \% estatica F

$\% \% \% \% \% \% \% \% \% \% \% \% \% \% \%$

$\%$ Resultados

coef $=$ fopen ('Coeficientes_Beta2.txt','at');

for $x=1$ : c

fprintf(coef, '\%2.3f', Beta(x));

end

fclose(coef);

rel = fopen('Analise_Regressao2.txt','at');

fprintf(rel, 'A equa do modelo de regress: $y(x)=\% 2.3 f \quad \% 2.3 f * x 1 \% 2.3 f$

$* x 2 \% 2.3 f * x 3 \% 2.3 f * x 4$ u', Beta(1), Beta(2), Beta(3), Beta(4), Beta(5));

fprintf(rel,'Coeficiente de determina: \%2.3f', r_2);

fprintf(rel,'Estatica: \%2.3f', F);

fclose(rel);

res $=$ fopen('Analise_Resultados2.txt', 'at');

for $x=1: m$

fprintf(res, $\% 2.3 f \% 2.3 f \% 2.3 f \% 2.3 f,, Y(x), Y_{-}$estimated(x), u(x));

end

fclose(res); 
Apêndice B. Códigos

\section{B.2 Código II}

\% Compensa Tica utilizando o Mdo de Regressltipla

clear all;

clc;

$\% \% \% \% \% \% \% \% \% \% \% \% \% \% \% \% \% \%$

\%Ler os dados do arquivo

\% Vetor entrada de temperatura

$X_{\text {_temp }}=$ load ('temp.txt');

size (X_temp);

$\%$ L valores dos coeficientes da equa do modelo de regress

Beta $=$ load ('Coeficientes_Beta2.txt');

length (Beta);

$\%$ Letor erro

$u_{-}$aux $=$load('Analise_Resultados2.txt');

$\mathrm{u}=\mathrm{u}_{-} \operatorname{aux}(:, 3)$;

$\mathrm{m}=$ length $(\mathrm{u})$;

$\mathrm{n}=$ length (X_temp $(:, 1)) ; \%$ nmero de linhas do vetor temperatura

$\mathbf{z}=\operatorname{ceil}(\mathrm{n} / \mathrm{m}) ; \%$ arredonda para cima a divisntre $\mathrm{n} / \mathrm{m}$

$\mathrm{X}_{-}$ones $=$ones $(\mathrm{n}, 1) ; \%$ constr vetor com $\mathrm{n}$ linhas e uma coluna apenas com numero 1

$\mathrm{X}_{-}$aux $=\left[\mathrm{X}_{-}\right.$ones $\mathrm{X}_{-}$temp $] ;$constratriz de temperatura

$\mathrm{X}=$ resample $\left(\mathrm{X}_{-}\right.$aux $\left., \mathrm{m}, \mathrm{n}\right) ; \%$ redimensionaliza a matriz $\mathrm{X}_{-} 1$ para que $\mathrm{X}_{-} 1$ e 
Y tenham o mesmo tamanho

\%\%\%\%\%\%\%\%\%\%\%\%\%\%\%\%\%\%

\%Valores Previstos de erro

\% Calcula os valores do erro de posicionamento previsto

$\mathrm{Y}_{-} \mathrm{calc}=\mathrm{X} *$ Beta $\mathrm{u}$;

$\mathrm{y}=\operatorname{length}\left(Y_{-}\right.$calc $)$;

prev $=$ fopen('ResultadosY_calculado.txt', 'at');

for $x=1: m$

fprintf (prev, , \%2.3f', Y_calc(x));

end

$\% \% \% \% \% \% \% \% \% \% \% \% \% \% \% \%$

\%Grco 3D

figure(1)

$\operatorname{plot3}\left(u, X(:, 2), Y,{ }^{\prime} O{ }^{\prime}, u, X(:, 3), Y, X^{\prime}, u, X(:, 4), Y,{ }^{\prime}, u, X(:, 5), Y\right.$, , , u, X $\left.(:, 6), Y,{ }^{\prime},\right)$;

xlabel ('Erro do Mdo $[\mu \mathrm{m}]$ ') ;

ylabel ('Temperatura [o C $]^{\prime}$ ) ;

zlabel('Erro de Posicionamento [ $\mu \mathrm{m}]^{\prime}$ ');

legend('Termopar1', 'Termopar2', 'Termopar3', 'Termopar4') ;

\%\%\%\%\%\%\%\%\%\%\%\%\%\%\%\%\%\%

$\%$ Grco 2D

figure(2)

$\mathrm{t}=1: 1: \mathrm{m} ;$

$\operatorname{plot}\left(t, Y,{ }^{\prime} O^{\prime}, t, u, x^{\prime} X^{\prime}\right)$; 
Apêndice B. Códigos

xlabel ('Tempo [min]');

ylabel ('Erro de Posicionamento [ $\mu \mathrm{m}]$ ') ;

legend('Y Previsto $[\mathrm{mm}]$ ', 'Erro do Mdo $[\mu \mathrm{m}]$ ') ;

figure(3)

$\mathrm{t}=1: 1: \mathrm{m} ;$

plot $\left(t, X(:, 2),{ }^{\prime} O^{\prime}, t, X(:, 3), X^{\prime}, t, X(:, 4),{ }^{\prime}, t, X(:, 5),{ }^{\prime}, t, X(:, 6),{ }^{\prime},\right)$;

xlabel ('Tempo [min]');

ylabel ('Temperatura [o $\mathrm{C}]$ ') ;

legend ('Termopar1', 'Termopar2', 'Termopar3' , 'Termopar4')

104 